\title{
A typology and literature review on stochastic multi-echelon inventory models
}

\author{
Ton de Kok ${ }^{a *} \quad$ Christopher Grob ${ }^{b} \quad$ Marco Laumanns $^{c}$ \\ Stefan Minner $^{d} \quad$ Jörg Rambau ${ }^{e} \quad$ Konrad Schade $^{f}$
}

March 2, 2018

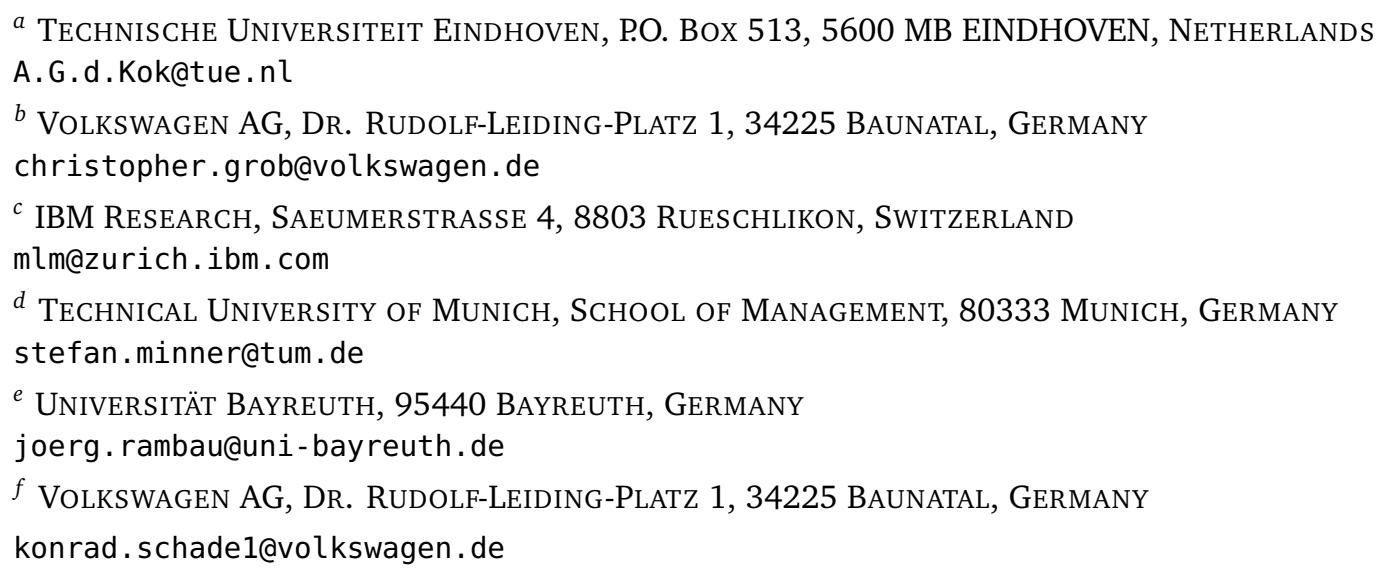

\begin{abstract}
We develop a typology for multi-echelon inventory management. The typology is used to classify and review the extensive research of multi-echelon inventory management under uncertain demand. We identify clusters of model assumptions, research goals and applied methodologies. Based on this review, existing research gaps and avenues for further research are proposed.
\end{abstract}

Keywords: Supply chain management, inventory, multi-echelon, demand uncertainty, typology

${ }^{*}$ Corresponding Author 


\section{Introduction}

Multi-echelon inventory management and theory have a research and publication history of more than 50 years. Ground-breaking seminal papers in the late 1950s/early 1960s stimulated a huge amount of theoretical and applied research, which resulted in trees of new and refined research directions. With the increasing popularity of supply chain management in the literature as well as in industrial practice, its core building block - multi-echelon inventory models - gained further attention and importance.

The earlier work under stochastic demand predominantly focused on exact models and on deriving structural properties of optimal inventory policies under very stylized assumptions. As determining optimal policy structures turned out to be intractable even for basic multi-echelon structures, such as pure divergent structures, due to complex non-linearity of cost functions and the well-known curses of dimensionality in dynamic programming, follow-up research during the 1980s and 1990s investigated the optimal or heuristic setting of parameters for given policy structures, e.g., base stock policies. Around the year 2000, this research resulted in various approaches to optimize policies for general structures, i.e., where items in the supply chain can have multiple successors and multiple predecessors. In doing so, the field enabled the "optimization" of real-world supply chains, which was recognized by multinational companies. It also led to the development of commercial multi-echelon inventory optimization software. The pioneering companies became known as SmartOps (acquired by SAP), Optiant (acquired by Logility), and LogicTools (acquired by IBM). The fact that operations research faculty start-ups were bought out shows both the interest in the field of multi-echelon inventory optimization, its high practical relevance and the complexity of the problem to be solved.

The next wave of multi-echelon inventory research under uncertain demand concerned the integration of different flexibility options. This type of research is rooted in the spare parts inventory management arena, as spare parts inventory systems are characterized by high capital investments, low demand rates, and high service requirements. Exploiting flexibility options such as expediting, transshipments and other forms of inventory pooling, as well as outsourcing of repairs, has a big impact on the capital investments needed to meet the customer service requirements. This research on spare parts systems was further stimulated by changes in business models of OEMs under the heading "power by the hour": OEMs do not deliver spare parts to their customers, but ensure uptime of the customers' equipment.

Another shift is a transition from mathematically elegant models to policies and algorithms for today's inventory decision support tools that can be implemented in practice, along with a shift from analytical to approximate/numerical studies due to enlarged computational capabilities. Interestingly, our assessment of the state-of-theart on multi-echelon inventory systems under uncertain demand shows that, over the last decade, there has been a renewed interest in the structure of optimal policies, 
albeit for small-scale systems with a specific structure and specific assumptions on demand and replenishment processes.

\subsection{Motivation and objectives}

Over the years, several review papers have structured the field of multi-echelon inventory models (see Section 1.2). What is still missing is a structured classification of model assumptions that enables a fast and well-accepted terminology for core assumptions of a model and its underlying system. Such classification schemes are common in other areas of operations management and operations research, see Kendall (1953) and Buzacott and Shanthikumar (1993) for queuing models, Dyckhoff (1990) and Wäscher et al. (2007) for cutting and packing, Graham et al. (1979) for scheduling models, Brucker et al. (1999) for project planning, Boysen et al. (2007) for assembly line balancing, and Copil et al. (2017) for lot-sizing and scheduling.

We provide such a classification scheme for multi-echelon inventory models and showcase it in an up-to-date literature review on models under demand uncertainty for the reason of keeping focus, and realizing, to a certain degree, similar kinds of assumptions and methodologies, compared to literature streams on lot-sizing and scheduling, which primarily focussed on deterministic demands. In more recent articles, we see the assessment of deterministic models regarding their effectiveness under stochastic demand (e.g., de Kok and Fransoo (2003), Jansen et al. (2013)) and the inclusion of uncertain demand into lot-sizing and scheduling problems.

The contributions of this paper are the following:

- We propose a typology for multi-echelon inventory systems.

- We provide an extensive literature review of 394 papers under demand uncertainty until end of 2016, classified according to our typology.

- We identify seminal papers that started research streams and have been mostcited.

- We identify research gaps.

Moreover, we present a documentation of our classification process that shows how the classification can be kept up-to-date in the future. The objectives of developing a typology in the first place are:

1. We want to explicitly state all important dimensions of modeling assumptions (e.g., the structure of the system, the demand processes, the replenishment processes, the objectives, ...) so that methods can be compared appropriately.

2. We want to assess how modeling assumptions disseminate over time so that pivotal papers and the emergence of separate research branches become visible. 
3. We want to guide practitioners towards characterizing their real-world supply chain structures so that it becomes easy to link the supply chain problems they encounter in practice to the existing literature.

We documented our classification in the form of a bibtex database. This database allows us to generate further insights into the state-of-the-art through exploratory data analysis. We present our findings in the form of qualitative statements. Our data analysis, finally, leads to the above-mentioned identification of research gaps, i.e., practically and scientifically relevant models of multi-echelon inventory systems that need further study.

As an additional service to the research community, we make publically available a continuously updated bibtex database of multi-echelon inventory literature that contains our classification data at

http://wWw. modus . uni-bayreuth.de/en/Projects/projects_academia/MEI0/ index.html.

\subsection{Methodology}

In the following, we describe our literature search and classification strategy (Denyer and Trenfield 2009). The initial search was based on a literature list compiled from earlier review articles on multi-echelon inventory systems under uncertain demand. First, the handbooks on operations research and management science, in particular the chapters by Axsäter (1993a), Federgruen (1993), Graves and Willems (2003), Axsäter (2003c), Song and Zipkin (2003), and de Kok and Fransoo (2003) were used. Second, reviews from the European Journal of Operational Research were included: van Houtum, Inderfurth, et al. (1996) and Diks, de Kok, and Lagodimos (1996). More recent reviews are Gümüs and Güneri (2007), Simchi-Levi and Zhao (2011) and Eruguz, Sahin, et al. (2016). This list was then supplemented by a backward search using Google Scholar. To remain as focused as possible, we excluded all manuscripts that assume deterministic demand, single periods or single stages. For each of the remaining papers, two members of the team of authors were randomly assigned to classify them using the typology introduced in Section 2. In several consensus meetings with all the authors, conflicting classifications were resolved to obtain the final classification. Publications classified as being out of scope were removed from the list. In this way, we considered all papers with a publication date up to the end of 2016.

\subsection{Structure of the paper}

The paper is organized as follows. In Section 2, we present the typology of (stochastic) multi-echelon inventory systems, i.e., the structural elements that constitute these 
systems. In Sections 3 and 4, we use our typology to classify and discuss the current state of the art concerning stochastic multi-echelon inventory systems and to identify research gaps and topics for further research. In Section 5, we reflect on our findings and summarize the main conclusions.

\section{Typology}

In Table 1, we present the typology. The first column names the dimension of the typology, the second column the possible values, the third column is the explanation, and the fourth column shows the number of papers for which the classification includes this value for papers under stochastic demand. Note that counts for singleechelon and deterministic models are not available (n.a.) as these are out of scope for our literature review. As papers can have multiple values within one dimension of the typology, the sum of these numbers can exceed the total number of classified papers. We further introduce the following typology string:

$$
\begin{aligned}
<\text { No. of Echelons }>,<\text { Structure }>, & <\text { Time }>,<\text { Information }>\mid<\text { Capacity }>,<\text { Delay }>\mid \\
<\text { Demand }>,<\text { Customer }>\mid & <\text { Policy }>,<\text { Lotsize }>,<\text { Flexibility }>\mid<\text { Performance Indicator }>\| \mid \\
& <\text { Methodology }>,<\text { Research Goal }>
\end{aligned}
$$

This string is divided into two main parts. The first part concerns the problem under investigation and is divided into five sections. The first section is the system specification and contains information about the supply chain as a network hosting a dynamic process. The second section specifies how resources can be used for the materials flow. Interaction with the external market is represented in the third section. The fourth section deals with the business rules that may restrict the types of policies that can be used. Finally, the last section characterizes what "good performance of a policy in the system" is supposed to mean. This last dimension has to be distinguished from the performance assessment of an optimization algorithm used to compute a policy, like CPU time or approximation quality. The second part contains information about the methodology of the paper, i.e., how the results have been derived, and the research goal, i.e., what type of result has been presented.

\begin{tabular}{ll}
\hline Typology & Number \\
Dimension values Explanation & \\
\hline The problem under investigation: & \\
\hline System Specification: & \\
\hline Echelons Number of echelons & \\
\hline
\end{tabular}




\begin{tabular}{|c|c|c|c|}
\hline Typology & & & \\
\hline \multirow[t]{7}{*}{ Dimension } & Values & Explanation & $\begin{array}{l}\text { Number } \\
\text { of papers }\end{array}$ \\
\hline & 1 & single echelon & n.a. \\
\hline & 2 & two echelons & 244 \\
\hline & 3 & three echelons & 6 \\
\hline & 4 & four echelons & 1 \\
\hline & $n$ & general number of echelons & 146 \\
\hline & $x$ & continuous & 1 \\
\hline \multirow[t]{5}{*}{ Structure } & \multicolumn{3}{|c|}{ Relationship between items } \\
\hline & $\mathrm{C}$ & $\begin{array}{l}\text { convergent material structure: } \\
\text { one successor, multiple predecessors }\end{array}$ & 42 \\
\hline & $\mathrm{D}$ & $\begin{array}{l}\text { divergent material structure: } \\
\text { multiple successors, one predecessor }\end{array}$ & 189 \\
\hline & G & $\begin{array}{l}\text { general material structure: } \\
\text { multiple successors, multiple predecessors }\end{array}$ & 88 \\
\hline & $\mathrm{S}$ & $\begin{array}{l}\text { serial material structure: } \\
\text { one successor, one predecessor }\end{array}$ & 91 \\
\hline \multirow[t]{3}{*}{ Time } & \multicolumn{3}{|c|}{ Moments in time where relevant events occur } \\
\hline & $\mathrm{C}$ & $\begin{array}{l}\text { continuous: } \\
\text { actions possible at any point in time }\end{array}$ & 198 \\
\hline & $\mathrm{D}$ & $\begin{array}{l}\text { discrete: } \\
\text { actions possible at specific points in time }\end{array}$ & 197 \\
\hline \multirow[t]{4}{*}{ Information } & \multicolumn{3}{|c|}{ Level of information needed to perform the computations } \\
\hline & $\mathrm{E}$ & echelon: everything downstream & 5 \\
\hline & G & global: everything & 380 \\
\hline & $\mathrm{L}$ & local: single node only & 12 \\
\hline \multicolumn{4}{|c|}{ Resources Specification: } \\
\hline \multirow[t]{3}{*}{ Capacity } & \multicolumn{3}{|c|}{ Restriction on availability of resources } \\
\hline & $\mathrm{F}$ & bounded storage and/or processing capacity & 71 \\
\hline & I & infinite capacity (no constraint) & 325 \\
\hline \multirow[t]{5}{*}{ Delay } & \multicolumn{3}{|c|}{$\begin{array}{l}\text { Time it takes to deliver an item } \\
\text { (including production times, excluding stock-out delays) }\end{array}$} \\
\hline & $\mathrm{C}$ & constant & 299 \\
\hline & $\mathrm{E}$ & exponential & 38 \\
\hline & G & general stochastic & 62 \\
\hline & $\mathrm{O}$ & $\begin{array}{l}\text { other: for a restricted set of distributions, } \\
\text { different from } C, E, G\end{array}$ & 2 \\
\hline \multicolumn{4}{|c|}{ Market Specification: } \\
\hline Demand & Exogen & us demand for an item & \\
\hline
\end{tabular}




\begin{tabular}{|c|c|c|c|}
\hline \multicolumn{4}{|l|}{ Typology } \\
\hline \multirow[t]{10}{*}{ Dimension } & Values & Explanation & $\begin{array}{l}\text { Number } \\
\text { of papers }\end{array}$ \\
\hline & c & deterministic & n.a. \\
\hline & B & compound "batch" Poisson & 40 \\
\hline & D & discrete stochastic & 15 \\
\hline & G & general stochastic & 138 \\
\hline & M & Markovian, i.e., state-dependent Poisson & 6 \\
\hline & $\mathrm{N}$ & Normal & 50 \\
\hline & $P$ & Poisson & 127 \\
\hline & $\mathrm{R}$ & compound renewal & 9 \\
\hline & $u$ & $\begin{array}{l}\text { upper-bounded: typically used in } \\
\text { guaranteed service models }\end{array}$ & 44 \\
\hline \multirow[t]{4}{*}{ Customer } & \multicolumn{3}{|c|}{ Attributes (reactions to disservice, advanced demand, etc.) } \\
\hline & B & backordering & 321 \\
\hline & G & guaranteed service & 42 \\
\hline & L & lost sales & 43 \\
\hline \multicolumn{4}{|c|}{ Control Type Specification: } \\
\hline \multirow[t]{9}{*}{ Policy } & \multicolumn{3}{|c|}{ Prescribed type of replenishment policy } \\
\hline & $\mathrm{N}$ & none & 61 \\
\hline & B & echelon base stock & 42 \\
\hline & b & installation base stock & 163 \\
\hline & $\mathrm{s}$ & echelon $(s, S)$ & 2 \\
\hline & $\mathrm{s}$ & installation $(s, S)$ & 10 \\
\hline & Q & echelon $(s, n Q)$ & 17 \\
\hline & q & installation $(s, n Q)$ & 67 \\
\hline & O & other & 49 \\
\hline \multirow[t]{4}{*}{ Lot-sizing } & \multicolumn{3}{|c|}{ Constraint on release quantity } \\
\hline & $\mathrm{F}$ & flexible: no restriction & 310 \\
\hline & Q & $\begin{array}{l}\text { fixed order quantity: order quantity is restricted, } \\
\text { but multiple orders of prescribed size } \\
\text { at the same moment are allowed }\end{array}$ & 85 \\
\hline & O & other & 3 \\
\hline \multirow[t]{7}{*}{$\begin{array}{l}\text { Operational } \\
\text { flexibility }\end{array}$} & \multicolumn{3}{|c|}{$\begin{array}{l}\text { Capability to use other means of satisfying unexpected } \\
\text { requirements than originally foreseen }\end{array}$} \\
\hline & N & none & 267 \\
\hline & A & allocation & 29 \\
\hline & E & expediting & 24 \\
\hline & $\mathrm{O}$ & outsourcing & 12 \\
\hline & $\mathrm{R}$ & $\begin{array}{l}\text { routing flexibility: item from another source } \\
\text { to customer, another item to customer }\end{array}$ & 36 \\
\hline & u & unspecified & 37 \\
\hline
\end{tabular}




\begin{tabular}{|c|c|c|c|}
\hline \multicolumn{4}{|l|}{ Typology } \\
\hline Dimension & Values & Explanation & $\begin{array}{l}\text { Number } \\
\text { of papers }\end{array}$ \\
\hline \multicolumn{4}{|c|}{ Performance Specification: } \\
\hline \multirow[t]{6}{*}{$\begin{array}{l}\text { Performance } \\
\text { indicator }\end{array}$} & \multicolumn{3}{|c|}{$\begin{array}{l}\text { Objective to be achieved as a result of selection of control } \\
\text { policy and its parameters }\end{array}$} \\
\hline & $E$ & equilibrium & 6 \\
\hline & $\mathrm{S}$ & meeting operational service requirements & 75 \\
\hline & $\mathrm{C}$ & minimization of costs & 335 \\
\hline & M & multi-objective (efficient frontier) & 15 \\
\hline & $U$ & unspecified & 8 \\
\hline \multicolumn{4}{|c|}{ Generic scientific aspects of the Paper: } \\
\hline \multirow[t]{6}{*}{ Methodology } & \multicolumn{3}{|c|}{ Techniques applied to achieve the results } \\
\hline & $A$ & approximative & 221 \\
\hline & $\mathrm{C}$ & computational experiments & 196 \\
\hline & $E$ & exact & 173 \\
\hline & $\mathrm{F}$ & field study & 17 \\
\hline & $\mathrm{S}$ & simulation & 48 \\
\hline \multirow[t]{5}{*}{ Research goal } & \multicolumn{3}{|c|}{ Goal of the investigations } \\
\hline & $\mathrm{C}$ & comparison & 46 \\
\hline & $\mathrm{F}$ & formulae & 14 \\
\hline & $\mathrm{O}$ & optimization & 277 \\
\hline & $P$ & performance evaluation & 75 \\
\hline
\end{tabular}

Table 1: Typology

For completeness, the typology includes single-echelon systems and deterministic demand. Obviously, several other categories are not relevant for such models, e.g. the structure and information for single echelon system or demand distributions and flexibility measure for deterministic demand. The classification with regard to the number of echelons and the distinction of network topologies into the three basic types of serial, convergent (comprises assembly and multi-sourcing, usually the first), divergent (comprises distribution and disassembly, so far only the first) and general is straightforward, as is the separation between continuous and discrete time approaches. In the information category, most publications were classified as requiring global information. Even though demand information was only partially available, the overall optimization of system parameters across stages requires such global information. Capacity issues were divided into infinite and finite, where the latter includes any kind of manufacturing and space limitations. Furthermore, we use the term delay instead of lead time to distinguish between the pure delivery process 
and delays caused by stockouts, which themselves are a result of the policy applied and can therefore not be regarded as being data of the problem statement.

In categorizing demand, we selected several popular distributions in multi-echelon inventory theory, such as Poisson, compound Poisson or normal, while including general continuous and discrete as being other desirable entries. As the guaranteed service model has received particular attention in the research area but at the same time often includes a specific model of demand being bounded, we added it as an additional entry. In the policy categorization, the main distinction is between installation and echelon stock policies on the one hand and $(s, S)$ and $(s, n Q)$-type policies on the other hand. The combination of both subproblems spans the entries in this field. For lot-sizing, we allow quantities both to be fixed or flexible, which includes papers investigating optimal policies that require no upfront limitation with regard to quantities.

A particular interest of our later analysis is devoted to the use of flexibility. Although the majority of papers classified follows a linear, unique, and direct flow through the network, multi-echelon systems include a variety of deviations from this assumption to allow for more flexibility. In order to indicate these different types of flexibility options, we included allocation, expediting, outsourcing, and routing flexibility, the last including the famous transshipment option.

In the category of performance measurement, we allow for the widely used metrics of cost minimization and attaining required service levels. For a broader perspective, the category equilibrium allows for multiple decision makers and we might also have multiple objectives.

With regard to methodology, we distinguish between approximative and exact methods. The choice depends on whether an approximation (abstraction from reality through modeling) is made when introducing the system assumptions or later during the analysis. For example, METRIC introduces random demand resulting in random delays which are replaced by their expected value during the analysis. Therefore, the METRIC papers are classified as approximate. However, the guaranteed service model (GSM) makes the assumption that such delays are covered by flexibility measures (or excluded by bounded demand). Therefore, the GSM papers are classified as exact. Furthermore, computational experiments and simulation are distinguished. Only those papers that use simulation to quantify performance measures were classified as such whereas the use of simulation to test the quality of approximations was subsumed under computational experiments. The category describing the research goal allows for optimization approaches. Other ambitions might include the derivation of closed-form formulas or performance evaluation of strategies or their comparison.

Of course, several choices had to be made in the above classification scheme. We use standard terminology where convenient, although other choices might be more appropriate depending on the application context. 
Obviously, the full typology string for a problem specification is difficult to decipher. Thus, we present a condensed variant of it. The fine-grained typology above can then be used in a longer introduction to technically put a result into context. In our opinion, the condensed typology string should reflect differences in the problem setting that also have an impact on the methods used to investigate them.

\begin{tabular}{|c|c|c|c|}
\hline \multicolumn{4}{|c|}{ Condensed Typology } \\
\hline Dimension & Values & Explanation & $\begin{array}{l}\text { Number } \\
\text { of papers }\end{array}$ \\
\hline \multirow[t]{4}{*}{ Echelons } & \multicolumn{3}{|c|}{ Number of echelons } \\
\hline & 1 & single echelon & n.a. \\
\hline & 2 & two echelons & 244 \\
\hline & $n$ & general number of echelons & 153 \\
\hline \multirow[t]{5}{*}{ Structure } & \multicolumn{3}{|c|}{ Relationship between items } \\
\hline & $\mathrm{C}$ & convergent material structure & 42 \\
\hline & $\mathrm{D}$ & divergent material structure & 189 \\
\hline & G & general material structure & 88 \\
\hline & $\mathrm{S}$ & serial material structure & 91 \\
\hline \multirow[t]{3}{*}{ Capacity } & \multicolumn{3}{|c|}{ Restriction on availability of resources } \\
\hline & $\mathrm{F}$ & finite storage and/or processing capacity & 71 \\
\hline & I & infinite capacity (no constraint) & 325 \\
\hline \multirow[t]{4}{*}{ Delay } & \multicolumn{3}{|c|}{$\begin{array}{l}\text { Time it takes to deliver an item } \\
\text { (including production times, excluding stock-out delays) }\end{array}$} \\
\hline & $\mathrm{C}$ & constant & 299 \\
\hline & G & general stochastic & 62 \\
\hline & $\mathrm{O}$ & other: prescribed distribution & 40 \\
\hline \multirow[t]{7}{*}{ Demand } & \multicolumn{3}{|c|}{ Exogenous demand for an item } \\
\hline & $\mathrm{C}$ & Deterministic & n.a. \\
\hline & G & general (including discrete) stochastic & 153 \\
\hline & $\mathrm{N}$ & Normal-type demand & 50 \\
\hline & $\mathrm{O}$ & other: prescribed distribution & 55 \\
\hline & $P$ & Poisson-type demand & 127 \\
\hline & $\mathrm{U}$ & $\begin{array}{l}\text { upper-bounded: typically used in } \\
\text { guaranteed service models }\end{array}$ & 44 \\
\hline \multirow[t]{4}{*}{ Customer } & \multicolumn{3}{|c|}{ Attributes (reactions to disservice, advanced demand, etc.) } \\
\hline & $\mathrm{B}$ & backordering & 321 \\
\hline & G & guaranteed service & 42 \\
\hline & $\mathrm{L}$ & lost sales & 43 \\
\hline Restrictions & \multicolumn{3}{|c|}{ Prescribed operational restrictions } \\
\hline
\end{tabular}




\begin{tabular}{llll}
\hline Condensed Typology & \\
\hline Dimension & Values & Explanation & $\begin{array}{l}\text { Number } \\
\text { of papers }\end{array}$ \\
& \multicolumn{4}{l}{ none: arbitrary policy possible } & 61 \\
& $\mathrm{~N}$ & policy: prescribed policy class & 332 \\
& $\mathrm{P}$ & quantity: prescribed lot-sizing policy & 97 \\
\hline Q & Objective to be achieved as a result of selection of control \\
indicator & policy and its parameters & \\
\hline & $\mathrm{C}$ & minimal cost (in the general sense) & 335 \\
& $\mathrm{~S}$ & achieve service-level (in the general sense) & 75 \\
\hline
\end{tabular}

Table 2: Condensed typology

For the condensed version, we add the dimensions as superscripts to the values in order to make the typology string decipherable without reference to a table or something similar to it. Thus, a general classification string would look like the following:

$$
<k>^{\text {ech }},<\text { top. }>^{\text {net }} \mid<\text { cap. }>^{\text {cap }},<\text { del . }>^{\text {del }} \mid<\text { dem. }>^{\text {dem }},<\text { cust. }>^{\text {cus }} \mid<\text { restr. }>^{\text {res }} \mid<\text { obj . }>^{\text {obj }}
$$

For illustration, we report the classification of six seminal papers in the field of multi-echelon inventory control under uncertainty by using our framework. In chronological order, Simpson (1958) and Clark and Scarf (1960) founded the so-called research streams on guaranteed and stochastic service models. Detailed foundations for divergent systems were Sherbrooke (1968) for continuous review low-demand systems and Eppen and Schrage (1981) for periodic review distribution systems. Later, Rosling (1989) treated convergent systems exactly while Lee, So, et al. (2000) is the most cited fundamental contribution on the bullwhip effect.

Our classification shows how each paper initiated a new research stream and added new knowledge to the field of multi-echelon optimization. We point this out by highlighting some key characteristics of each paper. Simpson (1958) introduced a serial system using a continuous time model and a guaranteed service model (structure $\mathrm{S}$, time $\mathrm{C}$, customer $\mathrm{G}$ ). Insights on serial systems with a discrete time model and a backorder customer type were first published by Clark and Scarf (1960) (structure S, time D, customer B). The restriction to serial systems was overcome by Sherbrooke (1968) (structure D, time C) for continuous time and by Eppen and Schrage (1981) (structure D, time D) for discrete time, who introduced divergent distribution systems. Subsequently, Rosling (1989) used a convergent system (structure C). Lee, So, et al. (2000) showed the bullwhip effect for a serial system with discrete time, and their methodology is exact as well as computational (methodology EC). While the research goal of all other seminal papers mentioned here is optimization, theirs is comparison (goal C). 
1. Simpson (1958): Long: $n, S, C, G|I, C| U, G|b, F, U| C|| E, 0$

Short: $n^{\text {ech }}, S^{\text {net }}\left|I^{\text {cap }}, C^{\text {del }}\right| U^{\text {dem }}, G^{\text {cus }}\left|P^{\text {res }}\right| C^{\text {obj }}$

2. Clark and Scarf (1960): Long: $n, D S, D, G|I, C| G, B|N, F, N| C|| E, 0$

Short: $\mathrm{n}^{\text {ech }}, \mathrm{DS}^{\text {net }}\left|\mathrm{I}^{\text {cap }}, \mathrm{C}^{\text {del }}\right| \mathrm{G}^{\mathrm{dem}}, \mathrm{B}^{\text {cus }}\left|\mathrm{N}^{\text {res }}\right| \mathrm{C}^{\text {obj }}$

3. Sherbrooke (1968): Long: $2, D, C, G|I, G| B, B|b, F, N| C|| A, 0$

Short: $2^{\text {ech }}, D^{\text {net }}\left|I^{\text {cap }}, G^{\text {del }}\right| P^{\text {dem }}, B^{\text {cus }}\left|P^{\text {res }}\right| C^{\text {obj }}$

4. Eppen and Schrage (1981): Long: 2, D , D , G|I , C $|N, B| B, F, N|C| \mid E, 0$

Short: $2^{\text {ech }}, D^{\text {net }}\left|I^{\text {cap }}, C^{\text {del }}\right| N^{\text {dem }}, B^{\text {cus }}\left|P^{\text {res }}\right| C^{\text {obj }}$

5. Rosling (1989): Long: $n, C, D, G|I, C| G, B|N, F, N| C|| E, 0$

Short: $\mathrm{n}^{\text {ech }}, \mathrm{C}^{\text {net }}\left|\mathrm{I}^{\text {cap }}, \mathrm{C}^{\mathrm{del}}\right| \mathrm{G}^{\mathrm{dem}}, \mathrm{B}^{\text {cus }}\left|\mathrm{N}^{\text {res }}\right| \mathrm{C}^{\text {obj }}$

6. Lee, So, et al. (2000): Long: 2, S, D , G|I, C|G, B|b , F , O|C ||$E C, C$

Short: $2^{\text {ech }}, S^{\text {net }}\left|I^{\text {cap }}, C^{\text {del }}\right| G^{\text {dem }}, B^{\text {cus }}\left|P^{\text {res }}\right| C^{\text {obj }}$

In the next two sections, we discuss the main insights obtained from the classification. We use our typology to categorize these insights. Let us remark here that those insights do not relate to managerial insights obtained in these papers, but to the development of knowledge over a period of about 60 years in terms of the assumptions necessary for rigorous analysis. All graphs present a longitudinal perspective on every one of the classification dimensions. Note that, since papers can serve more than one purpose at the same time, percentages may exceed $100 \%$.

\section{Insights on methodology and research goals}

In this section, we discuss the generic scientific aspects of the classified papers. This concerns the second part of our classification. The problem types (models) are discussed in Section 4.

\subsection{Methodology of the papers}

Figure 1 shows the use of various research methodologies that were applied to stochastic multi-echelon inventory systems. There is no clear trend in the preference for a particular methodology over time. Discrete event simulation as an optimization method starts in the early 1990s. A plausible explanation is that the computing power needed to optimize multi-echelon inventory systems by simulation was not available 


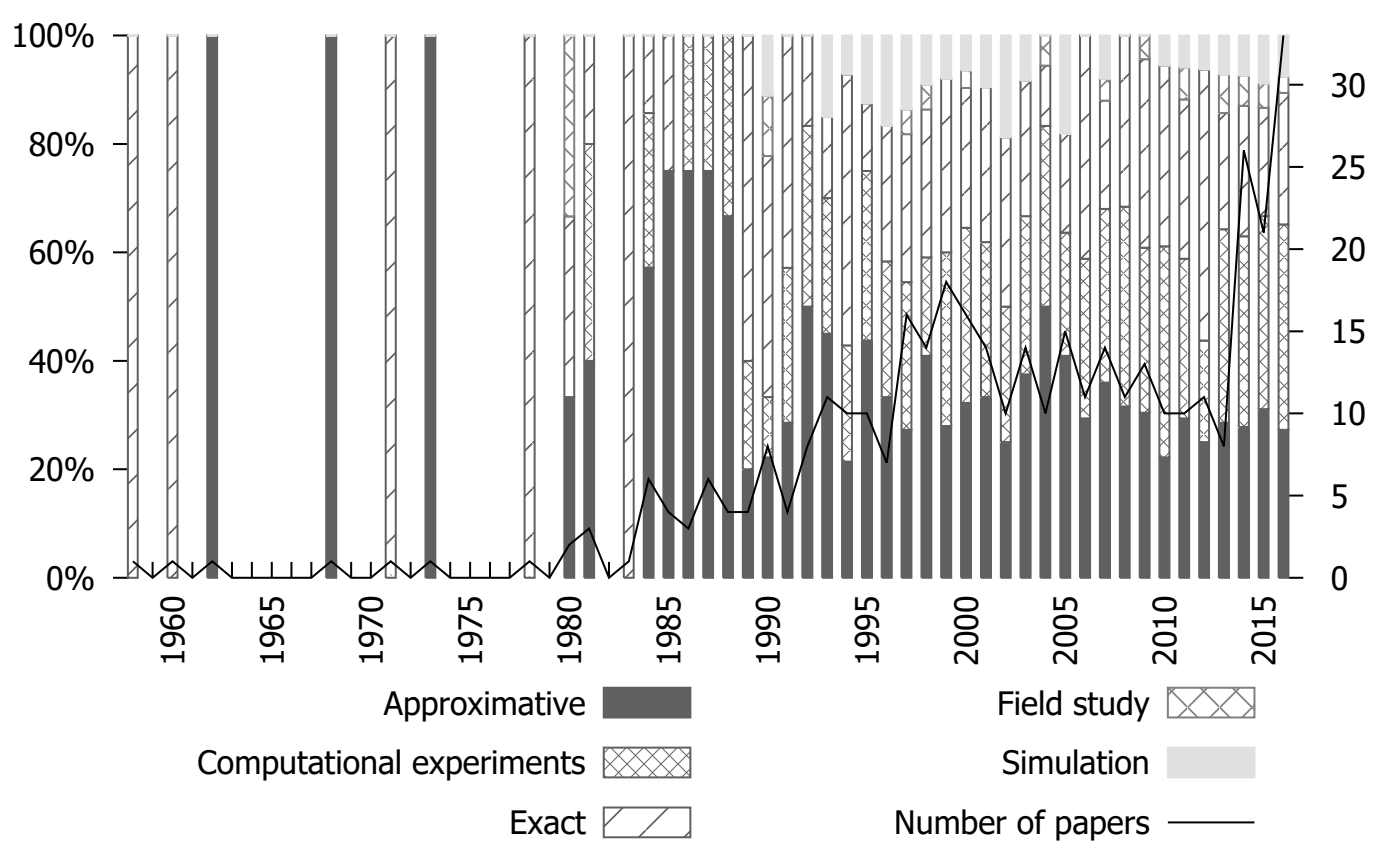

Figure 1: Methodology

before that point in time. As computers get faster, this methodology holds a promise for optimizing policy parameters for large-scale realistic systems.

The fact that $56 \%$ of the papers develop approximate expressions for performance measures shows the complexity of the analysis of multi-echelon inventory systems under stochastic demand. We have classified papers under the balance assumption and under the GSM assumption as exact if starting from these assumptions no additional assumptions were used that made the analysis approximate. Clearly, both the balance assumption, which relaxes the constraint that order release quantities must be non-negative, and the GSM assumption, which either strictly bounds demand or assumes unspecified flexibility to always satisfy stochastic demand, are assumptions that depart from reality. In the case of the balance assumption, various papers assess the impact of the relaxation on the validity of the mathematical analysis by discrete event simulation (Diks and de Kok 1999; Doğru, de Kok, et al. 2009; van der Heijden et al. 1997; Zipkin 1984). Exact analysis is presented in $44 \%$ of the papers. In $12 \%$ of the papers, discrete event simulation is used as the basis for optimization.

One striking insight derived from this count is that the number of papers documenting field studies is small for a field that claims to have a wide range of real-world applications. 


\subsection{Research goal}

The research goal of most publications is optimization (see Figure 2) in order to facilitate decision support. Earlier and seminal contributions determined optimal policy structures, whereas performance evaluation received more attention in later years, in particular in the 1990s. As more concepts and approaches evolved over time, comparisons were needed.

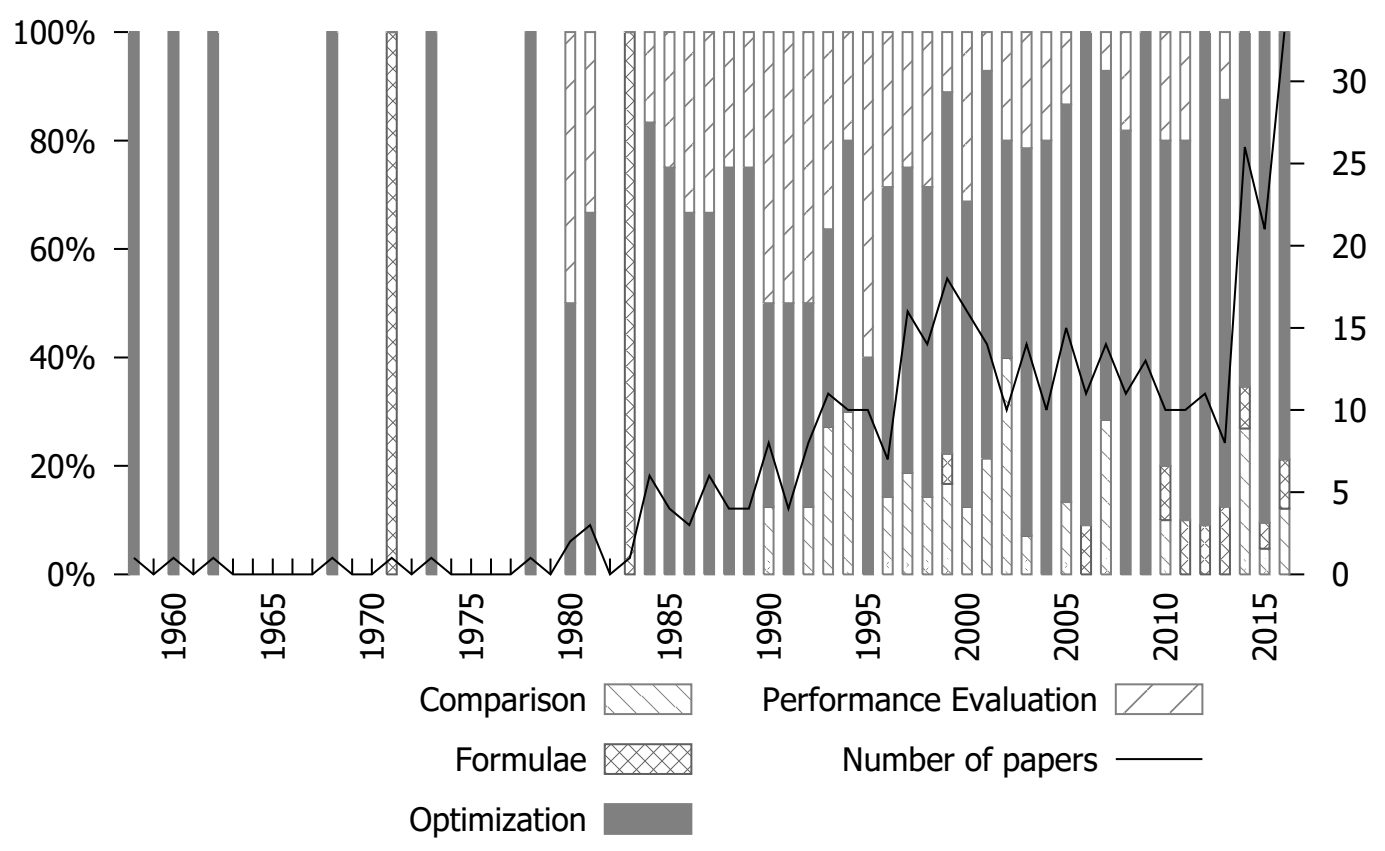

Figure 2: Research goal

\subsection{Applications in practice}

We found only a few field studies: less than $5 \%$ of the classified papers discuss an actual application of the methods in a real-world setting, which we classify as "Field Study" in the methodology dimension. Given this small number, and given the importance of the application aspect for supply chain research, it is worthwhile to briefly discuss these papers in more detail.

Overall, the application cases roughly fall into two types of business processes: managing service parts on the one hand and managing inventory through the manufacturing chain for either industrial or consumer products on the other hand. One exception is Cachon and Fisher (1997), who optimize reorder points in the distribution supply chain from warehouses to retailers in a vendor-managed inventory setup 
for Campbell Soup.

The first applications were reported by Muckstadt and Thomas (1980) for an anonymous industrial system and by Cohen, Kamesam, et al. (1990) for IBM's US aftersales service business. Both address the configuration of the parts distribution network, including a non-centrally controlled supply chain or the value of considering a multiechelon versus single-echelon model in order to quantify the inventory required for given service levels. Another application at IBM, this time as part of a larger, extended-enterprise strategic decision-support system that considers production materials, finished goods and service parts, is reported in Lin et al. (2000).

Another set of papers, from Graves, Kletter, et al. (1998) including Billington et al. (2004), Bossert and Willems (2007) and Schoenmeyr and Graves (2009) up to Farasyn et al. (2011), all consider strategic safety stock placement based on the guaranteed service model (GSM). To some extent, they represent the development of the GSM model over time, both conceptually and with respect to its dissemination through commercial off-the-shelf inventory management tools. The applications are all in the area of manufacturing for either consumer goods (Kodak, HP, Procter and Gamble) or industrial products (Celanese, Teradyne). Most of these papers have been published in the journal Interfaces.

In de Kok et al. (2005a) dynamic echelon base-stock policies as a basis for operational control of the supply chain of Philips Semiconductors and its downstream partners eliminate the bullwhip effect. The instantaneous calculation of materialfeasible plans is a distinct feature that comes with the application of base-stock policies from multi-echelon inventory systems under stochastic demand. Normally, computationally intensive mathematical programming heuristics are used for this purpose that do not allow for testing the impact of human overwrites during planning sessions involving multiple actors in the supply chain.

More recent papers look at different, more particular and more diverse aspects of supply chain and inventory system. Yang et al. (2013) investigate the value of lateral transshipments and pipeline stock for service parts of industrial (dredging) products. Moncayo-Martinez, Resendiz-Flores, et al. (2014) use the GSM model for strategic safety stock placement for an unnamed company in the automobile parts industry, while Klosterhalfen, Minner, and Willems (2014) combine the GSM model with dual sourcing aspects for an unnamed client in the industrial electronics industry.

Recently, the application areas have become more diverse. Berling and Marklund (2014) consider the distribution supply chain in the retail field, showing that a coordinated inventory policy can significantly reduce inventory investment while increasing service levels, using continuous review ( $R, n Q)$ policies. van den Berg et al. (2016) look at inventory allocation for service parts in the utility industry, where the service level quantification goes beyond the usual parts-based measure to capture the resulting unavailability in terms of relative minutes of downtime for the 
utility's clients. Doğru and Özen (2015) look at tactical inventory planning in the telecommunications equipment industry. Fleischhacker et al. (2015) study inventory positioning of pharmaceutical products in a clinical trials supply chain, which is by its nature a finite horizon problem. They use a stochastic programming model with chance constraints to determine the initial inventory as well as base-stock levels.

Overall, the reported savings are usually huge for the reported applications, in the multi-million dollar range or more. The applications typically involve large business transformation and organizational change projects. Such projects do not happen very often, which might be one reason for the rather small number of published field studies. Most likely, the adoption of supply chain and inventory research results in practice is much more common than the few cases reported in the literature suggest due to confidentiality or other constraints.

\section{Problem types studied in the papers}

In this section, we specify which types of problems have been studied and what the main achievements have been. We structured this following the dimensions of our typology. Since papers may study several problem types at the same time, the sum of percentages of type classes may exceed 100\%. For each dimension, we identify avenues for further research. This research should close the gap between the assumptions made so far and the assumptions required for application of the models developed in real-life situations.

\subsection{Number of echelons}

As we consider multi-echelon inventory systems under stochastic demand, it is of interest how many echelons the systems studied in literature consist of. We find that roughly $62 \%$ of the papers consider two-echelon systems and $39 \%$ of the papers consider $n$-echelon systems. Of the latter papers, $15 \%$ concern convergent systems, $41 \%$ concern serial systems, $22 \%$ concern divergent systems, and $31 \%$ concern general systems. Of the papers on general $n$-echelon systems, about $24 \%$ assume bounded demand. We can conclude that the majority of papers is on two-echelon systems, which shows that extending the analysis to more than two echelons is by no means trivial. We need specific assumptions like bounded demand or the balance assumption of Eppen and Schrage (1981) to allow for the analysis of $n$-echelon general structures. Otherwise, due to the curse of dimensionality, an approximate analysis of $n$-echelon systems seems inevitable.

As the number of echelons in a supply chain is primarily determined by the number of levels in the Bill of Material of the product family under consideration, two-echelon supply chains are seldom. Thus, it is important to pursue further research on $n$-echelon 
systems, where we identify policies that allow for mathematically tractable results or simulation-based optimization.

\subsection{Structure}

Considering the structure of the supply chain, it comes as no surprise that the first papers on multi-echelon inventory systems concern serial structures, e.g., Simpson (1958) and Clark and Scarf (1960). Muckstadt (1973) introduces a general many-tomany structure in the context of repairable products and components. The paper by Lambrecht et al. (1984) is the first on convergent structures, inspired by inventory management with MRP systems. For both structures, there is an increasing number in the following years, especially in the 2000s.

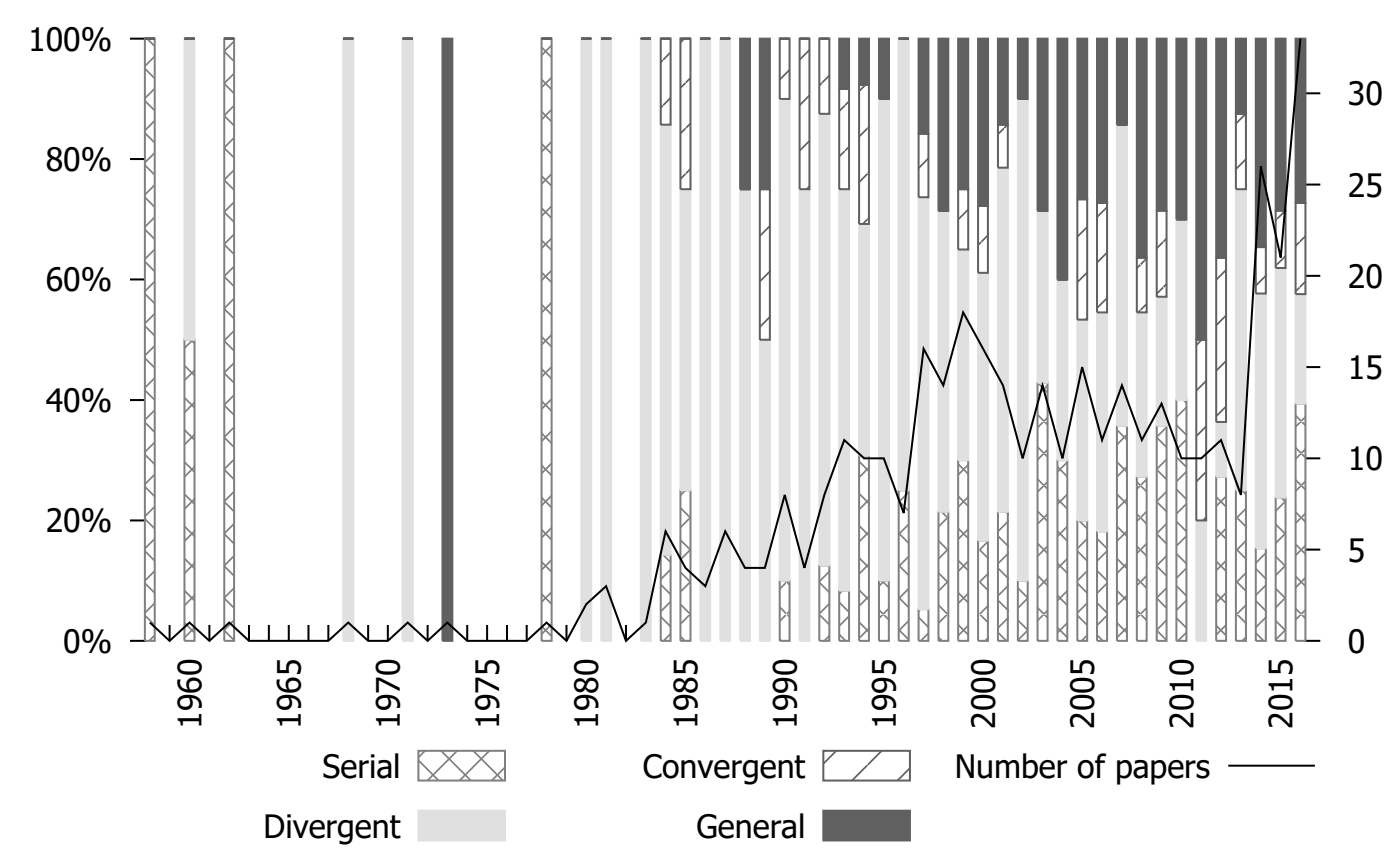

Figure 3: Structure

Clark and Scarf (1960) provide the methodological foundation of much of the work on multi-echelon inventory systems, as the convexity arguments they used to prove optimality of base stock policies and the recursive determination of optimal base stock levels has been used in many subsequent papers. Roughly $23 \%$ of the papers classified concern serial systems. Until 1980, divergent systems were considered together with serial systems, mainly in continuous time and in the context of repairable items. Eppen and Schrage (1981) initiated two decades of papers on divergent systems with major contributions in the 1980s from Federgruen and Zipkin (1984a,b,c) and 
Zipkin (1984). Rosling (1989) published his seminal paper on convergent systems in discrete time, showing the equivalence with serial systems. Interestingly, papers on convergent structures only concern $11 \%$ of the papers we classified.

Around the turn of the century, Assemble-To-Order (ATO) systems consisting of two BOM levels and a general structure, i.e., a component can have multiple parents and an end-product can have multiple children, become the focus of attention, see Chen and Song (2001), Song (1998), and Song, Xu, et al. (1999).

We find three different methods for analyzing general $n$-echelon systems. Ettl et al. (2000) determine the system performance under installation base stock policies and optimize the base stock levels by a tailor-made conjugate gradient method. de Kok and Visschers (1999) extend Rosling (1989) to general structures, which yields a class of echelon base stock policies called Synchronized Base Stock (SBS) policies (de Kok and Fransoo 2003), for which the optimal parameters can be determined efficiently (using results from Diks and de Kok (1999)).

Inderfurth (1991), Inderfurth and Minner (1998), Graves and Willems (2000), and Humair and Willems (2006) extend the work by Simpson (1958) to more general structures and this work marks the start of a huge amount of papers on general structures under the guaranteed service model (GSM) assumption. A second push for the GSM was triggered by Magnanti et al. (2006). They presented a mixed-integer linear programming model (MILP) for the (approximate) solution of the GSM in very general contexts. This step enables the treatment of the GSM by standard MILP solvers.

As, in practice, serial systems do not exist, the progress made since 1990 on divergent structures and general structures is of paramount importance. Still, more research on general structures is needed as the assumptions made regarding demand processes, lead times and lot-sizing are restrictive.

\subsection{Time}

Throughout the entire history of stochastic multi-echelon research, roughly 50\% of the papers assume discrete time, that means $50 \%$ of the papers assume continuous time. Discrete time assumptions are motivated by the underlying planning systems, such as MRP. The continuous time assumptions are motivated by the fact that user and customer demands trigger replenishments. From the beginning, both continuous and discrete time are used and no trends over time can be identified. The continuous-time papers are dominated by spare parts management, starting with the seminal paper of Sherbrooke (1968). The discrete time papers build on the work by Clark and Scarf (1960). GSM papers play a special role, starting with Simpson (1958). Although Simpson (1958) uses continuous time formally, the same modeling approach could be formulated for discrete time by just requiring the service times to be integral. 
This was actually exploited in the dynamic programming algorithms introduced by Inderfurth (1991).

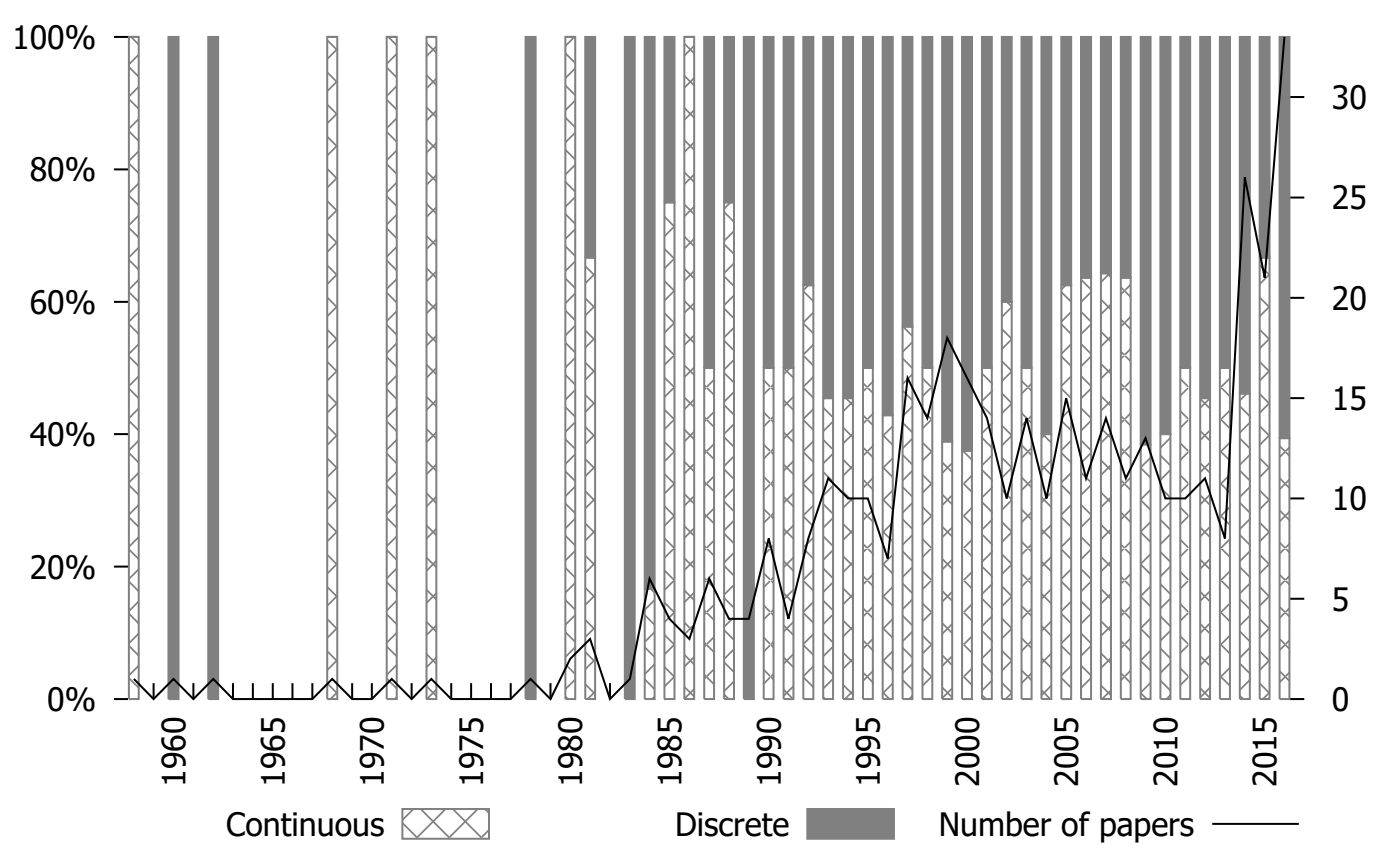

Figure 4: Time

When considering real-life situations, we can distinguish between the continuous time service supply chains, i.e. spare parts systems, and the discrete time initial supply chains, i.e. supply chains that create products. Due to the low demand rates in service supply chains and the many sources of demand, it is quite natural to assume continuous time demand-driven policies and Poisson demand. Many real-world aspects of service supply chains, such as transshipments and expediting, have been dealt with. This explains the success of quantitative models for service supply chains embedded in software since Sherbrooke (1968). The situation for initial supply chains is much different. The discrete time characteristics of the models comes with the fact that these supply chains are to a large extent forecast-driven. Decisions on order releases are taken weekly or daily, as order release requires careful coordination between different links in the supply chain. Control of initial supply chains is to a large extent still MRP-logic-based, despite its fundamental flaws as explained in de Kok and Fransoo (2003). The aforementioned software tools for multi-echelon system optimization are mainly used to set safety stock parameters in MRP. An exception is the implementation of the SBS policies at Philips Electronics as discussed in de Kok et al. (2005a). Hence, development of discrete time policies for operational control of general structures under demand and supply uncertainty is a prerequisite 
for further progress.

\subsection{Information}

Almost all papers assume global information (cf. Figure 5). This might be surprising at first sight, but it is a consequence of our convention to also categorize installation stock policy papers, which require global information to set coordinated parameters as global. For the identification of those contributions that only require local information for replenishment execution, we refer the reader to the policy classification into echelon and installation stock types. Although supply chain research has seen a large number of contributions on gaming and information issues over the last decade, there is still a research gap with regard to complex supply networks that go beyond two-stage serial systems or the analysis of contractual coordination problems without inventories or in single-period environments.

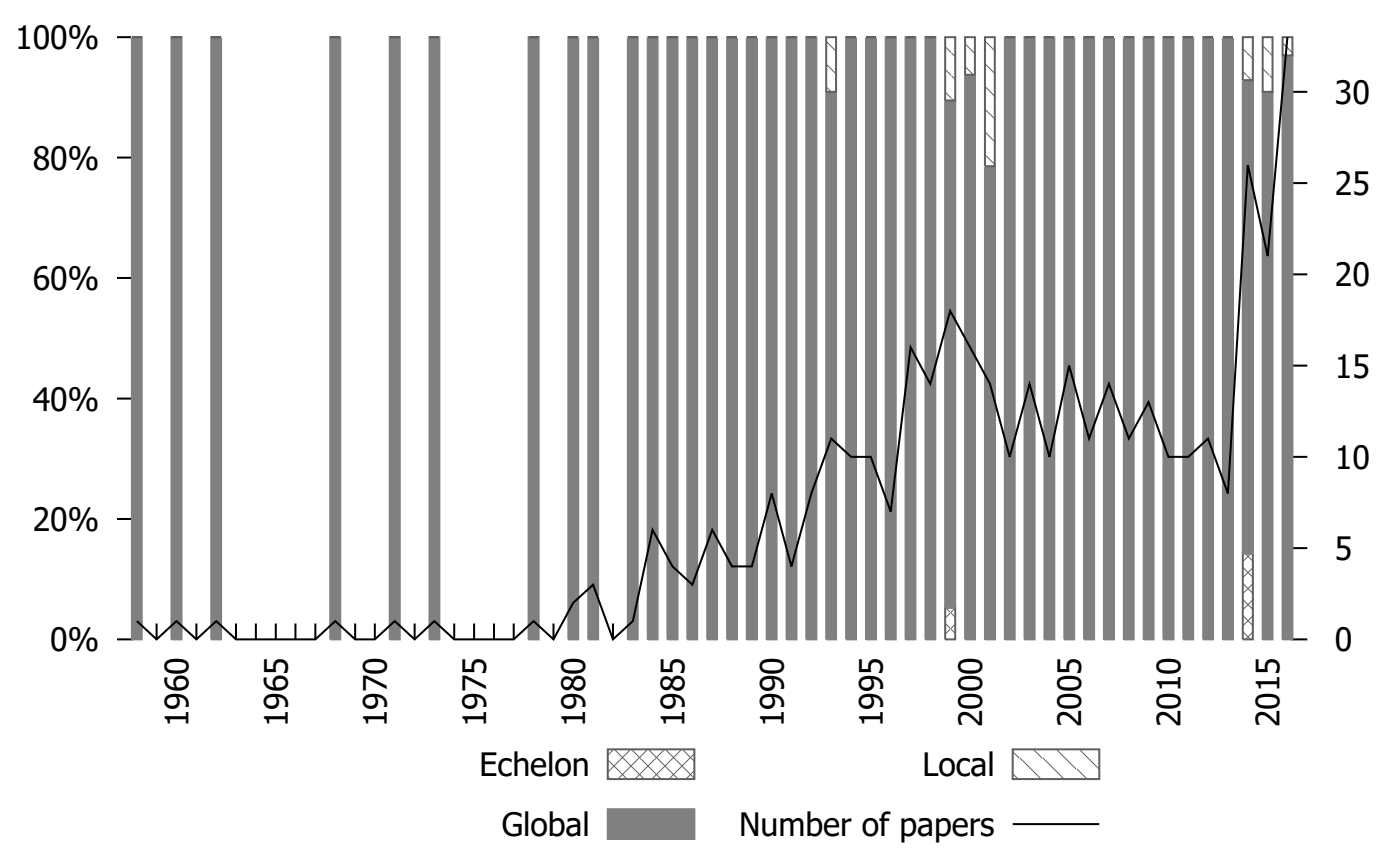

Figure 5: Information

\subsection{Capacity}

Early papers only considered systems with infinite capacity. The first paper assuming finite capacity by Lee and Moinzadeh (1987b) considers a service supply chain with finite repair capacity. From the beginning of the 1990's and onwards, papers assuming 
finite capacity were consistently published, but the majority of publications still uses infinite capacity, see Figure 6.

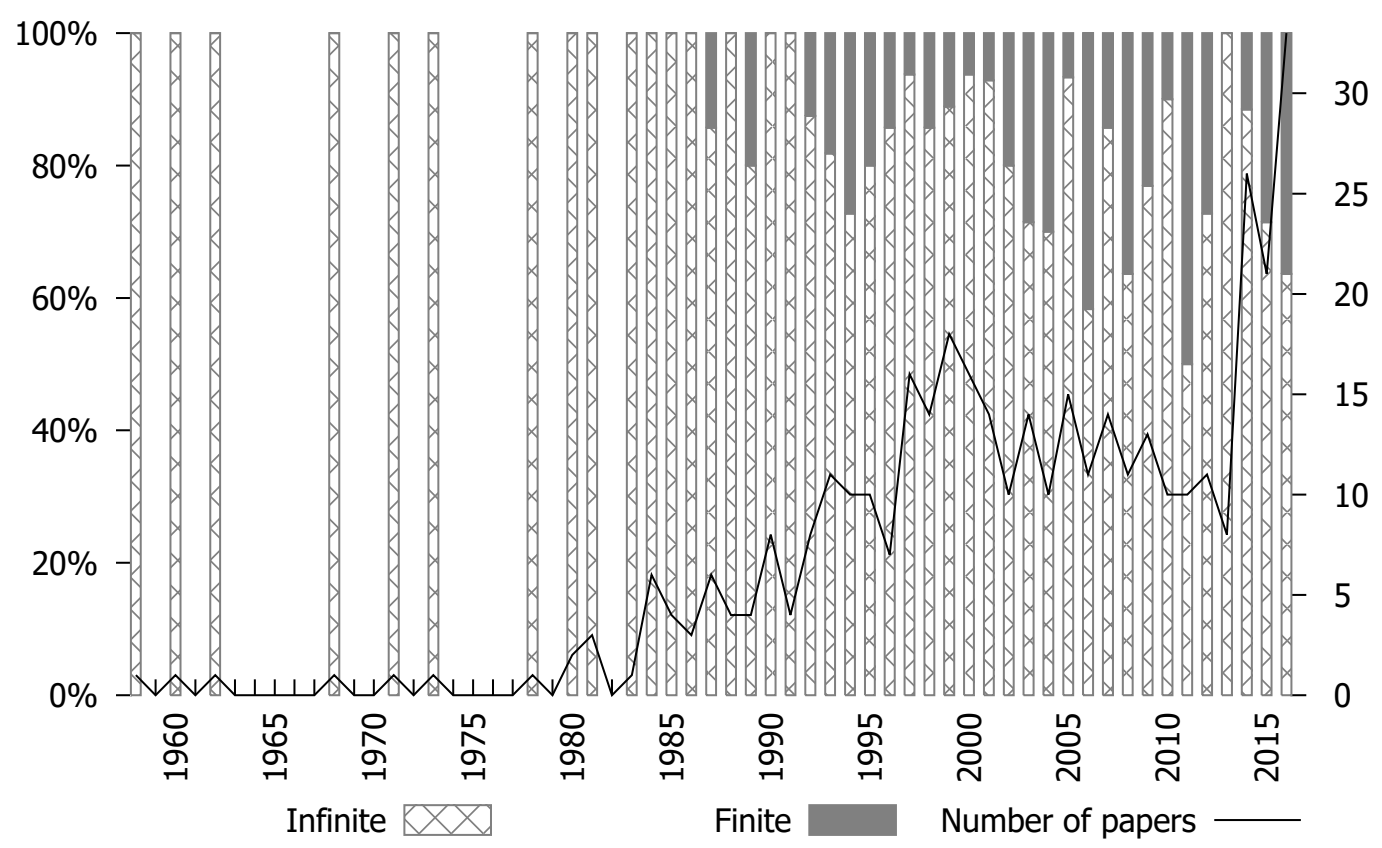

Figure 6: Capacity

Similar to lot-sizing, which is discussed later, finite capacity adds considerable complexity to multi-echelon inventory system optimization under stochastic demand. To date, there are no analytical results that enable calculation of (close-to-)optimal policies under finite capacity across a multi-echelon system. Assuming base-stock policies and finite capacity, Glasserman and Tayur (1994) and Glasserman and Tayur (1995) circumvent this analytical barrier by applying the Infinitesimal Perturbation Analysis (IPA) technique to sample paths from discrete event simulation to numerically compute gradients of the cost function as a function of base-stock levels.

It seems that the assumption of finite capacity at the most upstream system node (in the case of serial and divergent systems) does not add complexity in terms of determining an optimal policy compared to the infinite capacity case. However, as soon as we consider finite capacity at other nodes in the network, no results are available. Janakiraman and Muckstadt (2009) identified the structure of the optimal policy for capacitated serial systems, yet the structure of the policy is high-dimensional and intractable for practical purposes.

The complexity of the analysis of $n$-echelon models is due to the mutual dependencies between echelon inventory positions and echelon stocks of different items at different points in time. In the case of infinite capacity serial systems these mutual 
dependencies can be expressed in a set of recursive equations that link the inventory position of an item to the echelon stock of its predecessors: the inventory position of an item at any point in time is bounded by the echelon stock of its predecessor at the same point in time. These recursive equations are generalized to the case of divergent $n$-echelon systems in Diks and de Kok (1998) under the balance assumption (cf. Eppen and Schrage (1981)). However, when assuming finite capacity in serial systems, under echelon base-stock policies the mutual dependencies propagate over time, so that the inventory position of an item at some point in time depends on the echelon stock of its predecessors over multiple points in time in the past. Thus we loose the Markov property that it suffices to know the state of the system at the time of decision-making. This phenomenon of dependence of item inventory position on the evolution of the echelon stock of its predecessor over time also occurs when analyzing random yield in multi-echelon systems. It also explains why, except for papers on serial systems, most papers only assume two-echelon systems: complexity increases considerably with the extension from two to $n$-echelon systems. In view of the above, it comes as no surprise that more than $80 \%$ of the papers assume infinite capacity. We do see increased attention to finite capacity systems in the last three decades: from about 5\% before 1990 to 25\% since 2010. Furthermore, we note that about $55 \%$ of the finite capacity papers assume constant delays and about $30 \%$ assume exponential delays. Among the latter, we see both convergent and divergent systems, while in the former, we primarily see serial and divergent systems.

In real life, there is no such thing as infinite capacity. Despite the fact that lead time agreements can be made, such that anything ordered can be delivered within the agreed lead time, we need more insight into the impact of the dual constraints set by both resource and material availability. Concerning multi-echelon inventory models that assume finite capacity, we conclude that Janakiraman and Muckstadt (2009) provide the state-of-the-art regarding discrete time systems. The discrete time systems best represent the operational decision problem that has been supported by MRP systems since 1970. As Janakiraman and Muckstadt (2009) consider only serial systems, we need further research on capacitated convergent and capacitated divergent systems before we can make the leap towards general capacitated systems. Regarding finite capacity systems in continuous time, Abouee-Mehrizi et al. (2014) explicitly model finite capacity as an M/G/1 queue, while most papers so far now model finite capacity assuming exponential production (throughput) times, which essentially still represents infinite capacity. So, also for continuous time systems, finite capacity multi-echelon inventory systems require substantial research efforts to make real progress in understanding supply chain behavior. 


\subsection{Delay}

Delay is the time it takes for an order to get from the supplier to the customer, production time included, stock-out delays excluded. When considering the assumptions concerning the delay of replenishment orders, $76 \%$ of the papers assume constant delay, see Figure 7.

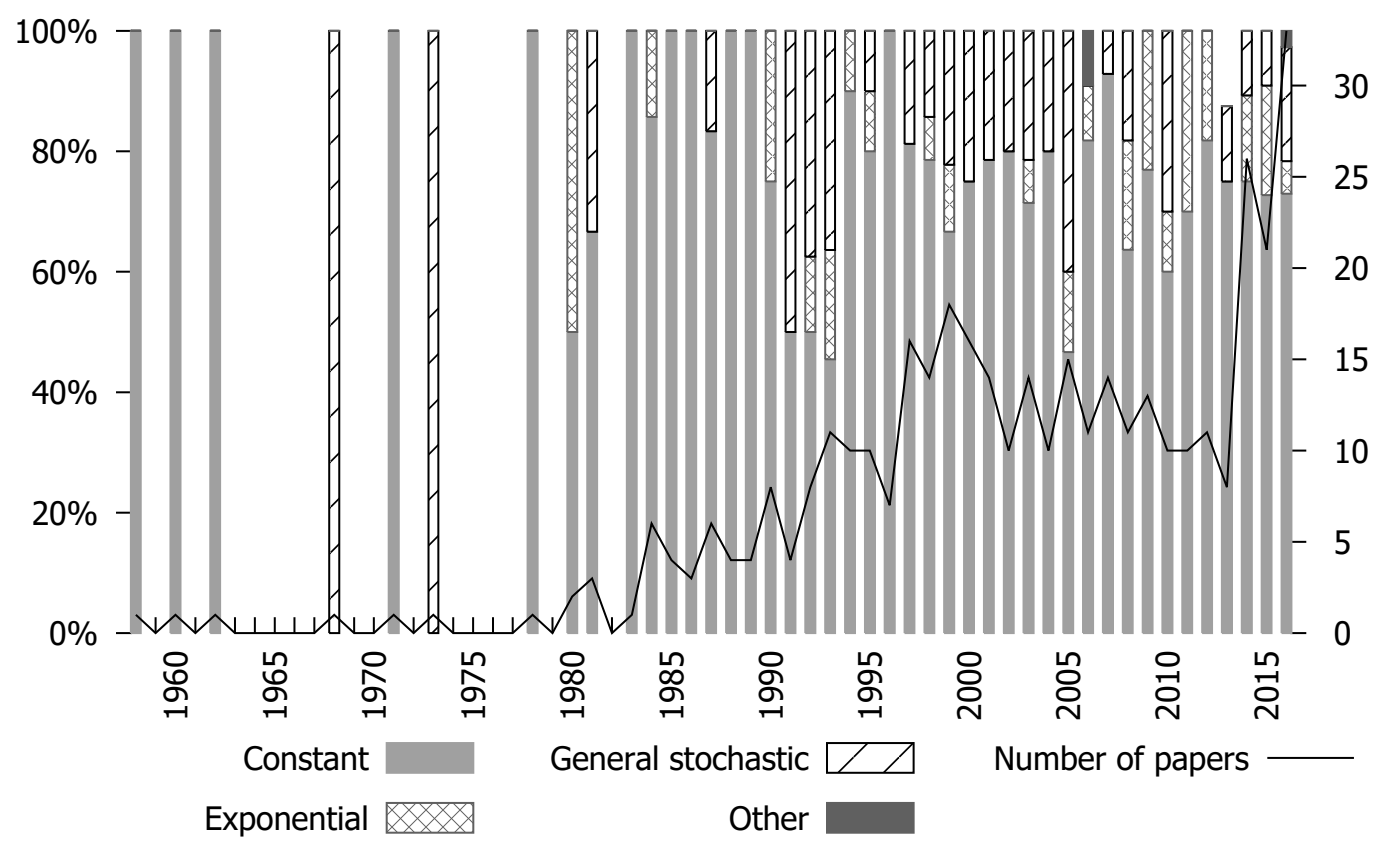

Figure 7: Delay

We find that an exact analysis usually assumes either constant delay or exponential delay. Under the latter, we find that the memoryless property of the exponential distribution allows for Markov decision process (MDP) formulations and the application of quasi-birth-death processes. The constant delay assumption ensures non-overtaking of orders, which is another assumption that underlies the tractability of analysis. In most cases, stochastic delays imply the assumption of continuous time control. Apparently, general stochastic delays induce considerable mathematical challenges, as only $23 \%$ of the papers assuming this provide an exact analysis. Furthermore, exponential delays are often assumed for tractability, after which, e.g., discrete event simulation studies show insensitivity of the results when non-exponential delays are considered. The seminal paper on spare parts systems by Sherbrooke (1968) was the first to exploit this insensitivity for spare parts distribution systems.

Like in the discussion concerning time, we should distinguish between service supply chains and initial supply chains when considering future research related to 
the delay dimension. In service supply chains, the quasi-birth death representation of the system allows for an incorporation of stochastic delays. Numerical methods are available to solve large-scale systems. The insensitivity results we found allow for the assumption of exponential delays, which reduces the state space. In initial supply chains, the combination of discrete time decision making and stochastic delays pose a major challenge for mathematical tractability. It is of great importance to make progress here as we need to develop a better understanding on how to operationally control multi-echelon systems for initial supply chains under stochastic delays.

\subsection{Demand}

The assumptions about the demand process (see Figure 8) are often essential for tractability. The assumption of Poisson demand is natural for spare parts systems (rare event perspective) and low quantities. We find that $32 \%$ of the papers assume Poisson demand and an additional 10\% compound Poisson demand. The assumption of Upper Bounded Demand in the recent (since 2000) GSM papers explains the high (15\%) percentage over the last two decades. About 35\% of the papers assume general stochastic demand. Of these papers, over 75\% assume discrete time and constant delays. This can be explained by the observation that, under discrete time and constant delays and assuming a convenient control policy, exact expressions for costs and service can be derived for serial and divergent systems. Another observation is that the normal distribution is often used as an approximation for a general distribution.

Most initial supply chains are forecast-driven, which implies that control parameters are updated weekly or monthly. There is virtually no paper that rigorously treats such situations. The stream of research on the bullwhip effect (cf. Wang and Disney (2016)) takes updating of the control parameters into account, which is probably the main source of the bullwhip effect. Yet the analysis in this stream of papers is not entirely rigorous, as upstream availability constraints are not taken into account when setting control parameters. The impact of explicitly taking into account upstream availability constraints is demonstrated in de Kok (2012), who shows that the bullwhip returns in the form of highly variable shipment quantities to the most downstream level, which requires a substantial increase in downstream safety stocks to maintain the required service level. Explicitly taking into account forecast errors is challenging, even for single-echelon models. Clearly, here is a subject of research awaiting further foundational contributions.

\subsection{Customer response to stockouts}

The first paper by Simpson (1958) used a guaranteed service approach, but in the following years only backorder type customers were considered. The majority of 


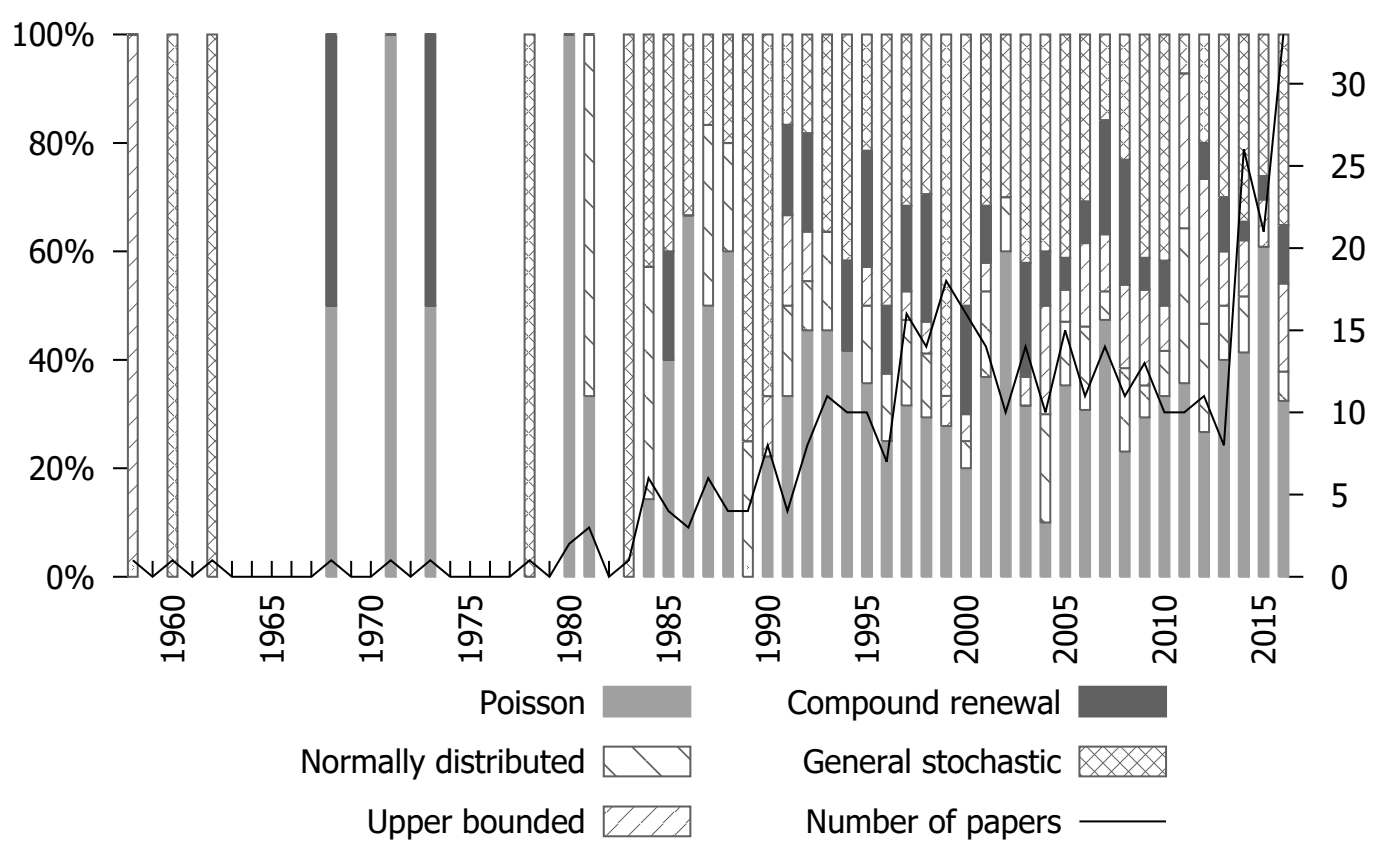

Figure 8: Demand

publications over time uses this type of customer behavior, see Figure 9. In the early and mid 1990s, guaranteed service models reappeared and the concept of lost demand was introduced.

Tractability is again the reason why $82 \%$ of the papers assume backordering of demand that cannot be satisfied in time. Optimal policies are only known under the assumption of backordering. In 10\% of the papers, the guaranteed service assumption is made, which implies that all demand is satisfied. This is realized by assuming upper bounded demand or some unspecified flexibility in supply. In $11 \%$ of all papers, demand not met in time is lost. In over 55\% of these papers, demand is assumed to be Poisson. Lost-sales models received more attention in the 2010s as the share increased to $17 \%$.

In practice, customer responses to stockouts vary. In business-to-consumer (B2C) environments, most customers choose another product or another retailer. With online sales, this has become easier than before. In business-to-business (B2B) a delivery time is negotiated when products are not available on time. If the proposed lead time is too long, the customer may still renege, otherwise the customer accepts the longer lead time. Thus, the demand process is impacted by the reneging behavior of the customers. Any form of reneging is likely to increase the state-space of the underlying Markov Decision Process to be solved, like with lost-sales for single echelon models. As it is not likely that a particular nice optimal policy can be found, it seems 


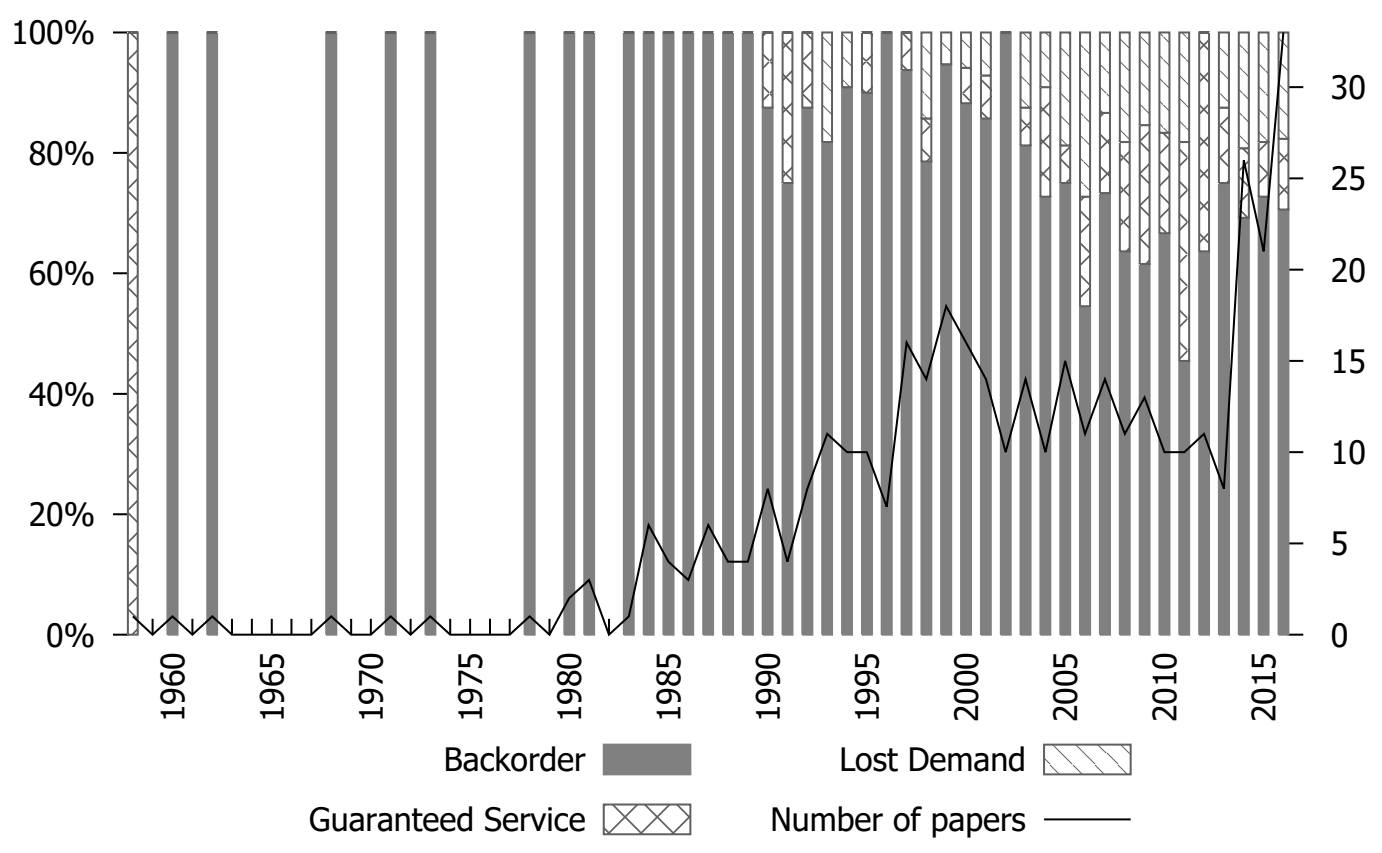

Figure 9: Customer

that the route to go is to propose classes of policies that allow for tractability, along with assumptions on the demand process and delay process, such as exponential or phase-type distributions, so that exact or approximate performance analysis is within reach. Managerial insights may be gained through carefully designed simulation experiments.

\subsection{Policy}

Remember that the specification of a policy class means that only policies in this class are considered. Whenever no policy class is prescribed, researchers seek an optimal or close-to-optimal policy. Some of the prescribed policy classes like base-stock policies happen to be the result of a search for an optimal policy. This has to be distinguished from the case where the search has been restricted to a particular class from the beginning.

\subsubsection{Optimal policies}

As in most other areas in the field of stochastic processes, researchers have strived to find optimal control policies. In the field of inventory management, it is commonly assumed that costs for holding inventory are linear in time and number on hand, 
while penalty costs are linear in time and number of backorders. Besides holding and penalty costs, fixed order costs are considered. Though other objective functions have been considered, we restrict ourselves to this cost structure, as it concerns the vast majority of papers devoted to the quest for optimal policy structures. In our analysis, we distinguish between serial, convergent, divergent and general structures.

For $n$-echelon serial systems, Clark and Scarf (1960) prove the optimality of echelon order-up-to policies under constant delays and discrete time for both the average cost case and the discounted cost case without fixed costs. In Clark and Scarf (1962), this result is extended to systems with a fixed cost at the upper echelon only. The stochastic delay case is proved by Muharremoglu and Tsitsiklis (2008) under the assumption that subsequent orders do not overtake and demand is discrete. For serial two-echelon capacitated systems, Parker and Kapuscinski (2004) prove that, if capacity at the downstream echelon is smaller than at the upstream echelon, a modified base stock policy is optimal for both stages. They observe that a so-called push-ahead effect is caused by a disguised base-stock level that cannot be achieved due to capacity limitations when the echelon-inventory position at the downstream stage is low, but can be reached if the inventory position at the downstream stage is high enough. For serial $n$-echelon capacitated systems with identical capacity limits at all stages, Janakiraman and Muckstadt (2009) characterize the optimal policy as a multi-tier base stock policy.

For $n$-echelon convergent systems with constant delays and no fixed ordering costs, Rosling (1989) proves that echelon order-up-to-policies are optimal and under these policies each convergent system is 1-1 related to a serial system. For $n$-echelon divergent systems with constant delays and no fixed ordering costs, Diks and de Kok (1998) show that echelon-order-up-to policies are optimal. However, this can only be shown under the assumption that negative shipment quantities to downstream stockpoints are allowed. This assumption was first proposed by Eppen and Schrage (1981). The implication is that echelon inventory positions after allocation can be lower than before the allocation, i.e., the option of free transshipments. As a consequence, the classical inventory balance equations for individual items may no longer hold. So far, it has been impossible to identify well-structured optimal policies for $n$-echelon divergent systems without this assumption.

For $n$-echelon general structures, there are no results on optimal policies. Various authors identified optimal policies for special general structures. Nadar et al. (2014) and Benjaafar, ElHafsi, et al. (2011) show that state-dependent order-up-to policies are optimal under multiple discrete demand classes and exponential delays, and that an optimal allocation is based on critical levels. These results have been developed only for two-echelon systems, mostly under the heading of Assemble-To-Order systems. For Assemble-To-Order systems in discrete time, Reiman and Wang (2015) derive asymptotically optimal policies using a stochastic programming approach. 
As indicated in Section 4.5, major challenges regarding optimal policies concern systems with finite capacity. It is fair to say that, for general structures there is no hope to find optimal policies under discrete time and constant lead times. The recently proposed stochastic programming approaches seem to lend themselves to application in the capacitated case. Research on the robustness of results under assumption of exponential delays, allowing for overtaking of orders, may lead to more extensive application of this assumption to initial supply chains, similar to its application to service supply chains. Another obvious avenue for identifying optimal policies concerns lot-sizing. Most results obtained so far relate to models without fixed costs. We discuss this more extensively in Subsection 4.10.

The above discussion implicitly assumes that demand is modeled as some stochastic process. A departure from that assumption is the GSM assumption, a notion coined by Graves and Willems (2000). The model under the GSM assumption was originally proposed by Simpson (1958). Under this assumption, optimal installation base stock policies can be derived computationally, as the optimization problem can be formulated as a concave programming problem. In our classification, we have indeed classified the solutions from models under the GSM assumption as optimal. On the other hand, optimality of a solution should be viewed in the context of the application of the model. The bounded demand model proposed by Simpson (1958) is different from the stochastic demand model proposed by Clark and Scarf (1960) and yields different solutions for optimal inventory deployment. This suggests the need for further research: i) Comparisons of different model paradigms on an identical set of benchmark problems, the data of which not necessarily meet all technical assumptions of the models, and ii) field studies where the empirical validity of the modeling assumptions can be assessed.

\subsubsection{Predetermined structured policies}

Figure 10 shows the development from few to many different policies over time. Initially, installation base-stock was popular or no policy was prescribed at all, i.e., the optimal policy was left to be determined in the research. Starting in the 1980s, more different policies that use the concept of echelon stock were introduced. $61 \%$ of the papers assume installation stock policies, whereas only about 16\% assume echelon stock policies. The remaining papers either leave the policy subject to analysis or assume other policies.

Close to $16 \%$ of the papers derive an optimal policy under various assumptions. It seems that this percentage has remained stable over the last three decades. In more than $50 \%$ of the papers, a base stock policy is assumed, $21 \%$ assume (s,nQ)-policies and only $3 \%$ assume $(\mathrm{s}, \mathrm{S})$-policies. This is another indicator for the complexity of multi-echelon inventory systems under stochastic demand. Under base stock policies, the customer demand propagates unchanged upstream, both in timing and quantity, 


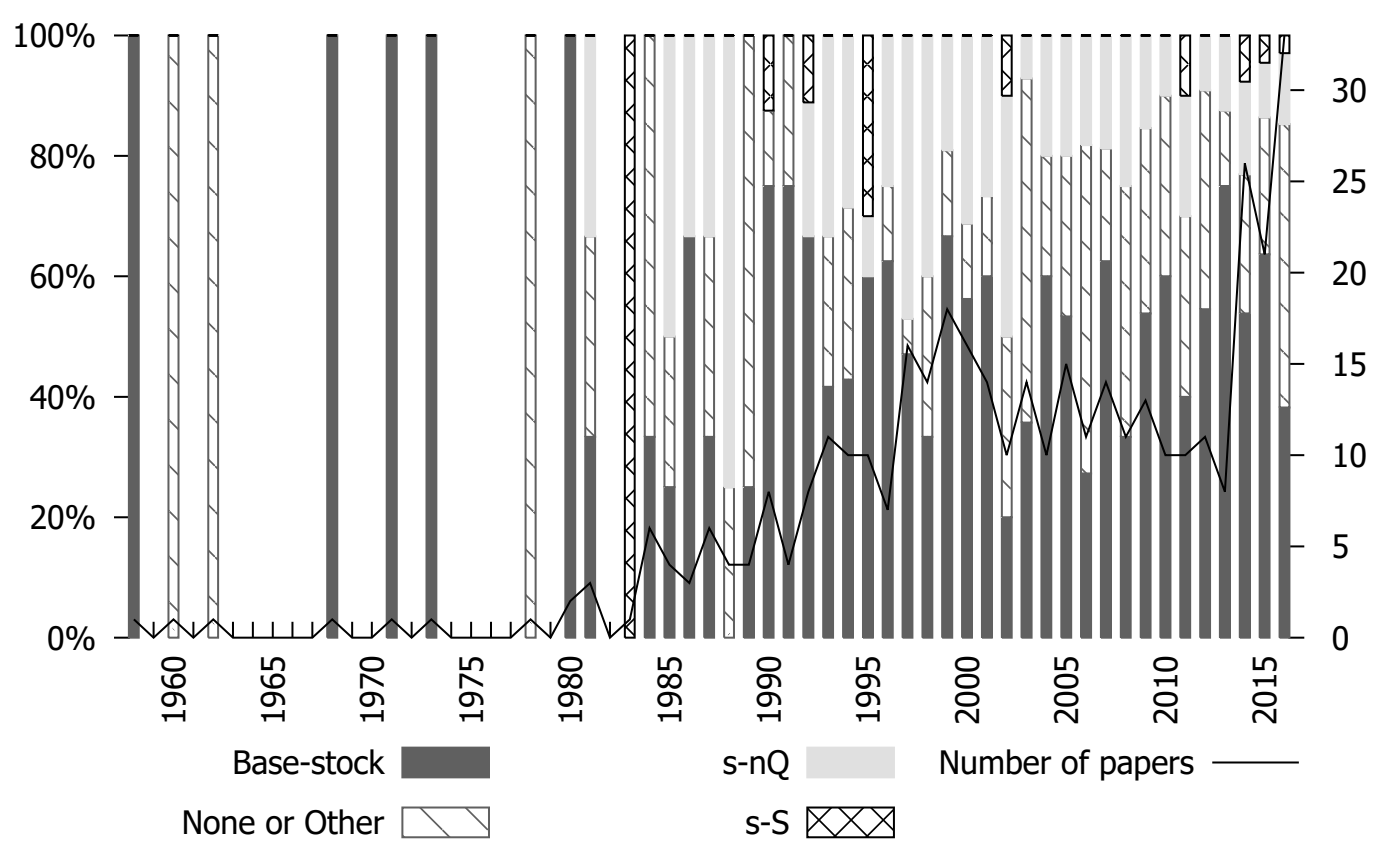

Figure 10: Policy

possibly in an aggregate form, e.g., when considering divergent systems. This is a cornerstone for the analysis of multi-echelon systems. As soon as lot-sizing or lost sales are assumed, the demand process at upstream echelons is affected in a more or less complicated manner.

We expect that pre-determined structured policies are the means to obtain scientifically and practically relevant results. Such policies should enable computationally tractable results, be it by using simulation or mathematical analysis or both, while at the same time ensuring close-to-optimal results. We expect that this is a rewarding direction as it requires both sophisticated mathematical analysis aimed at providing error bounds and sophisticated algorithms to cope with the natural structural complexity of supply chains.

With regard to policy structures, in order to operate a supply chain, we need formal order release rules, that take material and resource constraints into account. For example, the GSM model allows for calculating safety stock levels, but provides no indication how to resolve operational issues when material limits satisfaction of production requirements. Thus, research is needed to identify control mechanisms that enable operational control of general structures and to assess their performance. An interesting class of policies is that of rolling schedule policies derived from solving deterministic or stochastic finite horizon mathematical programming problems.

Another route towards identifying effective operational control rules for general 
structures is in line with the recent research on $\mathrm{N}, \mathrm{W}$, and M-models by Nadar et al. (2014), Nadar et al. (2016), and Lu, Song, and Zhang (2015). The basic structures and some additional assumptions allow for finding an optimal policy structure. These policy structures may be extendable to general $n$-echelon systems and are computationally tractable. This direction of research is both challenging and of great importance.

\subsection{Lot-sizing}

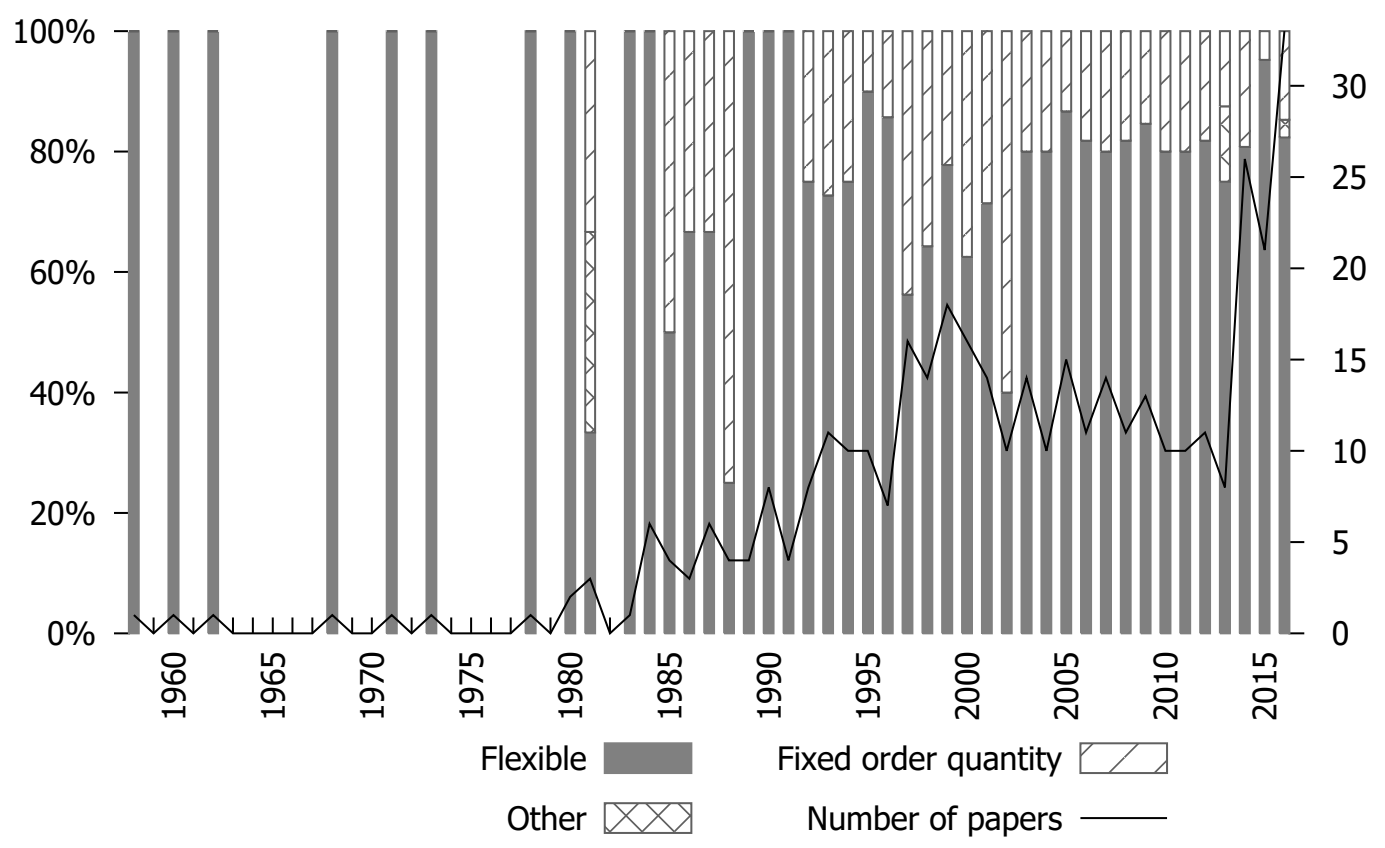

Figure 11: Lot-sizing

Lot-sizing has been a primary research subject in the context of multi-echelon systems under deterministic demand. Apparently, under the assumption of stochastic demand, lot-sizing, i.e., assuming that demand is batched into a lot to reduce the order-related costs over time, makes the analysis much harder. This is due to the fact that, under stochastic demand and fixed lot sizes, the timing of orders becomes general stochastic. Even under Poisson demand, lot-sizing induces Erlang distributed times between ordering, the renewal character of which does not "fit" with discrete time models and constant delays. We found that $80 \%$ of the papers assume no lot-sizing restrictions, see Figure 11. This includes the papers that derive the optimal policy structure, which are about $30 \%$ of all papers. About $50 \%$ of the papers assume base stock policies, either installation stock or echelon stock. Of the papers assuming 
fixed order quantities, almost $90 \%$ assume a serial or divergent structure. Both serial and divergent structures imply sequential decision making over time, while convergent structures imply parallel decision making over time. As stated above, the stochastic timing of orders when using fixed lot-sizing makes the analysis of convergent structures extremely difficult. Finally, $80 \%$ of the fixed order quantity papers assume continuous time. Flexible lot-sizing is dominant and was exclusively used until the 1980s. Subsequently, fixed order quantities were assumed in de Bodt and Graves (1985) and Schwarz et al. (1985).

When considering future challenges for research on lot-sizing in multi-echelon inventory systems under stochastic demand, we should carefully look at the typical cost structure in today's supply chains. Moving upstream in the chain, capital intensity tends to increase, whereby asset utilization becomes a major driver of profits. With high utilization comes the need for lot-sizing. We found that papers with exogenous lot-sizing constraints are few. Papers assuming lot-sizing constraints typically assume some form of nesting, i.e., upstream orders are triggered by downstream orders. To see the implication of this nesting assumption in general multi-echelon inventory systems, let us take a closer look at Rosling (1989). He shows that a convergent multi-echelon systems, i.e., an assembly system, without lot-sizing constraints is equivalent to a serial multi-echelon system. This result can be understood when realizing that the echelon inventory position of an item after ordering is the coverage of end-item demand over the sum of its cumulative lead time, i.e., the time from ordering the item until the item as part of the end-item is received in end-item stock, and its review period. The serial system follows from synchronizing each item's coverage with the coverages of items ordered earlier over the item's cumulative lead time plus review period. The analysis in Rosling (1989) can be extended to systems with lot-sizing if we maintain the equivalence with an associated serial system. In serial systems the nesting property comes natural, as it does not make sense to order an item more frequently than its successor. The required equivalence and the nesting property of the serial system implies that an item with a long cumulative lead time is ordered less frequently than an item with a short lead time. In Karaarslan et al. (2013) it is argued that this property does not hold in many supply chains: key components are expensive and have long delays, while non-key components are cheap and have short delays. The Economic Order Quantity finds that the key component has a small lot size and the non-key component a large lot size. This is against the nesting concept. Thus, we need new ideas to develop (close-to-) optimal policies with lot-sizing constraints for real-life situations.

An interesting observation from various empirical studies reported in de Kok (2015) is that upstream inventory has hardly any impact on customer service for the system's end-items. Assuming that large lot sizes create high cycle stocks, it may be possible to decompose the high-lot-size upstream part of the multi-echelon inventory 
system from the small-lot-size downstream part of the system. Such a decomposition may help to reduce the mathematical complexity of analyzing the system. Yet a thorough theoretical foundation for these findings is still lacking and important to ascertain.

\subsection{Flexibility}

Apart from Simpson (1958) who assumes that a system is always designed to cope with only bounded and operational flexibility to deal with excessive demands, the early decades see almost exclusively no flexibility (see Figure 12). Flexibility as a concept is introduced at the end of the 1980s and the early 1990s when use of allocation, expediting and routing flexibility begins.

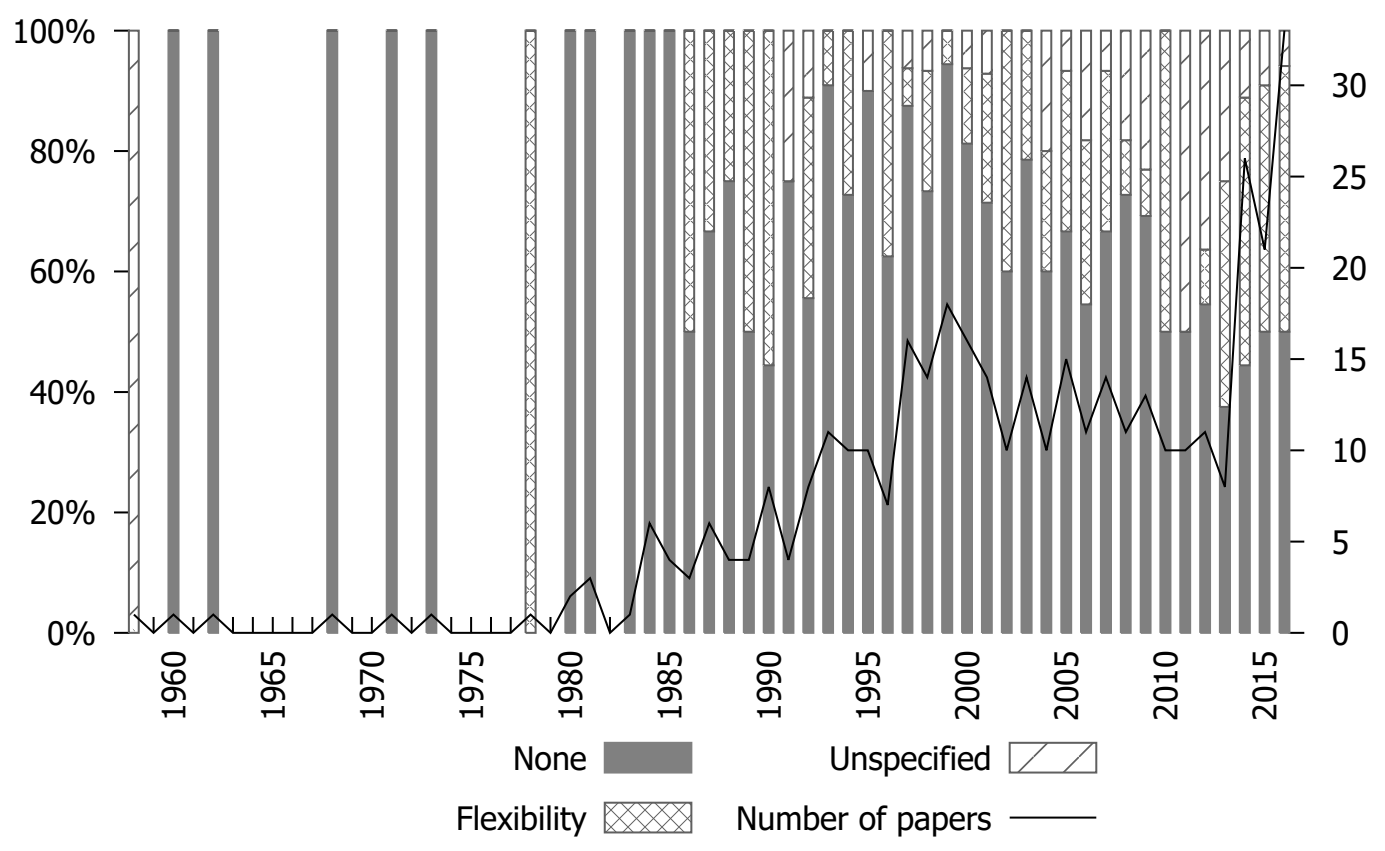

Figure 12: Flexibility

The concept of flexibility has received quite some attention since 2010 , as $50 \%$ of the papers assume some form of flexibility. We should emphasize that this correlates strongly with the GSM assumption, under which flexibility is assumed, yet no specification of the operational flexibility is provided. Over the entire set of papers, one third assumes some form of flexibility. Out of these papers, $30 \%$ assume unspecified flexibility as follows from the GSM assumption, 30\% routing flexibility, in particular transshipments, $20 \%$ concern expediting, $10 \%$ outsourcing, and $20 \%$ allocation flexibility. As routing flexibility is mainly about transshipments, divergent structures 
are dominant under this form of flexibility. We also find that $70 \%$ of those papers assume continuous time. This is mainly due to the focus on spare parts systems in this context.

The modeling of flexibility in multi-echelon inventory systems is important: with the growth of online sales and, as a consequence, the emergence of omnichannel supply chains, where a customer order may either be delivered from the brick-andmortar store or on-line from the DC without the customer being aware of it, we need new models and policies to deal with these complex operational processes. We foresee a mix of dual sourcing and multiple customer classes as modeling ingredients. In the past, flexibility assumptions have enabled the aggregation of inventory and resource availability across multiple locations. This may be a route to pursue further to avoid mathematical intractability. Discrete event simulation can be used to test the assumptions.

\subsection{Performance measures}

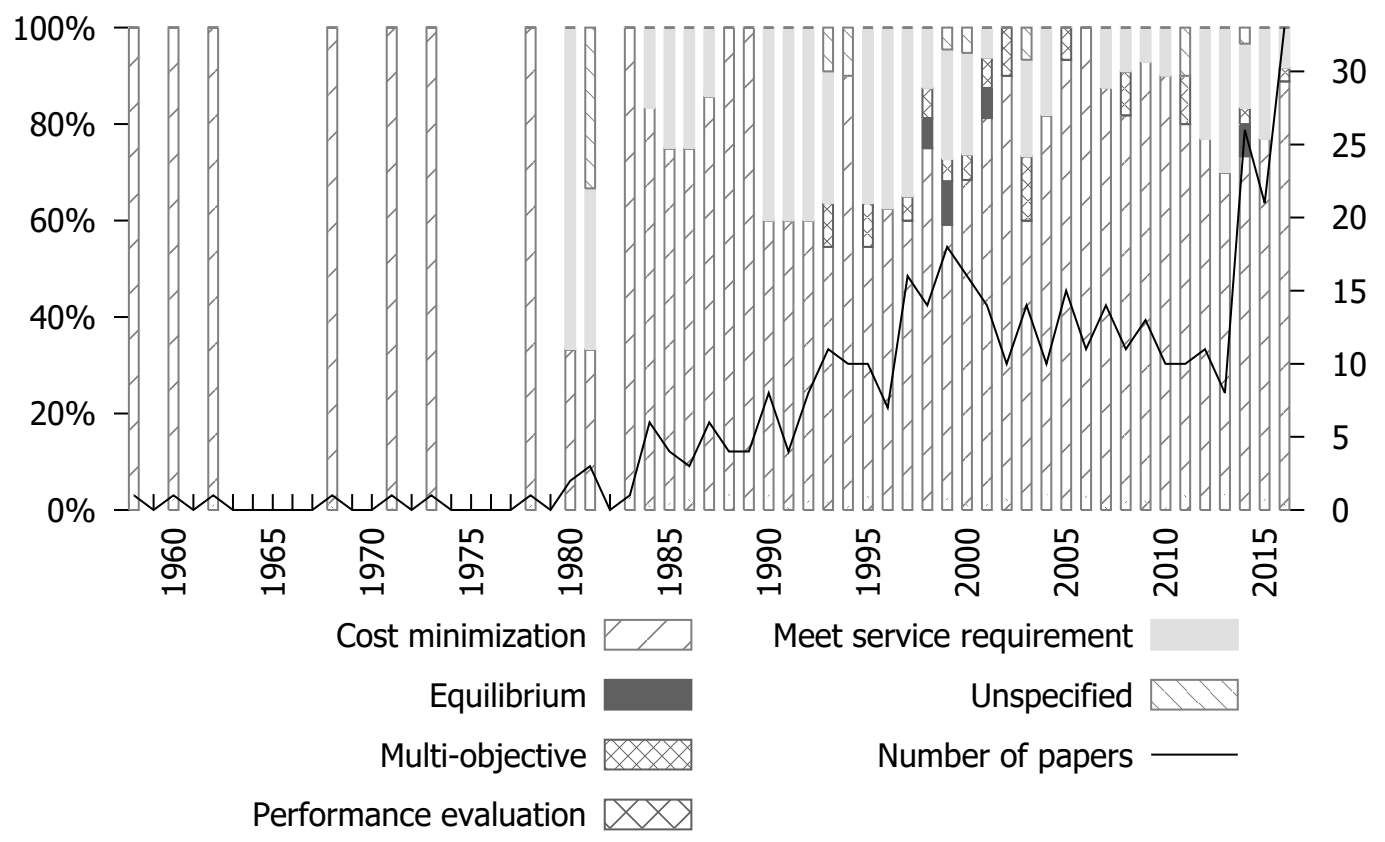

Figure 13: performance indicator

We find that $85 \%$ of the papers focus on cost minimization (see Figure 13). This may result into customer service constraints due to Newsvendor fractiles. Later, the objective to meet service requirements was introduced due to requirements of the industry and difficulties with deriving cost parameters for cost minimization, 
especially for backorders and lost sales. In the 1990s, $27 \%$ of the papers concerned performance measures other than cost, which is considerably higher than the $17 \%$ share in other decades. This may be due to the stronger focus on computational results for realistic large-scale systems during that period.

In practice, it is often hard to translate the company objectives into a single cost function. In the light of the recent discussion on corporate social responsibility, we suggest research on multiple criteria approaches, trading off costs and service measures and including sustainability measures simultaneously. Furthermore, companies have to take into account risk, which cannot be truly captured assuming an infinite horizon formulation of a cost minimization problem. The causes of risks have gained attention in our field in the form of supply chain disruptions. However, there are not many approaches including this into multi-echelon inventory systems, which are mainly based on stationary conditions, whereas the consideration of disruption would require the optimization of the best transition path back to regular operations. The same holds true for systems that include multiple (backup) supply modes in such systems. Thus, we need research starting from the correct risk modeling and the correct risk mitigation perspective.

\section{Conclusions}

Based on our classification, we were able to analyze the progress of research on multi-echelon inventory systems under stochastic demand since its emergence at the end of the 1950s. We assessed this progress from the perspective of real-life systems and their characteristics. In this assessment, we made a distinction between service supply chains and initial supply chains.

It is fair to say that Sherbrooke (1968) is the seminal paper that provides the model and the algorithm to determine control parameters in service supply chains. Over the years others have provided a more rigorous analysis of the model in Sherbrooke (1968) and included features of service supply chains that greatly add to their efficiency and effectiveness: transshipments and expediting. The fact that much of the work on service supply chain is now available in software and extensively used in practice should be seen as a great achievement.

Regarding the initial supply chains delivering products to users and consumers, the papers by Glasserman and Tayur (1995) on capacitated systems using Infinitesimal Perturbation Analysis (IPA), Graves and Willems (2000) on the Guaranteed Service Model, Ettl et al. (2000) on the Stochastic Service Model and de Kok and Visschers (1999) on Synchronized Base Stock policies, mark the moment when general structures commonly observed in practice are tackled. The four approaches start from the same model, i.e. general BOM model, nominal lead times, stochastic demand, but differ in assumptions regarding the operational control policy. The 
ultimate result is that the four approaches may yield different solutions for the same practical situations. This is clearly a topic for further research.

In our assessment of the state-of-the-art, we repeatedly mentioned the use of simulation as a means to tackle the complexity of real-world supply chains. Another important remark concerns the need for the analysis of finite capacity multi-echelon inventory systems. This stipulates the importance of Glasserman and Tayur (1995), who show that their IPA-based methodology applies for such systems. We conclude that extension of Glasserman and Tayur (1995) to systems with lot-sizing, operational flexibility (transshipments, outsourcing, expediting) is a promising direction for further research with great scientific and practical relevance.

We found that the two most cited papers by Lee, So, et al. (2000) and Chen, Drezner, et al. (2000) discuss the bullwhip effect, which is explained by decentralized, self-interested decision making by each link in the supply chain. It is much to our surprise that we hardly found papers that explicitly start from the assumption that information is not shared in the supply chain. Clearly, decentralized installation stock policies are extensively studied. We invariably assume that we can optimize parameters, such as base-stock levels, across the supply chain. Though it allows us to show the potential of centralized safety stock deployment, this perspective does not represent the current state of affairs in most supply chains. We need more empirical research on information sharing, whether strategic, tactical or operational, to provide solid ground for quantitative models that can eventually support effective decision making in real-life supply chains.

Despite its existence since the mid 1950s, multi-echelon inventory systems is still a highly active field of research. Most likely, its complexity and its practical relevance are the reasons for this. No packaged solutions exist. During our classification work we observed that some papers in non-OR journals formulated very general models and used mathematical programming techniques to "solve" the problem. Whenever the inherent stochasticity was not dealt with at least with some form of mathematical rigour, we considered the paper out-of-scope. At the same time it shows that the research on stochastic multi-echelon inventory systems needs to be broadcasted more strongly, as the application of the methods developed in these out-of-scope papers may be unjustified.

We are at the advent of a fourth industrial revolution, denoted as Industry 4.0. The availability of real-time information about location and condition of items throughout the supply chain that is required to implement the echelon base-stock policies shown to be optimal in Clark and Scarf (1960), is now a fact. 3D-printing and the Internet of Things will affect supply chain structures and supply chain planning, execution, and control. We expect that new ways of modeling information states of supply chains will generate a new wave of contributions from the field of multi-echelon inventory systems under stochastic demand. Though information delays are supposed to be 
reduced to zero, we must be aware that processing materials, repairing machines and shipping containers will always take time, not much different of what we are used to. Multi-echelon inventory models have been the main tool used in order to understand how delays and uncertainty in demand impact supply chain performance. Multi-echelon inventory models and their analysis are the means for an effective implementation of omnichannel retailing, 3D-printing in service supply chains and further collaboration in high-tech supply chains, all of which are to the benefit of the companies and markets involved.

\section{References}

The bibliography is subdivided into the classified research papers and other surveys.

\section{Classified Research Papers}

This part of the bibliography contains all the papers that we classified.

Abouee-Mehrizi, H., O. Baron, and O. Berman (2014). "Exact Analysis of Capacitated Two-Echelon Inventory Systems with Priorities". In: Manufacturing \& Service Operations Management 16.4, pp. 561-577.

Aggarwal, P. K. and K. Moinzadeh (1994). "Order expedition in multi-echelon production/distribution systems”. In: IIE Transactions 26.2, pp. 86-96.

Agrawal, N. and M. A. Cohen (2001). "Optimal material control in an assembly system with component commonality”. In: Naval Research Logistics 48.5, pp. 409-429.

Akçay, Y. and S. H. Xu (2004). "Joint Inventory Replenishment and Component Allocation Optimization in an Assemble-to-Order System". In: Management Science 50.1, pp. 99-116.

Albrecht, M. (2014). "Determining near optimal base-stock levels in two-stage general inventory systems". In: European Journal of Operational Research 232.2, pp. 342-349.

Albright, S. C. and A. Gupta (1993). "Steady-state approximation of a multiechelon multi-indentured repairable-item inventory system with a single repair facility". In: Naval Research Logistics 40.4, pp. 479-493.

Alfredsson, P. (1997). "Optimization of multi-echelon repairable item inventory systems with simultaneous location of repair facilities”. In: European Journal of Operational Research 99.3, pp. 584595.

Alfredsson, P. and J. H. C. M. Verrijdt (1999). "Modeling Emergency Supply Flexibility in a Two-Echelon Inventory System". In: Management Science 45.10, pp. 1416-1431.

Alvarez, E. and M. van der Heijden (2014). "On two-echelon inventory systems with Poisson demand and lost sales". In: European Journal of Operational Research 235.1, pp. 334-338.

Alvarez, E., M. C. van der Heijden, I. M. H. Vliegen, and W. H. M. Zijm (2014). "Service differentiation through selective lateral transshipments". In: European Journal of Operational Research 237.3, pp. 824-835.

Alvarez, E., M. C. van der Heijden, and W. H. M. Zijm (2015). "Service differentiation in spare parts supply through dedicated stocks". In: Annals of Operations Research 231.1, pp. 283-303.

Andersson, J., S. Axsäter, and J. Marklund (1998). "Decentralized multiechelon inventory control". In: Production and Operations Management 7.4, pp. 370-386.

Andersson, J. and J. Marklund (2000). "Decentralized inventory control in a two-level distribution system”. In: European Journal of Operational Research 127.3, pp. 483-506. 
Andersson, J. and P. Melchiors (2001). "A two-echelon inventory model with lost sales". In: International Journal of Production Economics 69.3, pp. 307-315.

Angelus, A. and Ö. Özer (2016). "Knowledge you can act on: optimal policies for assembly systems with expediting and advance demand information". In: Operations Research 64.6, pp. 1338-1371.

Axsäter, S. (1990a). "Modelling emergency lateral transshipments in inventory systems". In: Management Science 36.11, pp. 1329-1338.

- (1990b). "Simple solution procedures for a class of two-echelon inventory problems". In: Operations Research 38.1, pp. 64-69.

- (1993b). "Exact and approximate evaluation of batch-ordering policies for two-level inventory systems". In: Operations Research 41.4, pp. 777-785.

- (1993c). "Optimization of Order-up-to-S Policies in Two-Echelon Inventory Systems with Periodic Review". In: Naval Research Logistics 40.2, pp. 245-253.

- (1995). "Approximate Evaluation of Batch-Ordering Policies for a One-Warehouse, N Non-Identical Retailer System Under Compound Poisson Demand". In: Naval Research Logistics 42.5, pp. 807819.

- (1997a). "On deficiencies of common ordering policies for multi-level inventory control". In: OR Spektrum 19.2, pp. 109-110.

- (1997b). "Simple evaluation of echelon stock (R,Q) policies for two-level inventory systems". In: IIE Transactions 29.8, pp. 661-669.

- (1998). "Evaluation of installation stock based (R,Q)-policies for two-level inventory systems with Poisson demand". In: Operations Research 46.3, pp. 135-145.

- (2000). "Exact analysis of continuous review (R,Q) policies in two-echelon inventory systems with compound Poisson demand". In: Operations Research 48.5, pp. 686-696.

- (2001a). "A framework for decentralized multi-echelon inventory control". In: IIE Transactions 33.2, pp. 91-97.

- (2001b). "Scaling down multi-echelon inventory problems". In: International Journal of Production Economics 71.1-3, pp. 255-261.

- (2003a). "Approximate optimization of a two-level distribution inventory system". In: International Journal of Production Economics 81-82, pp. 545-553.

- (2003b). "Note: Optimal Policies for Serial Inventory Systems under Fill Rate Constraints". In: Managament Science 49.2, pp. 247-253.

- (2005a). "A simple decision rule for decentralized two-echelon inventory control". In: International Journal of Production Economics 93-94, pp. 53-59.

- (2005b). "Planning Order Releases for an Assembly System with Random Operation Times". In: OR Spectrum 27.2-3, pp. 459-470.

- (2007). "On the first come-first served rule in multi-echelon inventory control". In: Naval Research Logistics 54.5, pp. 485-491.

Axsäter, S., R. Forsberg, and W.-F. Zhang (1994). "Approximating general multi-echelon inventory systems by Poisson models". In: International Journal of Production Economics 35.1, pp. 201-206.

Axsäter, S. and L. Juntti (1996). "Comparison of echelon stock and installation stock policies for two-level inventory systems". In: International Journal of Production Economics 45.1, pp. 303-310.

Axsäter, S., M. Kleijn, and A. G. de Kok (2004). "Stock Rationing in a Continuous Review Two-Echelon Inventory Model”. In: Annals of Operations Research 126.1-4, pp. 177-194.

Axsäter, S. and J. Marklund (2008). "Optimal Position-Based Warehouse Ordering in Divergent Two-Echelon Inventory Systems”. In: Operations Research 56.4, pp. 976-991.

Axsäter, S., J. Marklund, and E. A. Silver (2002). "Heuristic Methods for Centralized Control of OneWarehouse, N-Retailer Inventory Systems". In: Manufacturing \& Service Operations Management 4.1, pp. 75-97. 
Axsäter, S., F. Olsson, and P. Tydesjö (2007). "Heuristics for Handling Direct Upstream Demand in Two-Echelon Distribution Inventory Systems". In: International Journal of Production Economics 108.1-2, pp. 266-270.

Axsäter, S. and K. Rosling (1993). "Notes: Installation vs. Echelon Stock Policies for Multilevel Inventory Control". In: Management Science 39.10, pp. 1274-1280.

- (1994). "Multi-level production-inventory control: Material requirements planning or reorder point policies?” In: European Journal of Operational Research 75.2, pp. 405-412.

- (1999). "Ranking of generalised multi-stage KANBAN policies". In: European Journal of Operational Research 113.3 , pp. 560-567.

Axsäter, S. and W.-F. Zhang (1996). "Recursive Evaluation of Order-up-to-S Policies for Two-Echelon Inventory Systems With Compound Poisson Demand". In: Naval Research Logistics 43.1, pp. 151157.

- (1999). “A joint replenishment policy for multi-echelon inventory control”. In: International Journal of Production Economics 59.1, pp. 243-250.

Badinelli, R. D. (1992). "A model for continuous-review pull policies in serial inventory systems". In: Operations Research 40.1, pp. 142-156.

Badinelli, R. D. and L. B. Schwarz (1988). "Backorders optimization in a one-warehouse N-identical retailer distribution system". In: Naval Research Logistics 35.5, pp. 427-440.

Banerjee, A., J. Burton, and S. Banerjee (2003). "A simulation study of lateral shipments in single supplier, multiple buyers supply chain networks". In: International Journal of Production Economics 81-82, pp. 103-114.

Banerjee, S., A. Banerjee, J. Burton, and W. Bistline (2001). "Controlled partial shipments in twoechelon supply chain networks: A simulation study”. In: International Journal of Production Economics 71.1, pp. 91-100.

Basten, R. J., M. C. van der Heijden, J. M. J. Schutten, and E. Kutanoglu (2015). “An approximate approach for the joint problem of level of repair analysis and spare parts stocking". In: Annals of Operations Research 224.1, pp. 121-145.

Benjaafar, S. and M. ElHafsi (2006). "Production and inventory control of a single product assembleto-order system with multiple customer classes". In: Management Science 52.12, pp. 1896-1912.

Benjaafar, S., M. ElHafsi, C.-Y. Lee, and W. Zhou (2011). "Optimal Control of an Assembly System with Multiple Stages and Multiple Demand Classes". In: Operations Research 59.2, pp. 522-529.

Berling, P. and M. Farvid (2014). "Lead-time investigation and estimation in divergent supply chains". In: International Journal of Production Economics 157, pp. 177-189.

Berling, P. and J. Marklund (2006). "Heuristic Coordination of Decentralized Inventory Systems Using Induced Backorder Costs". In: Production and Operations Management 15.2, pp. 294-310.

- (2013). "A model for heuristic coordination of real life distribution inventory systems with lumpy demand". In: European Journal of Operational Research 230.3, pp. 515-526.

- (2014). "Multi-echelon inventory control: an adjusted normal demand model for implementation in practice". In: International Journal of Production Research 52.11, pp. 3331-3347.

Berling, P. and V. Martínez-de-Albéniz (2016a). "A characterization of optimal base-stock levels for a multistage serial supply chain". In: Naval Research Logistics (NRL) 63.1, pp. 32-46.

- (2016b). "Dynamic Speed Optimization in Supply Chains with Stochastic Demand". In: Transportation Science 50.3, pp. 1114-1127.

Bertazzi, L., A. Bosco, and D. Laganà (2016). "Min-Max exact and heuristic policies for a two-echelon supply chain with inventory and transportation procurement decisions". In: Transportation Research Part E: Logistics and Transportation Review 93, pp. 57-70.

Billington, C., G. Callioni, B. Crane, J. D. Ruark, J. Unruh Rapp, T. White, and S. P. Willems (2004). "Accelerating the profitability of Hewlett-Packard's Supply Chains". In: Interfaces 34.1, pp. 59-72. 
Bollapragada, R., S. Kuppusamy, and U. S. Rao (2015). "Component procurement and end product assembly in an uncertain supply and demand environment". In: International Journal of Production Research 53.3, pp. 969-982.

Bollapragada, S., R. Akella, and R. Srinivasan (1998). "Centralized ordering and allocation policies in a two-echelon system with non-identical warehouses". In: European Journal of Operational Research 106.1, pp. 74-81.

Bossert, J. M. and S. P. Willems (2007). "A Periodic-Review Modeling Approach for Guaranteed Service Supply Chains". In: Interfaces 37.5, pp. 420-435.

Boulaksil, Y. (2016). "Safety stock placement in supply chains with demand forecast updates". In: Operations Research Perspectives 3, pp. 27-31.

Braun, M., D. Rivera, M. Flores, W. Carlyle, and K. G. Kempf (2003). "A Model Predictive Control framework for robust management of multi-product, multi-echelon demand networks". In: Annual Reviews in Control 27.2, pp. 229-245.

Burton, J. and A. Banerjee (2005). "Cost-parametric analysis of lateral transshipment policies in two-echelon supply chains". In: International Journal of Production Economics 93-94, pp. 169-178.

Buyukkurt, M. and M. Parlar (1993). "A comparison of allocation policies in a two-echelon repairableitem inventory model”. In: International Journal of Production Economics 29.3, pp. 291-302.

Cachon, G. P. (1999). "Managing supply chain demand variability with scheduled ordering policies". In: Management Science 45.6, pp. 843-856.

- (2001). "Exact evaluation of batch-ordering inventory policies in two-echelon supply chains with periodic review”. In: Operations Research 49.1, pp. 79-98.

Cachon, G. P. and M. Fisher (1997). "Campbell Soup's continuous replenishment program: evaluation and enhanced inventory decision rules". In: Production and Operations Management 6.3, pp. 266276.

- (2000). "Supply Chain Inventory Management and the Value of Shared Information". In: Management Science 46.8, pp. 1032-1048.

Cachon, G. P. and P. H. Zipkin (1999). "Competitive and Cooperative Inventory Policies in a Two-Stage Supply Chain". In: Management Science 45.7, pp. 936-953.

Caggiano, K. E., P. L. Jackson, J. A. Muckstadt, and J. A. Rappold (2007). "Optimizing Service Parts Inventory in a Multiechelon, Multi-Item Supply Chain with Time-Based Customer Service-Level Agreements". In: Operations Research 55.2, pp. 303-318.

Caggiano, K. E., J. A. Muckstadt, and J. A. Rappold (2006). "Integrated Real-Time Capacity and Inventory Allocation for Reparable Service Parts in a Two-Echelon Supply System". In: Manufacturing \& Service Operations Management 8.3, pp. 292-319.

Cao, D.-b. and E. A. Silver (2005). "A Dynamic Allocation Heuristic for Centralized Safety Stock”. In: Naval Research Logistics 52.6, pp. 513-526.

Ceryan, O., I. Duenyas, and Y. Koren (2012). "Optimal control of an assembly system with demand for the end-product and intermediate components". In: IIE Transactions 44.5, pp. 386-403.

Chao, X. and S. X. Zhou (2007). "Probabilistic Solution and Bounds for Serial Inventory Systems with Discounted and Average Costs". In: Naval Research Logistics 54.6, pp. 623-631.

- (2009). "Optimal Policy for a Multiechelon Inventory System with Batch Ordering and Fixed Replenishment Intervals". In: Operations Research 57.2, pp. 377-390.

Chen, F. (1998). "Echelon reorder points, installation reorder points, and the value of centralized demand information". In: Management Science 44.12, pp. 221-234.

- (1999a). "94\%-effective policies for a two-stage serial inventory system with stochastic demand". In: Management Science 45.12, pp. 1679-1696.

- (1999b). "Decentralized supply chains subject to information delays". In: Management Science 45.8, pp. 1076-1090. 
Chen, F. (2000). "Optimal policies for multi-echelon inventory problems with batch ordering". In: Operations Research 48.3, pp. 376-389.

Chen, F. and R. Samroengraja (2000). "A staggered ordering policy for one-warehouse, multiretailer systems". In: Operations Research 48.2, pp. 281-293.

Chen, F. and J.-S. Song (2001). "Optimal policies for multiechelon inventory problems with Markovmodulated demand". In: Operations Research 49.2, pp. 226-234.

Chen, F. and Y.-S. Zheng (1994a). "Evaluating echelon stock (R,nQ) policies in serial production/inventory systems with stochastic demand". In: Management Science 40.10, pp. 1262-1275.

- (1994b). "Lower bounds for multi-echelon stochastic inventory systems". In: Management Science 40.11, pp. 1426-1443.

- (1997). "One-warehouse multiretailer systems with centralized stock information". In: Operations Research 45.2, pp. 275-287.

- (1998). "Near-optimal echelon-stock(R,nQ) policies in multistage serial systems". In: Operations Research 46.4, pp. 592-602.

Chen, F. Y., Y. Feng, and D. Simchi-Levi (2002). "Uniform distribution of inventory positions in twoechelon periodic review systems with batch-ordering policies and interdependent demands". In: European Journal of Operational Research 140.3, pp. 648-654.

Chen, F., Z. Drezner, J. K. Ryan, and D. Simchi-Levi (2000). "Quantifying the bullwhip effect in a simple supply chain: The impact of forecasting, lead times, and information". In: Management Science 46.3, pp. 436-443.

Chen, H. and P. Li (2015). "Optimization of (R, Q) policies for serial inventory systems using the guaranteed service approach". In: Computers \& Industrial Engineering 80, pp. 261-273.

Chen, L., J.-S. Song, and Y. Zhang (2016). "Serial Inventory Systems with Markov-Modulated Demand: Derivative Bounds, Asymptotic Analysis, and Insights". In:

Chen, S. and A. Muharremoglu (2014). "Optimal Policies for Assembly Systems: Completing Rosling's Characterization". In: Working paper SSRN 2475218.

Chen, S.-P. and B.-H. Cheng (2014). "Optimal echelon stock policies for multi-stage supply chains in fuzzy environments". In: International Journal of Production Research 52.11, pp. 3431-3449.

Cheng, F., M. Ettl, G. Lin, and D. D. Yao (2002). "Inventory-Service Optimization in Configure-to-Order Systems". In: Manufacturing \& Service Operations Management 4.2, pp. 114-132.

Cheng, T. C. E., C. Gao, and H. Shen (2011). "Production planning and inventory allocation of a single-product assemble-to-order system with failure-prone machines". In: International Journal of Production Economics 131.2, pp. 604-617.

Cheung, K. L. and W. H. Hausman (2000). "An Exact Performance Evaluation for the Supplier in a Two-Echelon Inventory System”. In: Operations Research 48.4, pp. 646-653.

Cheung, K. L. and H. L. Lee (2002). "The inventory benefit of shipment coordination and stock rebalancing in a supply chain". In: Management Science 48.2, pp. 300-306.

Chew, E. P. and L. A. Johnson (1995). "Service levels in distribution systems with random customer order size". In: Naval Research Logistics 42.1, pp. 39-56.

Chew, E. P. and L. C. Tang (1995). "Warehouse-retailer system with stochastic demands - Non-identical retailer case". In: European Journal of Operational Research 82.1, pp. 98-110.

Chiang, W.-y. and G. E. Monahan (2005). "Managing inventories in a two-echelon dual-channel supply chain”. In: European Journal of Operational Research 162.2, pp. 325-341.

Clark, A. J. and H. Scarf (1960). "Optimal policies for a multi-echelon inventory problem”. In: Management Science 6.4, pp. 475-490.

- (1962). "Approximate Solutions to a Simple Multi-Echelon Inventory Problem". In: Applied Probability and Management Science 23, pp. 88-110.

Cobb, B. R. (2016). "Lead time uncertainty and supply chain coordination in lost sales inventory models". In: International Journal of Inventory Research 3.1, pp. 5-30. 
Cohen, M. A., P. R. Kleindorfer, and H. L. Lee (1986). "Optimal stocking policies for low usage items in multi-echelon inventory systems". In: Naval Research Logistics Quarterly 33.1, pp. 17-38.

Cohen, M. A. and H. L. Lee (1988). "Strategic analysis of integrated production-distribution systems: models and methods". In: Operations Research 36.2, pp. 216-228.

Cohen, M., P. V. Kamesam, P. Kleindorfer, H. L. Lee, and A. Tekerian (1990). “Optimizer: IBM's multiechelon inventory system for managing service logistics". In: Interfaces 20.1, pp. 65-82.

Dada, M. (1992). "A two-echelon inventory system with priority shipments". In: Management Science 38.8, pp. $1140-1153$.

Dayanik, S., J.-S. Song, and S. H. Xu (2003). "The effectiveness of several performance bounds for capacitated production, partial-order-service, assemble-to-order systems". In: Manufacturing \& Service Operations Management 5.3, pp. 230-251.

de Bodt, M. A. and S. C. Graves (1985). "Continuous-review policies for a multi-echelon inventory problem with stochastic demand". In: Management Science 31.10, pp. 1286-1299.

de Kok, A. G. (1990). "Hierarchical production planning for consumer goods". In: European Journal of Operational Research 45.1, pp. 55-69.

de Kok, A. G., F. Janssen, J. van Doremalen, E. van Wachem, M. Clerkx, and W. Peeters (2005b). "Philips electronics synchronizes its supply chain to end the bullwhip effect". In: Interfaces 35.1, pp. 37-48.

de Kok, A. G. and J. W. C. H. Visschers (1999). "Analysis of assembly systems with service level constraints". In: International Journal of Production Economics 59.1, pp. 313-326.

DeCroix, G. A. (2006). "Optimal Policy for a Multiechelon Inventory System with Remanufacturing". In: Operations Research 54.3, pp. 532-543.

DeCroix, G. A., J.-S. Song, and P. H. Zipkin (2009). "Managing an Assemble-to-Order System with Returns". In: Manufacturing \& Service Operations Management 11.1, pp. 144-159.

DeCroix, G. A. and P. H. Zipkin (2005). "Inventory Management for an Assembly System with Product or Component Returns". In: Management Science 51.8, pp. 1250-1265.

Dekker, R., M. J. Kleijn, and A. G. de Kok (1998). “The break quantity rule's effect on inventory costs in a 1-warehouse, N-retailers distribution system". In: International Journal of Production Economics 56-57, pp. 61-68.

Demirel, S., I. Duenyas, and R. Kapuscinski (2015). "Production and Inventory Control for a Make-toStock/Calibrate-to-Order System with Dedicated and Shared Resources". In: Operations Research 63.4, pp. 823-839.

Deuermeyer, B. L. and L. B. Schwarz (1981). "A model for the analysis of system service level in warehouse-retailer distribution systems: The identical retailer case". In: Multi-Level Production/Inventory Control Systems: Theory and Practice. Ed. by L. B. Schwarz. Vol. 16. TIMS Studies in the Management Sciences. North-Holland, pp. 163-193.

Diaz, A. and M. C. Fu (1997). "Models for multi-echelon repairable item inventory systems with limited repair capacity". In: European Journal of Operational Research 97.3, pp. 480-492.

Diks, E. B. and A. G. de Kok (1996). "Controlling a divergent 2-echelon network with transshipments using the consistent appropriate share rationing policy". In: International Journal of Production Economics 45.1, pp. 369-379.

- (1998). "Optimal control of a divergent multi-echelon inventory system". In: European Journal of Operational Research 111.1, pp. 75-97.

- (1999). "Computational results for the control of a divergent N-echelon inventory system". In: International Journal of Production Economics 59.1, pp. 327-336.

Doğru, M., M. I. Reiman, and Q. Wang (2010). "Stochastic programming based inventory control policy for assemble-to-order systems with application to the W-model". In: Operations Research 58.4-part-1, pp. 849-864. 
Doğru, M., M. I. Reiman, and Q. Wang (2016). “Assemble-to-Order Inventory Management via Stochastic Programming: Chained BOMs and the M-System". In: Production and Operations Management.

Doğru, M. K., A. G. de Kok, and G. van Houtum (2009). "A Numerical Study on the Effect of Balance Assumption in One-Warehouse Multi-Retailer Inventory Systems". In: Flexible Service and Manufacturing Journal 21, pp. 114-147.

Doğru, M. K. and U. Özen (2015). "Tactical Inventory Planning at Alcatel-Lucent's Repair and Exchange Services". In: Interfaces 45.3, pp. 228-242.

Dong, L. and H. L. Lee (2003). "Optimal policies and approximations for a serial multiechelon inventory system with time-correlated demand”. In: Operations Research 51.6, pp. 969-980.

Egri, P. (2012). "Safety stock placement in non-cooperative supply chains". In: Artificial Intelligence and Logistics - AILog 2012 Workshop Proceedings. Ed. by L. Frommberger, K. Schill, and B. Scholz-Reiter, pp. 31-36.

Ekanayake, N., N. Joshi, and S. A. Thekdi (2016). "Comparison of single-echelon vs. multi-echelon inventory systems using multi-objective stochastic modelling". In: International Journal of Logistics Systems and Management 23.2, pp. 255-280.

ElHafsi, M. (2009). "Optimal integrated production and inventory control of an assemble-to-order system with multiple non-unitary demand classes". In: European Journal of Operational Research 194.1, pp. 127-142.

ElHafsi, M., H. Camus, and E. Craye (2008). "Optimal control of a nested-multiple-product assembleto-order system". In: International Journal of Production Research 46.19, pp. 5367-5392.

ElHafsi, M. and E. Hamouda (2015). "Managing an assemble-to-order system with after sales market for components". In: European Journal of Operational Research 242.3, pp. 828-841.

ElHafsi, M., L. Zhi, H. Camus, and E. Craye (2015). "An assemble-to-order system with product and components demand with lost sales". In: International Journal of Production Research 53.3, pp. 718-735.

Eppen, G. and L. Schrage (1981). "Centralized ordering policies in a multi-warehouse system with lead times and random demand". In: Multi-level Production/Inventory Control Systems: Theory and Practice. Ed. by L. B. Schwarz. Vol. 16. TIMS Studies in the Management Sciences. North-Holland, Amsterdam, pp. 51-67.

Erkip, N., W. H. Hausman, and S. Nahmias (1990). "Optimal centralized ordering policies in multiechelon inventory systems with correlated demands". In: Management Science 36.3, pp. 381392.

Ernst, R. and D. F. Pyke (1992). "Component part stocking policies". In: Naval Research Logistics 39.4, pp. 509-529.

Eruguz, A. S., Z. Jemai, E. Sahin, and Y. Dallery (2013). "Cycle-Service-Level in Guaranteed-Service supply chains". In: 5th International Conference on Modeling, Simulation and Applied Optimization, 2013. IEEE, pp. 1-6.

Eruguz, A. S., Z. Jemai, E. Sahin, and Y. Dallery (2014). "Optimising reorder intervals and order-up-to levels in guaranteed service supply chains". In: International Journal of Production Research 52.1, pp. 149-164.

Ettl, M., G. E. Feigin, G. Y. Lin, and D. D. Yao (2000). "A supply network model with base-stock control and service requirements". In: Operations Research 48.2, pp. 216-232.

Farasyn, I., S. Humair, J. I. Kahn, J. J. Neale, O. Rosen, J. Ruark, W. Tarlton, W. van de Velde, G. Wegryn, and S. P. Willems (2011). "Inventory optimization at Procter \& Gamble: Achieving real benefits through user adoption of Inventory Tools". In: Interfaces 41.1, pp. 66-78.

Fattahi, M., M. Mahootchi, S. M. Moattar Husseini, E. Keyvanshokooh, and F. Alborzi (2015). "Investigating replenishment policies for centralised and decentralised supply chains using stochastic programming approach". In: International Journal of Production Research 53.1, pp. 41-69. 
Federgruen, A. and P. Zipkin (1984a). "Allocation policies and cost approximations for multilocation inventory systems". In: Naval Research Logistics Quarterly 31.1, pp. 97-129.

- (1984b). "Approximation of dynamic, multi-location production and inventory problems". In: Management Science 30.1, pp. 69-84.

- (1984c). "Computational issues in an infinite-horizon, multiechelon inventory model". In: Operations Research 32.4, pp. 818-836.

Feigin, G. E. (1999). "Inventory planning in large assembly supply chains". In: Quantitative Models for Supply Chain Management. Ed. by S. Tayur, R. Ganeshan, and M. Magazine. Springer, pp. 761-787.

Feng, J., L. Liu, and Y.-w. Wan (2012). "Irreducibility of joint inventory positions in an assemble-to-order system under (r,nQ) policies". In: Naval Research Logistics 59.1, pp. 18-25.

Feng, K. and U. S. Rao (2007). "Echelon-stock (R, nT) control in two-stage serial stochastic inventory systems". In: Operations Research Letters 35.1, pp. 95-104.

Feng, T. and F. Zhang (2014). "The impact of modular assembly on supply chain efficiency". In: Production and Operations Management 23.11, pp. 1985-2001.

Feng, Y., J. Ou, and Z. Pang (2008). "Optimal control of price and production in an assemble-to-order system". In: Operations Research Letters 36.4, pp. 506-512.

Fleischhacker, A., A. Ninh, and Y. Zhao (2015). "Positioning Inventory in Clinical Trial Supply Chains". In: Production and Operations Management 24.6, pp. 991-1011.

Forsberg, R. (1995). "Optimization of order-up-to-S policies for two-level inventory systems with compound Poisson demand". In: European Journal of Operational Research 81.1, pp. 143-153.

- (1997a). "Evaluation of (R, Q) -policies for two-level inventory systems with generally distributed customer inter-arrival times". In: European Journal of Operational Research 99.2, pp. 401-411.

- (1997b). "Exact evaluation of (R, Q) -policies for two-level inventory systems with Poisson demand". In: European Journal of Operational Research 96.1, pp. 130-138.

$\mathrm{Fu}, \mathrm{K}$. , V. N. Hsu, and C.-Y. Lee (2006). "Inventory and Production Decisions for an Assemble-to-Order System with Uncertain Demand and Limited Assembly Capacity". In: Operations Research 54.6, pp. 1137-1150.

Funaki, K. (2012). "Strategic safety stock placement in supply chain design with due-date based demand". In: International Journal of Production Economics 135.1, pp. 4-13.

Gallego, G. and Ö. Özer (2005). "A new algorithm and a new heuristic for serial supply systems". In: Operations Research Letters 33.4, pp. 349-362.

Gallego, G., Ö. Özer, and P. Zipkin (2007). "Bounds, heuristics, and approximations for distribution systems". In: Operations Research 55.3, pp. 503-517.

Gallego, G. and P. Zipkin (1999). "Stock Positioning and Performance Estimation in Serial ProductionTransportation Systems". In: Manufacturing \& Service Operations Management 1.1, pp. 77-88.

Gallien, J. and L. M. Wein (2001). "A simple and effective component procurement policy for stochastic assembly systems". In: Queueing Systems 38.2, pp. 221-248.

Ganeshan, R. (1999). "Managing supply chain inventories: A multiple retailer, one warehouse, multiple supplier model". In: International Journal of Production Economics 59.1, pp. 341-354.

Gao, C., H. Shen, and T. C. E. Cheng (2010). "Order-fulfillment performance analysis of an assemble-toorder system with unreliable machines". In: International Journal of Production Economics 126.2, pp. 341-349.

Garcia-Herreros, P., A. Agarwal, J. M. Wassick, and I. E. Grossmann (2016). "Optimizing inventory policies in process networks under uncertainty". In: Computers \& Chemical Engineering 92, pp. 256272.

Gavirneni, S. (2002). "Information flows in capacitated supply chains with fixed ordering costs". In: Management Science 48.5, pp. 644-651.

Gerchak, Y. and M. Henig (1989). "Component commonality in assemble-to-order systems: Models and properties". In: Naval Research Logistics 36.1, pp. 61-68. 
Giannoccaro, I., P. Pontrandolfo, and B. Scozzi (2003). "A fuzzy echelon approach for inventory management in supply chains". In: European Journal of Operational Research 149.1, pp. 185-196.

Glasserman, P. and S. Tayur (1994). "The stability of a capacitated, multi-echelon production-inventory system under a base-stock policy". In: Operations Research 42.5, pp. 913-925.

- (1995). "Sensitivity analysis for base-stock levels in multiechelon production-inventory systems". In: Management Science 41.2, pp. 263-281.

- (1996). "A simple approximation for a multistage capacitated production-inventory system". In: Naval Research Logistics 43.1, pp. 41-58.

Glasserman, P. and Y. Wang (1998). "Leadtime-inventory trade-offs in assemble-to-order systems". In: Operations Research 46.6, pp. 858-871.

Goh, J. and E. L. Porteus (2016). "Multi-Echelon Inventory Management under Short-Term Take-or-Pay Contracts". In: Production and Operations Management 25.8, pp. 1415-1429.

Grahl, J., S. Minner, and D. Dittmar (2016). "Meta-heuristics for placing strategic safety stock in multi-echelon inventory with differentiated service times". In: Annals of Operations Research 242.2, pp. 489-504.

Grahovac, J. and A. Chakravarty (2001). "Sharing and lateral transshipment of inventory in a supply chain with expensive low-demand items". In: Management Science 47.4, pp. 579-594.

Graman, G. A. and D. F. Rogers (1997). "Delivery delay variation in multi-echelon inventory problems". In: Journal of the Operational Research Society 48.10, pp. 1029-1036.

Graves, S. C. (1985). "A multi-echelon inventory model for a repairable item with one-for-one replenishment". In: Management Science 31.10, pp. 1247-1256.

- (1996). "A multi-echelon inventory model with fixed replenishment intervals". In: Management Science 42.1, pp. 1-18.

Graves, S. C., D. B. Kletter, and W. B. Hetzel (1998). "A dynamic model for requirements planning with application to supply chain optimization". In: Operations Research 46.3-supplement-3, pp. 35-49.

Graves, S. C. and T. Schoenmeyr (2016). "Strategic safety-stock placement in supply chains with capacity constraints". In: Manufacturing \& Service Operations Management 18.3, pp. 445-460.

Graves, S. C. and S. P. Willems (2000). "Optimizing strategic safety stock placement in supply chains". In: Manufacturing \& Service Operations Management 2.1, pp. 68-83.

- (2005). "Optimizing the supply chain configuration for new products". In: Management Science 51.8 , pp. 1165-1180.

- (2008). "Strategic inventory placement in supply chains: nonstationary demand". In: Manufacturing \& Service Operations Management 10.2, pp. 278-287.

Güllü, R. and N. Erkip (1996). "Optimal allocation policies in a two-echelon inventory problem with fixed shipment costs". In: International Journal of Production Economics 46-47, pp. 311-321.

Gupta, A. and S. C. Albright (1992). "Steady-state approximations for a multi-echelon multi-indentured repairable-item inventory system”. In: European Journal of Operational Research 62.3, pp. 340-353.

Gürbüz, M. C., K. Moinzadeh, and Y.-P. Zhou (2007). "Coordinated replenishment strategies in inventory/distribution systems”. In: Management Science 53.2, pp. 293-307.

Haji, R., H. Tayebi, and B. G. Jeddi (2014). "One-for-one-period ordering policy for inventory systems with unidirectional lateral transshipments". In: The International Journal of Advanced Manufacturing Technology 74.9-12, pp. 1159-1166.

Hausman, W. H. and N. K. Erkip (1994). "Multi-echelon vs. single-echelon inventory control policies for low-demand items". In: Management Science 40.5, pp. 597-602.

Hill, R. M., M. Seifbarghy, and D. K. Smith (2007). "A two-echelon inventory model with lost sales". In: European Journal of Operational Research 181.2, pp. 753-766.

Hillestad, R. J. and M. J. Carrillo (1980). "Models and Techniques for Recoverable Item Stockage when Demand and the Repair Process Are Nonstationary, Part 1: Performance Measurement". In: The Rand Corporation 1.1482-AF, pp. 1-35. 
Hillier, M. S. (1999). "Component commonality in a multiple-period inventory model with service level constraints". In: International Journal of Production Research 37.12, pp. 2665-2683.

- (2000). "Component commonality in multiple-period, assemble-to-order systems". In: IIE Transactions 32.8 , pp. 755-766.

Howard, C. and J. Marklund (2011). "Evaluation of stock allocation policies in a divergent inventory system with shipment consolidation". In: European Journal of Operational Research 211.2, pp. 298309.

Hu, M. and Y. Yang (2014). "Modified Echelon (r, Q) Policies with Guaranteed Performance Bounds for Stochastic Serial Inventory Systems". In: Operations Research 62.4, pp. 812-828.

Hua, N. G. and S. P. Willems (2016a). "Analytical insights into two-stage serial line supply chain safety stock". In: International Journal of Production Economics 181.Part A, pp. 107-112.

Hua, N. G. and S. P. Willems (2016b). "Optimally configuring a two-stage serial line supply chain under the guaranteed service model". In: International Journal of Production Economics 181.Part A, pp. 98-106.

Huang, K. (2014). "Benchmarking non-first-come-first-served component allocation in an assemble-toorder system". In: Annals of Operations Research 223.1, pp. 217-237.

Huh, W. T. and G. Janakiraman (2010). "On the optimal policy structure in serial inventory systems with lost sales". In: Operations Research 58.2, pp. 486-491.

- (2012). "Technical Note - On Optimal Policies for Inventory Systems with Batch Ordering”. In: Operations Research 60.4, pp. 797-802.

Huh, W. T., G. Janakiraman, and M. Nagarajan (2016). "Capacitated multiechelon inventory systems: Policies and bounds". In: Manufacturing \& Service Operations Management 18.4, pp. 570-584.

Humair, S., J. Ruark, B. Tomlin, and S. P. Willems (2013). "Incorporating Stochastic Lead Times into the Guaranteed Service Model of Safety Stock Optimization”. In: Interfaces 43.5, pp. 421-434.

Humair, S. and S. P. Willems (2006). "Optimizing strategic safety stock placement in supply chains with clusters of commonality". In: Operations Research 54.4, pp. 725-742.

- (2011). "Technical Note - Optimizing Strategic Safety Stock Placement in General Acyclic Networks". In: Operations Research 59.3, pp. 781-787.

Hwarng, H., C. S. P. Chong, N. Xie, and T. F. Burgess (2005). "Modelling a complex supply chain: understanding the effect of simplified assumptions". In: International Journal of Production Research 43.13, pp. 2829-2872.

Iida, T. (2001). "The infinite horizon non-stationary stochastic multi-echelon inventory problem and near-myopic policies". In: European Journal of Operational Research 134.3, pp. 525-539.

Inderfurth, K. (1991). "Safety stock optimization in multi-stage inventory systems". In: International Journal of Production Economics 24.1, pp. 103-113.

- (1992). "Multistage Safety Stock Optimization with Dynamic Programming". In: OR Spektrum 14.1, pp. 19-32.

- (1995). "Multistage safety stock planning with item demands correlated across products and through time". In: Production and Operations Management 4.2, pp. 127-144.

Inderfurth, K. and S. Minner (1998). "Safety stocks in multi-stage inventory systems under different service measures". In: European Journal of Operational Research 106.1, pp. 57-73.

Iravani, S. M. R., K. . Luangkesorn, and D. Simchi-Levi (2003). "On assemble-to-order systems with flexible customers". In: IIE Transactions 35.5, pp. 389-403.

Jackson, P. L. (1988). "Stock allocation in a two-echelon distribution system or what to do until your ship comes in”. In: Management Science 34.7, pp. 880-895.

Jackson, P. L. and J. A. Muckstadt (1989). "Risk pooling in a two-period, two-echelon inventory stocking and allocation problem". In: Naval Research Logistics 36.1, pp. 1-26.

Janakiraman, G. and J. A. Muckstadt (2009). "A Decomposition Approach for a Class of Capacitated Serial Systems". In: Operations Research 57, pp. 1384-1393. 
Jansen, M. M., A. G. de Kok, and J. C. Fransoo (2013). "Lead time anticipation in supply chain operations planning". In: OR Spectrum 35.1, pp. 251-290.

Ji, Q., L. Sun, X. Hu, and J. Hou (2016). "Optimal policies of a two-echelon serial inventory system with general limited capacities". In: International Journal of Production Research 54.20, pp. 6142-6155.

Jönsson, H. and E. A. Silver (1987a). "Analysis of a two-echelon inventory control system with complete redistribution". In: Management Science 33.2, pp. 215-227.

- (1987b). "Stock allocation among a central warehouse and identical regional warehouses in a particular push inventory control system". In: International Journal of Production Research 25.2, pp. 191-205.

Karaarslan, A. G., G. P. Kiesmüller, and A. G. de Kok (2013). "Analysis of an assemble-to-order system with different review periods". In: International Journal of Production Economics 143.2, pp. 335341.

- (2014). "Effect of modeling fixed cost in a serial inventory system with periodic review". In: OR Spectrum 36.2, pp. 481-502.

Keblis, M. F. and Y. Feng (2012). "Optimal Pricing and Production Control in an Assembly System With a General Stockout Cost". In: IEEE Transactions on Automatic Control 57.7, pp. 1821-1826.

Kiesmüller, G. P., A. G. de Kok, S. R. Smits, and P. J. M. van Laarhoven (2004). "Evaluation of divergent N-echelon (s, nQ)-policies under compound renewal demand". In: OR Spectrum 26.4, pp. 547-577.

Kim, C., D. Klabjan, and D. Simchi-Levi (2015). "Optimal Expediting Policies for a Serial Inventory System with Stochastic Lead Time". In: Production and Operations Management 24.10, pp. 15241536.

Klosterhalfen, S. T., D. Dittmar, and S. Minner (2013). "An integrated guaranteed- and stochasticservice approach to inventory optimization in supply chains". In: European Journal of Operational Research 231.1, pp. 109-119.

Klosterhalfen, S. T. and S. Minner (2007). "Comparison of stochastic- and guaranteed- service approaches to safety stock optimization in supply chains". In: Operations Research Proceedings 2006. Ed. by K.-H. Waldmann and U. M. Stocker. Springer, pp. 485-490.

- (2010). "Safety stock optimisation in distribution systems: A comparison of two competing approaches". In: International Journal of Logistics Research and Applications 13.2, pp. 99-120.

Klosterhalfen, S. T., S. Minner, and S. P. Willems (2014). "Strategic Safety Stock Placement in Supply Networks with Static Dual Supply". In: Manufacturing \& Service Operations Management 16.2, pp. 204-219.

Ko, S.-S., J. Y. Choi, and D.-W. Seo (2011). "Approximations of lead-time distributions in an assembleto-order system under a base-stock policy”. In: Computers \& Operations Research 38.2, pp. 582590.

Köchel, P. and U. Nieländer (2005). "Simulation-based optimisation of multi-echelon inventory systems". In: International Journal of Production Economics 93-94, pp. 505-513.

Korugan, A. and S. M. Gupta (1998). "A Multi-Echelon Inventory System with Returns". In: Computers \& Industrial Engineering 35.1, pp. 145-148.

Kutanoglu, E. and M. Mahajan (2009). "An inventory sharing and allocation method for a multilocation service parts logistics network with time-based service levels". In: European Journal of Operational Research 194.3, pp. 728-742.

Lagodimos, A. G. (1992). "Multi-echelon service models for inventory systems under different rationing policies". In: International Journal of Production Research 30.4, pp. 939-956.

- (1993). "Models for evaluating the performance of serial and assembly MRP systems". In: European Journal of Operational Research 68.1, pp. 49-68.

Lagodimos, A. G. and E. J. Anderson (1993). "Optimal positioning of safety stocks in MRP”. In: The International Journal of Production Research 31.8, pp. 1797-1813. 
Lagodimos, A. G., A. G. de Kok, and J. H. C. M. Verrijdt (1995). “The Robustness of Multi-Echelon Service Models under Autocorrelated Demands". In: Journal of the Operational Research Society 46.1, pp. 92-103.

Lagodimos, A. G. and S. Koukoumialos (2008). "Service performance of two-echelon supply chains under linear rationing". In: International Journal of Production Economics 112.2, pp. 869-884.

Lagodimos, A. G., K. Skouri, and I. T. Christou (2015). "Global optimization of two-echelon serial chains with replenishment costs". In: IMA Journal of Management Mathematics 27.1, pp. 1-29.

Lambrecht, M. R., J. A. Muckstadt, and R. Luyten (1984). "Protective stocks in multi-stage production systems". In: International Journal of Production Research 22.6, pp. 1001-1025.

Langenhoff, L. J. G. and W. H. M. Zijm (1990). "An analytical theory of multi-echelon production/distribution systems". In: Statistica Neerlandica 44.3, pp. 149-174.

Lee, H. L. (1987). "A multi-echelon inventory model for repairable items with emergency lateral transshipments". In: Management Science 33.10, pp. 1302-1316.

Lee, H. L. and C. Billington (1993). "Material management in decentralized supply chains". In: Operations Research 41.5, pp. 835-847.

Lee, H. L. and K. Moinzadeh (1987a). "Operating characteristics of a two-echelon inventory system for repairable and consumable items under batch ordering and shipment policy". In: Naval Research Logistics 34.3, pp. 365-380.

- (1987b). "Two-parameter approximations for multi-echelon repairable inventory models with batch ordering policy". In: IIE Transactions 19.2, pp. 140-149.

Lee, H. L., K. C. So, and C. S. Tang (2000). "The value of information sharing in a two-level supply chain”. In: Management Science 46.5, pp. 626-643.

Lee, H. L. and S. Whang (1999). "Decentralized multi-echelon supply chains: Incentives and information". In: Management Science 45.5, pp. 633-640.

Lee, Y.-J. and P. Zipkin (1995). "Processing networks with inventories: sequential refinement systems". In: Operations Research 43.6, pp. 1025-1036.

Lesnaia, E. (2004). "Optimizing safety stock placement in general network supply chains". PhD thesis. Massachusetts Institute of Technology.

Levi, R., R. Roundy, V. A. Truong, and X. Wang (2017). "Provably near-optimal balancing policies for multi-echelon stochastic inventory control models". In: Mathematics of Operations Research 42.1, pp. 256-276.

Li, H. and D. Jiang (2012). "New model and heuristics for safety stock placement in general acyclic supply chain networks". In: Computers \& Operations Research 39.7, pp. 1333-1344.

Liberopoulos, G. and Y. Dallery (2003). "Comparative modelling of multi-stage production-inventory control policies with lot sizing". In: International Journal of Production Research 41.6, pp. 12731298.

Liberopoulos, G. and S. Koukoumialos (2005). "Tradeoffs between base stock levels, numbers of kanbans, and planned supply lead times in production/inventory systems with advance demand information". In: International Journal of Production Economics 96.2, pp. 213-232.

Lin, G., M. Ettl, S. Buckley, S. Bagchi, D. D. Yao, B. L. Naccarato, R. Allan, K. Kim, and L. Koenig (2000). "Extended-enterprise supply-chain management at IBM personal systems group and other divisions". In: Interfaces 30.1, pp. 7-25.

Liu, L., X. Liu, and D. D. Yao (2004). "Analysis and optimization of a multistage inventory-queue system”. In: Management Science 50.3, pp. 365-380.

Lu, L., J.-S. Song, and H. Zhang (2015). "Optimal and Asymptotically Optimal Policies for Assembleto-Order N- and W-Systems". In: Naval Research Logistics 62.8, pp. 617-645.

Lu, Y. (2008). "Performance analysis for assemble-to-order systems with general renewal arrivals and random batch demands". In: European Journal of Operational Research 185.2, pp. 635-647. 
Lu, Y. and J.-S. Song (2005). "Order-based cost optimization in assemble-to-order systems". In: Operations Research 53.1, pp. 151-169.

Lu, Y., J.-S. Song, and D. D. Yao (2003). "Order fill rate, leadtime variability, and advance demand information in an assemble-to-order system". In: Operations Research 51.2, pp. 292-308.

- (2005). "Backorder minimization in multiproduct assemble-to-order systems". In: IIE Transactions 37.8, pp. 763-774.

Lu, Y., J.-S. Song, and Y. Zhao (2010). "No-Holdback Allocation Rules for Continuous-Time Assembleto-Order Systems". In: Operations Research 58.3, pp. 691-705.

Magnanti, T. L., Z.-J. M. Shen, J. Shu, D. Simchi-Levi, and C.-P. Teo (2006). "Inventory placement in acyclic supply chain networks". In: Operations Research Letters 34.2, pp. 228-238.

Mahmoodi, A. and A. Haji (2014). "(1, T) policy for a Two-echelon Inventory System with Perishableon-the-Shelf Items". In: Journal of Optimization in Industrial Engineering 7.16, pp. 31-40.

Marklund, J. (2002). "Centralized Inventory Control in a Two-Level Distribution System with Poisson Demand”. In: Naval Research Logistics 49.8, pp. 798-822.

- (2006). "Controlling Inventories in Divergent Supply Chains with Advance-Order Information". In: Operations Research 54.5, pp. 988-1010.

- (2011). "Inventory Control in Divergent Supply Chains with Time-Based Dispatching and Shipment Consolidation”. In: Naval Research Logistics 58.1, pp. 59-71.

Marklund, J. and K. Rosling (2012). "Lower Bounds and Heuristics for Supply Chain Stock Allocation". In: Operations Research 60.1, pp. 92-105.

Masters, J. M. (1993). "Determination of near optimal stock levels for multi-echelon distribution inventories". In: Journal of Business Logistics 14.2, pp. 165-195.

McGavin, E. J., L. B. Schwarz, and J. E. Ward (1993). "Two-interval Inventory-allocation Policies in a One-warehouse N-identical-retailer Distribution System”. In: Management Science 39.9, pp. 10921107.

Minner, S. (1997). "Dynamic programming algorithms for multi-stage safety stock optimization”. In: OR Spektrum 19.4, pp. 261-271.

- (2001). "Strategic safety stocks in reverse logistics supply chains". In: International Journal of Production Economics 71.1-3, pp. 417-428.

Minner, S., E. B. Diks, and A. G. de Kok (2003). "A two-echelon inventory system with supply lead time flexibility". In: IIE Transactions 35.2, pp. 117-129.

Mitra, S. and A. K. Chatterjee (2004a). "Echelon stock based continuous review (R, Q) policy for fast moving items". In: Omega 32.2, pp. 161-166.

- (2004b). "Leveraging information in multi-echelon inventory systems". In: European Journal of Operational Research 152.1, pp. 263-280.

Moinzadeh, K. (2002). "A Multi-Echelon Inventory System with Information Exchange”. In: Management Science 48.3, pp. 414-426.

Moinzadeh, K. and P. K. Aggarwal (1997). "An information based multiechelon inventory system with emergency orders". In: Operations Research 45.5, pp. 694-701.

Moinzadeh, K. and H. L. Lee (1986). "Batch size and stocking levels in multi-echelon repairable systems". In: Management Science 32.12, pp. 1567-1581.

Moinzadeh, K. and Y.-P. Zhou (2008). "Incorporating a delay mechanism in ordering policies into multi-echelon distribution systems". In: IIE Transactions 40.4, pp. 445-458.

Molinder, A. (1997). "Joint optimization of lot-sizes, safety stocks and safety lead times in an MRP system". In: International Journal of Production Research 35.4, pp. 983-994.

Moncayo-Martinez, L. A., E. O. Resendiz-Flores, D. Mercado, and C. Sanchez-Ramirez (2014). "Placing Safety Stock in Logistic Networks under Guaranteed-Service Time Inventory Models: An Application to the Automotive Industry". In: Journal of Applied Research and Technology 12.3, pp. 538-550. 
Moncayo-Martinez, L. A., A. Ramirez-Lopez, and G. Recio (2016). "Managing inventory levels and time to market in assembly supply chains by swarm intelligence algorithms". In: The International Journal of Advanced Manufacturing Technology 82.1-4, pp. 419-433.

Muckstadt, J. A. (1973). "A model for a multi-item, multi-echelon, multi-indenture inventory system". In: Management Science 20.4, pp. 472-481.

Muckstadt, J. A. and L. J. Thomas (1980). "Are multi-echelon inventory methods worth implementing in systems with low-demand-rate items?” In: Management Science 26.5, pp. 483-494.

Muharremoglu, A. and J. N. Tsitsiklis (2008). "A Single-Unit Decomposition Approach to Multiechelon Inventory Systems". In: Operations Research 56.5, pp. 1089-1103.

Muharremoglu, A. and N. Yang (2010). "Inventory Management with an Exogenous Supply Process". In: Operations Research 58.1, pp. 111-129.

Nadar, E., M. Akan, and A. Scheller-Wolf (2014). "Technical note-optimal structural results for assemble-to-order generalized m-systems". In: Operations Research 62.3, pp. 571-579.

- (2016). "Experimental Results Indicating Lattice-Dependent Policies May Be Optimal for General Assemble-To-Order Systems". In: Production and Operations Management 25.4, pp. 647-661.

Nahmias, S. and S. A. Smith (1994). "Optimizing inventory levels in a two-echelon retailer system with partial lost sales". In: Management Science 40.5, pp. 582-596.

Neale, J. J. and S. P. Willems (2009). "Managing inventory in supply chains with nonstationary demand". In: Interfaces 39.5, pp. 388-399.

Needham, P. M. and P. T. Evers (1998). "The influence of individual cost factors on the use of emergency transshipments". In: Transportation Research Part E: Logistics and Transportation Review 34.2, pp. 149-160.

Nepal, B., L. Monplaisir, and O. Famuyiwa (2011). "A multi-objective supply chain configuration model for new products". In: International Journal of Production Research 49.23, pp. 71077-134.

$\mathrm{Ni}$, W. and J. Shu (2015). "Trade-off between service time and carbon emissions for safety stock placement in multi-echelon supply chains". In: International Journal of Production Research 53.22, pp. 6701-6718.

Nozick, L. K. and M. A. Turnquist (2001). "A two-echelon inventory allocation and distribution center location analysis". In: Transportation Research Part E: Logistics and Transportation Review 37.6, pp. 425-441.

Oh, S., K. Sourirajan, and M. Ettl (2014). "Joint Pricing and Production Decisions in an Assemble-toOrder System". In: Manufacturing \& Service Operations Management 16.4, pp. 529-543.

Ohno, K., T. Boh, K. Nakade, and T. Tamura (2016). "New approximate dynamic programming algorithms for large-scale undiscounted Markov decision processes and their application to optimize a production and distribution system". In: European Journal of Operational Research 249.1, pp. 22-31.

Özer, Ö. (2003). "Replenishment strategies for distribution systems under advance demand information". In: Management Science 49.3, pp. 255-272.

Özkan, E., G.-J. van Houtum, and Y. Serin (2015a). "A new approximate evaluation method for two-echelon inventory systems with emergency shipments". In: Annals of Operations Research 224.1, pp. 147-169.

- (2015b). "A new approximate evaluation method for two-echelon inventory systems with emergency shipments". In: Annals of Operations Research 224.1, pp. 147-169.

Parker, R. P. and R. Kapuscinski (2004). "Optimal policies for a capacitated two-echelon inventory system”. In: Operations Research 52.5, pp. 739-755.

Patriarca, R., F. Costantino, and G. Di Gravio (2016). "Inventory model for a multi-echelon system with unidirectional lateral transshipment". In: Expert Systems with Applications 65, pp. 372-382. 
Perlman, Y., A. Mehrez, and M. Kaspi (2001). "Setting expediting repair policy in a multi-echelon repairable-item inventory system with limited repair capacity". In: Journal of the Operational Research Society 52.2, pp. 198-209.

Petrovic, D., R. Roy, and R. Petrovic (1998). "Modelling and simulation of a supply chain in an uncertain environment". In: European Journal of Operational Research 109.2, pp. 299-309.

- (1999). "Supply chain modelling using fuzzy sets". In: International Journal of Production Economics 59.1, pp. 443-453.

Plambeck, E. L. (2008). "Asymptotically optimal control for an Assemble-to-Order System with Capacitated Component Production and Fixed Transport Costs". In: Operations Research 56.5, pp. 1158-1171.

Plambeck, E. L. and A. R. Ward (2006). "Optimal Control of a High-Volume Assemble-to-Order System". In: Mathematics of Operations Research 31.3, pp. 453-477.

- (2007). "Note: A Separation Principle for a Class of Assemble-to-Order Systems with Expediting". In: Operations Research 55.3, pp. 603-609.

Pyke, D. F. (1990). "Priority repair and dispatch policies for reparable-item logistics systems". In: Naval Research Logistics 37.1, pp. 1-30.

Raghunathan, S. (2001). "Information sharing in a supply chain: A note on its value when demand is nonstationary". In: Management Science 47.4, pp. 605-610.

Rambau, J. and K. Schade (2010). "The stochastic guaranteed service model with recourse for multiechelon warehouse management". In: Electronic Notes in Discrete Mathematics 36, pp. 783-790.

- (2014). "The stochastic guaranteed service model with recourse for multi-echelon warehouse management". In: Mathematical Methods of Operations Research 79.3, pp. 293-326.

Rappold, J. A. and J. A. Muckstadt (2000). "A computationally efficient approach for determining inventory levels in a capacitated multiechelon production-distribution system". In: Naval Research Logistics 47.5, pp. 377-398.

Rappold, J. A. and B. D. van Roo (2009). "Designing multi-echelon service parts networks with finite repair capacity". In: European Journal of Operational Research 199.3, pp. 781-792.

Reiman, M. I., H. Wan, and Q. Wang (2016a). "On the Use of Independent Base-Stock Policies in Assemble-to-Order Inventory Systems with Nonidentical Lead Times". In: Operations Research Letters 44.4, pp. 436-442.

Reiman, M. I., H. Wan, and Q. Wang (2016b). "On the use of independent base-stock policies in assemble-to-order inventory systems with nonidentical lead times". In: Operations Research Letters 44.4, pp. 436-442.

Reiman, M. I. and Q. Wang (2012). "A stochastic program based lower bound for assemble-to-order inventory systems". In: Operations Research Letters 40.2, pp. 89-95.

- (2015). "Asymptotically Optimal Inventory Control for Assemble-to-Order Systems with Identical Lead Times". In: Operations Research 63.3, pp. 716-732.

Al-Rifai, M. H., M. D. Rossetti, and A. Sheikhzadeh (2016). "A heuristic optimisation algorithm for two-echelon ( $R, Q$ ) inventory systems with non-identical retailers". In: International Journal of Inventory Research 3.2, pp. 166-193.

Rong, Y., Z. Atan, and L. V. Snyder (2014). "Heuristics for Base-Stock Levels in Multi-Echelon Distribution Networks with First-Come First Served Policies". In: Working paper SSRN 1475469.

Rosenbaum, B. A. (1981). "Service level relationships in a multi-echelon inventory system". In: Management Science 27.8, pp. 926-945.

Rosling, K. (1989). "Optimal inventory policies for assembly systems under random demands". In: Operations Research 37.4, pp. 565-579.

Routroy, S. and R. Kodali (2005). "Differential evolution algorithm for supply chain inventory planning". In: Journal of Manufacturing Technology Management 16.1, pp. 7-17. 
Roy, D. and N. R. S. Raghavan (2014). "A constrained Nash bargaining approach to the stock rationing problem in multi-echelon supply chains". In: The International Journal of Advanced Manufacturing Technology 72.5-8, pp. 571-587.

Salzarulo, P. A. and F. R. Jacobs (2014). "The incremental value of central control in serial supply chains". In: International Journal of Production Research 52.7, pp. 1989-2006.

Santos, A. F. and C. F. Bispo (2016). "Simulation Based Optimization Package for Periodic Review Inventory Control". In: Proceedings of the 2016 Winter Simulation Conference. WSC '16. Arlington, Virginia: IEEE Press, pp. 2867-2878.

Schildbach, G. and M. Morari (2016). "Scenario-based model predictive control for multi-echelon supply chain management”. In: European Journal of Operational Research 252.2, pp. 540-549.

Schmidt, C. P. and S. Nahmias (1985). "Optimal policy for a two-stage assembly system under random demand”. In: Operations Research 33.5, pp. 1130-1145.

Schneider, H., D. B. Rinks, and P. Kelle (1995). "Power Approximations For A Two-Echelon Inventory System Using Service Levels". In: Production and Operations Management 4.4, pp. 381-400.

Schoenmeyr, T. and S. C. Graves (2009). "Strategic Safety Stocks in Supply Chains with Evolving Forecasts". In: Manufacturing \& Service Operations Management 11, pp. 657-673.

Schultz, C. R. (1983). "Computing demand properties at the wholesale warehouse level”. In: Naval Research Logistics Quarterly 30.1, pp. 37-48.

Schwarz, L. B. (1989). "A model for assessing the value of warehouse risk-pooling: risk-pooling over outside-supplier leadtimes". In: Management Science 35.7, pp. 828-842.

Schwarz, L. B., B. L. Deuermeyer, and R. D. Badinelli (1985). "Fill-rate optimization in a one-warehouse $\mathrm{N}$-identical retailer distribution system”. In: Management Science 31.4, pp. 488-498.

Seferlis, P. and N. F. Giannelos (2004). "A two-layered optimisation-based control strategy for multiechelon supply chain networks”. In: Computers \& Chemical Engineering 28.5, pp. 799-809.

Seifbarghy, M. and M. R. A. Jokar (2006). "Cost evaluation of a two-echelon inventory system with lost sales and approximately Poisson demand". In: International Journal of Production Economics 102.2, pp. 244-254.

Seo, Y., S. Jung, and J. Hahm (2002). "Optimal reorder decision utilizing centralized stock information in a two-echelon distribution system". In: Computers \& Operations Research 29.2, pp. 171-193.

Shang, K. H. (2008). "Note: A simple heuristic for serial inventory systems with fixed order costs". In: Operations Research 56.4, pp. 1039-1043.

- (2012). "Single-Stage Approximations for Optimal Policies in Serial Inventory Systems with Nonstationary Demand". In: Manufacturing \& Service Operations Management 14.3, pp. 414-422.

Shang, K. H. and J.-S. Song (2003). "Newsvendor bounds and heuristic for optimal policies in serial supply chains". In: Management Science 49.5, pp. 618-638.

- (2006). "A Closed-Form Approximation for Serial Inventory Systems and Its Application to System Design". In: Manufacturing \& Service Operations Management 8.4, pp. 394-406.

- (2007). "Serial supply chains with economies of scale: bounds and approximations". In: Operations Research 55.5, pp. 843-853.

Shang, K. H., J.-S. Song, and P. H. Zipkin (2009). "Coordination mechanisms in decentralized serial inventory systems with batch ordering". In: Management Science 55.4, pp. 685-695.

Shang, K. H., Z. Tao, and S. X. Zhou (2015). "Optimizing reorder intervals for two-echelon distribution systems with stochastic demand”. In: Operations Research 62.2, pp. 458-475.

Shang, K. H. and S. X. Zhou (2009). "A simple heuristic for echelon (r, nQ, T) policies in serial supply chains". In: Operations Research Letters 37.6, pp. 433-437.

- (2010). "Optimal and heuristic echelon (r, nQ, T) policies in serial inventory systems with fixed costs". In: Operations Research 58.2, pp. 414-427. 
Shang, K. H., S. X. Zhou, and G.-J. van Houtum (2010). "Improving supply chain performance: Real-time demand information and flexible deliveries". In: Manufacturing \& Service Operations Management 12.3 , pp. 430-448.

Sherbrooke, C. C. (1968). "METRIC: A multi-echelon technique for recoverable item control". In: Operations Research 16.1, pp. 122-141.

- (1986). "VARI-METRIC: Improved approximations for multi-indenture, multi-echelon availability models". In: Operations Research 34.2, pp. 311-319.

- (1992). "Multiechelon inventory systems with lateral supply". In: Naval Research Logistics 39.1, pp. 29-40.

Shi, J. J. and Y. Zhao (2014). "Component commonality under no-holdback allocation rules". In: Operations Research Letters 42.6, pp. 409-413.

Shu, J. and I. A. Karimi (2009). "Efficient heuristics for inventory placement in acyclic networks". In: Computers Operations Research 36.11, pp. 2899-2904.

Simchi-Levi, D. and Y. Zhao (2003). "The value of information sharing in a two-stage supply chain with production capacity constraints". In: Naval Research Logistics 50.8, pp. 888-916.

Simon, R. M. (1971). "Stationary properties of a two-echelon inventory model for low demand items". In: Operations Research 19.3, pp. 761-773.

Simpson, K. F. (1958). "In-process inventories”. In: Operations Research 6.6, pp. 863-873.

Simpson, V. P. (1978). "Optimum solution structure for a repairable inventory problem". In: Operations Research 26.2, pp. 270-281.

Sinha, A. K. and A. Krishnamurthy (2016). "Dual index production and subcontracting policies for assemble-to-order systems". In: IIE Transactions 48.5, pp. 415-427.

Sitompul, C., E.-H. Aghezzaf, W. Dullaert, and H. van Landeghem (2008). "Safety stock placement problem in capacitated supply chains". In: International Journal of Production Research 46.17, pp. 4709-4727.

Slay, F. M. (1984). "Vari-metric: An approach to modelling multi-echelon resupply when the demand process is poisson with a gamma prior". In: Logistics Management Institute, Washington, DC Report AF301-3 AF 301-3.

Sleptchenko, A., M. C. van der Heijden, and A. van Harten (2002). "Effects of finite repair capacity in multi-echelon, multi-indenture service part supply systems". In: International Journal of Production Economics 79.3, pp. 209-230.

Song, J.-S. (1998). "On the order fill rate in a multi-item, base-stock inventory system". In: Operations Research 46.6, pp. 831-845.

- (2000). "A note on assemble-to-order systems with batch ordering". In: Management Science 46.5, pp. 739-743.

Song, J.-S., S. H. Xu, and B. Liu (1999). "Order-fulfillment performance measures in an assemble-toorder system with stochastic leadtimes". In: Operations Research 47.1, pp. 131-149.

Song, J.-S. and Y. Zhao (2009). "The Value of Component Commonality in a Dynamic Inventory System with Lead Times". In: Manufacturing \& Service Operations Management 11.3, pp. 493-508.

Stenius, O., A. G. Karaarslan, J. Marklund, and A. G. de Kok (2016). "Exact analysis of divergent inventory systems with time-based shipment consolidation and compound Poisson demand". In: Operations Research 64.4, pp. 906-921.

Svoronos, A. and P. Zipkin (1988). "Estimating the performance of multi-level inventory systems". In: Operations Research 36.1, pp. 57-72.

- (1991). "Evaluation of one-for-one replenishment policies for multiechelon inventory systems". In: Management Science 37.1, pp. 68-83.

Tee, Y.-S. and M. D. Rossetti (2002). "A robustness study of a multi-echelon inventory model via simulation". In: International Journal of Production Economics 80.3, pp. 265-277. 
Tempelmeier, H. (1993). "Safety stock allocation in a two-echelon distribution system". In: European Journal of Operational Research 65.1, pp. 96-117.

Tian, F, S. P. Willems, and K. G. Kempf (2011). "An iterative approach to item-level tactical production and inventory planning". In: International Journal of Production Economics 133.1, pp. 439-450.

Topan, E., Z. P. Bayındır, and T. Tan (2010). "An exact solution procedure for multi-item two-echelon spare parts inventory control problem with batch ordering in the central warehouse". In: Operations Research Letters 38.5, pp. 454-461.

van den Berg, D., M. C. van der Heijden, and P. C. Schuur (2016). "Allocating service parts in twoechelon networks at a utility company". In: International Journal of Production Economics 181, Part A, pp. 58-67.

van der Heijden, M. C. (1992). "Analysing divergent logistic networks with local (R, S) inventory control". In: International Journal of Production Economics 27.3, pp. 187-219.

- (1997). "Supply rationing in multi-echelon divergent systems". In: European Journal of Operational Research 101.3, pp. 532-549.

- (1999). "Multi-echelon inventory control in divergent systems with shipping frequencies". In: European Journal of Operational Research 116.2, pp. 331-351.

- (2000). "Near cost-optimal inventory control policies for divergent networks under fill rate constraints". In: International Journal of Production Economics 63.2, pp. 161-179.

van der Heijden, M. C., E. B. Diks, and A. G. de Kok (1997). "Stock allocation in general multi-echelon distribution systems with (R, Q) order-up-to-policies". In: International Journal of Production Economics 49.2, pp. 157-174.

- (1999). "Inventory control in multi-echelon divergent systems with random lead times". In: OR Spektrum 21.3, pp. 331-359.

van Donselaar, K. (1990). "Integral stock norms in divergent systems with lot-sizes". In: European Journal of Operational Research 45.1, pp. 70-84.

van Donselaar, K. and J. Wijngaard (1987). "Commonality and safety stocks". In: Engineering Costs and Production Economics 12.1, pp. 197-204.

van Houtum, G.-J., A. Scheller-Wolf, and J. Yi (2007). "Optimal control of serial inventory systems with fixed replenishment intervals". In: Operations Research 55.4, pp. 674-687.

van Houtum, G.-J. and W. H. M. Zijm (1991). "Computational procedures for stochastic multi-echelon production systems". In: International Journal of Production Economics 23.1, pp. 223-237.

van Jaarsveld, W. and A. Scheller-Wolf (2015). "Optimization of industrial-scale assemble-to-order systems". In: INFORMS Journal on Computing 27.3, pp. 544-560.

van Wijk, A. C. C., I. J. B. F. Adan, and G.-J. van Houtum (2013). "Optimal allocation policy for a multi-location inventory system with a quick response warehouse". In: Operations Research Letters 41.3, pp. 305-310.

Veatch, M. H. and L. M. Wein (1994). "Optimal control of a two-station tandem production/inventory system”. In: Operations Research 42.2, pp. 337-350.

Verrijdt, J. H. C. M. and A. G. de Kok (1995). "Distribution planning for a divergent N-echelon network without intermediate stocks under service restrictions". In: International Journal of Production Economics 38.2, pp. 225-243.

- (1996). "Distribution planning for a divergent depotless two-echelon network under service constraints". In: European Journal of Operational Research 89.2, pp. 341-354.

Wang, Q. and S. Axsäter (2013). "Fixed-Interval Joint-Replenishment Policies for Distribution Systems with Multiple Retailers and Stochastic Demand". In: Naval Research Logistics 60.8, pp. 637-651.

Wang, X. and S. M. Disney (2016). "The bullwhip effect: Progress, trends and directions". In: European Journal of Operational Research 250.3, pp. 691-701. 
Wang, Y., M. A. Cohen, and Y.-S. Zheng (2000). "A two-echelon repairable inventory system with stocking-center-dependent depot replenishment lead times". In: Management Science 46.11, pp. 1441-1453.

Wheatley, D., F. Gzara, and E. Jewkes (2015). "Logic-based Benders decomposition for an inventorylocation problem with service constraints". In: Omega 55, pp. 10-23.

Wieland, B., P. Mastrantonio, S. P. Willems, and K. G. Kempf (2012). "Optimizing Inventory Levels Within Intel's Channel Supply Demand Operations”. In: Interfaces 42.6, pp. 517-527.

Woerner, S., M. Laumanns, and S. M. Wagner (2016). "Simulation-Based Optimization of Capacitated Assembly Systems under Beta-Service Level Constraints". In: Decision Sciences.

Wong, H., D. Cattrysse, and D. van Oudheusden (2005). "Stocking decisions for repairable spare parts pooling in a multi-hub system". In: International Journal of Production Economics 93-94, pp. 309-317.

Wong, H., B. Kranenburg, G.-J. van Houtum, and D. Cattrysse (2007). "Efficient heuristics for twoechelon spare parts inventory systems with an aggregate mean waiting time constraint per local warehouse". In: OR Spectrum 29.4, pp. 699-722.

Xiang, Y. and M. D. Rossetti (2014). "The effect of backlog queue and load-building processing in a multi-echelon inventory network". In: Simulation Modelling Practice and Theory 43, pp. 54-66.

Xu, X., Y. Zhao, and C.-Y. Chen (2016). "Project-driven supply chains: integrating safety-stock and crashing decisions for recurrent projects". In: Annals of Operations Research 241.1-2, pp. 225-247.

Yang, G., R. Dekker, A. F. Gabor, and S. Axsäter (2013). "Service Parts Inventory Control with Lateral Transshipment and Pipeline Stock Flexibility". In: International Journal of Production Economics 142.2, pp. 278-289.

Ye, W. and F. You (2016). "A computationally efficient simulation-based optimization method with region-wise surrogate modeling for stochastic inventory management of supply chains with general network structures". In: Computers \& Chemical Engineering 87, pp. 164-179.

Yoo, Y.-j., W.-s. Kim, and J.-t. Rhee (1997). "Efficient inventory management in multi-echelon distribution systems". In: Computers \& Industrial Engineering 33.3, pp. 729-732.

Yoon, H., S. Jung, and S. Lee (2015). "The effect analysis of multi-echelon inventory models considering demand rate uncertainty and limited maintenance capacity". In: International Journal of Operational Research 24.1, pp. 38-58.

You, F. and I. E. Grossmann (2011). "Stochastic inventory management for tactical process planning under uncertainties: MINLP models and algorithms". In: AIChE Journal 57.5, pp. 1250-1277.

Zanjani, M. K. and M. Nourelfath (2014). "Integrated spare parts logistics and operations planning for maintenance service providers". In: International Journal of Production Economics 158, pp. 44-53.

Zhang, A. X. (1997). "Demand fulfillment rates in an assemble-to-order system with multiple products and dependent demands". In: Production and Operations Management 6.3, pp. 309-324.

Zijm, W. H. M. and G.-J. van Houtum (1994). "On multi-stage production/inventory systems under stochastic demand". In: International Journal of Production Economics 35.1, pp. 391-400.

Zipkin, P. (1984). "On the imbalance of inventories in multi-echelon systems". In: Mathematics of Operations Research 9.3, pp. 402-423.

- (1991). "Evaluation of base-stock policies in multiechelon inventory systems with compoundpoisson demands". In: Naval Research Logistics 38.3, pp. 397-412.

\section{Additional References and Surveys}

This part of the bibliography contains papers and surveys not classified that are referenced in order to provide context information. 
Axsäter, S. (1993a). "Continuous review policies for multi-level inventory systems with stochastic demand". In: Handbooks in operations research and management science. Ed. by S. Graves, A. Rinnooy Kan, and P. Zipkin. Vol. 4. Elsevier, pp. 175-197.

- (2003c). "Supply chain operations: Serial and distribution inventory systems". In: ed. by A. G. de Kok and S. C. Graves. Vol. 11. Elsevier, pp. 525-559.

Boysen, N., M. Fliedner, and A. Scholl (2007). "A classification of assembly line balancing problems". In: European Journal of Operational Research 183.2, pp. 674-693.

Brucker, P., A. Drexl, R. Möhring, K. Neumann, and E. Pesch (1999). "Resource-constrained project scheduling: Notation, classification, models, and methods". In: European Journal of Operational Research 112.1, pp. 3-41.

Buchanan, D. and A. Bryman (2009). The SAGE handbook of organizational research methods. Sage Publications Ltd.

Buzacott, J. A. and J. G. Shanthikumar (1993). Stochastic models of manufacturing systems. Vol. 4. Prentice Hall Englewood Cliffs, NJ.

Copil, K., M. Wörbelauer, H. Meyr, and H. Tempelmeier (2017). "Simultaneous lotsizing and scheduling problems: a classification and review of models". In: OR Spectrum 39.1, pp. 1-64.

de Kok, A. G. (2012). "The return of the bullwhip". In: Review of Business and Economic Literature 57.3, pp. 381-392.

- (2015). "Buffering against uncertainty in high-tech supply chains". In: Winter Simulation Conference (WSC), 2015. IEEE, pp. 1-10.

de Kok, A. G. and J. C. Fransoo (2003). "Planning supply chain operations: definition and comparison of planning concepts". In: Handbooks in operations research and management science. Ed. by A. G. de Kok and S. C. Graves. Vol. 11. Elsevier, pp. 597-675.

de Kok, A. G., F. Janssen, J. van Doremalen, E. van Wachem, M. Clerkx, and W. Peeters (2005a). "Philips electronics synchronizes its supply chain to end the bullwhip effect". In: Interfaces 35.1, pp. 37-48.

Denyer, D. and D. Trenfield (2009). "Producing a Systematic Review". In: The SAGE Handbook of Organizational Research Methods. SAGE Publication Limited.

Diks, E. B., A. G. de Kok, and A. G. Lagodimos (1996). "Multi-echelon systems: A service measure perspective". In: European Journal of Operational Research 95.2, pp. 241-263.

Dyckhoff, H. (1990). "A typology of cutting and packing problems". In: European Journal of Operational Research 44.2, pp. 145-159.

Eruguz, A. S., E. Sahin, Z. Jemai, and Y. Dallery (2016). "A comprehensive survey of guaranteedservice models for multi-echelon inventory optimization". In: International Journal of Production Economics 172, pp. 110-125.

Federgruen, A. (1993). "Centralized planning models for multi-echelon inventory systems under uncertainty". In: Handbooks in operations research and management science. Ed. by S. Graves, A. Rinnooy Kan, and P. Zipkin. Vol. 4. Elsevier, pp. 133-173.

Graham, R. L., E. L. Lawler, J. K. Lenstra, and A. R. Kan (1979). "Optimization and approximation in deterministic sequencing and scheduling: a survey". In: Annals of Discrete Mathematics 5, pp. 287326.

Graves, S. C. and S. P. Willems (2003). "Supply chain design: safety stock placement and supply chain configuration". In: Handbooks in operations research and management science. Ed. by A. G. de Kok and S. C. Graves. Vol. 11. Elsevier, pp. 95-132.

Gümüs, A. T. and A. F. Güneri (2007). "Multi-echelon inventory management in supply chains with uncertain demand and lead times: literature review from an operational research perspective". In: Proceedings of the Institution of Mechanical Engineers, Part B: Journal of Engineering Manufacture 221.10, pp. 1553-1570. 
Kendall, D. G. (1953). "Stochastic processes occurring in the theory of queues and their analysis by the method of the imbedded Markov chain". In: The Annals of Mathematical Statistics, pp. 338-354.

Simchi-Levi, D. and Y. Zhao (2011). "Performance evaluation of stochastic multi-echelon inventory systems: A survey". In: Advances in Operations Research 2012.

Song, J.-S. and P. Zipkin (2003). "Supply chain operations: Assemble-to-order systems". In: Handbooks in operations research and management science. Ed. by A. G. de Kok and S. C. Graves. Vol. 11. Elsevier, pp. 561-596.

van Houtum, G., K. Inderfurth, and W. H. Zijm (1996). "Materials coordination in stochastic multiechelon systems". In: European Journal of Operational Research 95.1, pp. 1-23.

Wäscher, G., H. Haußner, and H. Schumann (2007). "An improved typology of cutting and packing problems". In: European Journal of Operational Research 183.3, pp. 1109-1130.

\section{A Complete classification of papers through 2016}

This appendix provides the classification of all papers that we considered in scope in tabular form. We added the number of citation according to Google Scholar, manually retrieved in July 2017, in order to indicate the impact of the contributions. As was said earlier, some classification could have been decided in another way in some details. Thus, the classification string is our subjective perception of where the main contributions of the respective papers are.

\begin{tabular}{|c|c|c|}
\hline Reference & Classification & Citations \\
\hline Abouee-Mehrizi et al. (2014) & $2, D, C, E G|F, G| P, B|b, F, A| C|| C E, C O$ & 2 \\
\hline Aggarwal and Moinzadeh (1994) & $2, D, C, G|I, C| P, B|b, F, E| C \| A C, 0$ & 48 \\
\hline Agrawal and Cohen (2001) & $2, G, D, G|I, C| G N, B|b, F, N| C S \| A, 0$ & 131 \\
\hline Akçay and Xu (2004) & $2, G, D, G|I, C| G, B|b, F, N| C|| A C, 0$ & 104 \\
\hline Albrecht (2014) & $2, G, D, G|I, C| P, B|b, F, A| C \| A C, C O$ & 4 \\
\hline Albright and Gupta (1993) & $2, D, C, G|F, E| P, B|b, F, N| S \| A C, P$ & 48 \\
\hline Alfredsson (1997) & $4, G, C, G|I, G| P, B|b, F, N| M|| A C, 0$ & 116 \\
\hline Alfredsson and Verrijdt (1999) & $2, D, C, G|I, E| P, B|b, F, R| C|| A, P$ & 236 \\
\hline Al-Rifai et al. (2016) & $2, D, C, G|I, C| P, B|q, Q, N| C S|| A C, 0$ & 1 \\
\hline Alvarez and van der Heijden (2014) & $2, D, C, G|I, C E| P, L|b, F, R| S \| A C, P$ & 5 \\
\hline Alvarez, van der Heijden, Vliegen, et al. (2014) & $2, D, C, G|I, E| P, B|b, F, R| C S|| A C S, O P$ & 4 \\
\hline Alvarez, van der Heijden, and Zijm (2015) & $2, D, C, G|I, C E| P, B L|b, F, R| C S \| A S, 0$ & 13 \\
\hline Andersson, Axsäter, et al. (1998) & $2, D, C, G|I, C| B, B|q, Q, N| C|| A C, 0$ & 46 \\
\hline Andersson and Marklund (2000) & $2, D, C, G|I, G| N, B|q, Q, N| C|| A C, 0$ & 99 \\
\hline Andersson and Melchiors (2001) & $2, D, C, G|I, C| P, L|b, F, N| C \| A C, 0$ & 72 \\
\hline Angelus and Özer (2016) & $n, C, D, G|I, C| G, B|N, F, E| C|| C E, 0$ & 2 \\
\hline Axsäter (1990a) & $2, D, C, G|I, E| P, B|b, F, R| C \| A C, P$ & 343 \\
\hline Axsäter (1990b) & $2, D, C, G|I, C| P, B|b, F, N| C|| E, P$ & 290 \\
\hline Axsäter (1993b) & $2, D, C, G|I, C| P, B|q, Q, N| C \| A E, 0$ & 229 \\
\hline Axsäter (1993c) & $2, D, D, G|I, C| P, B|b, F, N| C|| E, 0$ & 63 \\
\hline Axsäter (1995) & $2, D, C, G|I, C| B, B|q, Q, N| C|| A, P$ & 28 \\
\hline Axsäter (1997a) & $2, D, C, G|I, C| G, B|Q q, Q, N| C|| E, C$ & 16 \\
\hline Axsäter (1997b) & $2, D, C, G|I, C| B, B|Q, Q, N| C|| E, 0$ & 94 \\
\hline Axsäter (1998) & $2, D, C, G|I, C| P, B|q, Q, N| C \| A C E, P$ & 78 \\
\hline Axsäter (2000) & $2, D, C, G|I, C| B, B|q, Q, N| C|| E, P$ & 139 \\
\hline Axsäter (2001a) & $2, D, C, L|I, C| P, B|b q, Q, R| C E \| E, 0$ & 83 \\
\hline Axsäter (2001b) & $2, D, C, G|I, C| B, B|q, Q, N| C \| A C, C$ & 32 \\
\hline Axsäter (2003a) & $2, D, C, G|I, C| B, B|q, Q, N| C|| A C, 0$ & 94 \\
\hline Axsäter (2003b) & $\mathrm{n}, \mathrm{S}, \mathrm{C}, \mathrm{G}|\mathrm{I}, \mathrm{C}| \mathrm{B}, \mathrm{B}|\mathrm{N}, \mathrm{Q}, \mathrm{N}| \mathrm{CS} \| \mathrm{E}, 0$ & 41 \\
\hline Axsäter (2005a) & $2, D, C, G|I, C| G, B|q, Q, N| C|| A, 0$ & 42 \\
\hline
\end{tabular}




\begin{tabular}{|c|c|c|}
\hline Reference & Classification & Citations \\
\hline Axsäter (2005b) & $n, C, C, G|I, G| G, B|N, F, N| C|| A, 0$ & 56 \\
\hline Axsäter (2007) & $2, D, C, G|I, C| B P, B|b, F, N| C|| A C, C$ & 13 \\
\hline Axsäter, Forsberg, et al. (1994) & $2, D, C, G|I, C| B, B|b q, F Q, N| C \| A C, 0$ & 29 \\
\hline Axsäter and Juntti (1996) & $2, D S, C, G|I, C| P, B|Q q, Q, N| C \| E S, C$ & 72 \\
\hline Axsäter, Kleijn, et al. (2004) & $2, D, C, G|I, C| P, B|b, F, A| C|| A C, 0$ & 19 \\
\hline Axsäter and Marklund (2008) & $2, D, C, G|I, C| P, B|0 q, Q, N| C|| E, 0$ & 37 \\
\hline Axsäter, Marklund, and Silver (2002) & $2, D, D, G|I, C| G, B|0, F, A| C \| A S, 0$ & 65 \\
\hline Axsäter, Olsson, et al. (2007) & $2, D, C, G|I, C| B, B|q, Q, N| C \| A C, 0$ & 8 \\
\hline Axsäter and Rosling (1993) & $\mathrm{n}, \mathrm{C}, \mathrm{C}, \mathrm{G}|\mathrm{I}, \mathrm{G}| \mathrm{G}, \mathrm{B}|\mathrm{Qq}, \mathrm{Q}, \mathrm{N}| \mathrm{U} \| \mathrm{E}, \mathrm{C}$ & 255 \\
\hline Axsäter and Rosling (1994) & $n, G, D, G|I, C| G, B|B 0 Q q, F Q, N| U|| E, C$ & 65 \\
\hline Axsäter and Rosling (1999) & $n, C G, D, L|F, C| G, B|q, Q, N| U \| E, C$ & 24 \\
\hline Axsäter and Zhang (1996) & $2, D, C, G|I, C| B, B|b, F, N| C|| E, P$ & 11 \\
\hline Axsäter and Zhang (1999) & $2, D, C, G|I, C| P, B|q, Q, N| C|| E, 0$ & 93 \\
\hline Badinelli (1992) & $\mathrm{n}, \mathrm{S}, \mathrm{C}, \mathrm{G}|\mathrm{I}, \mathrm{C}| \mathrm{B}, \mathrm{B}|\mathrm{q}, \mathrm{Q}, \mathrm{N}| \mathrm{CS} \| \mathrm{E}, \mathrm{P}$ & 56 \\
\hline Badinelli and Schwarz (1988) & $2, D, C, G|I, C| P, B|q, Q, N| C \| A C, 0$ & 34 \\
\hline Banerjee, Burton, et al. (2003) & $2, D, D, G|I, C| G, B|0, F, R| M|| S, P$ & 95 \\
\hline Banerjee, Banerjee, et al. (2001) & $2, D, D, L|I, C| N, B|q, Q, N| M|| S, P$ & 51 \\
\hline Basten et al. (2015) & $n, G, C, G|I, G| P, B|b, F, N| C S|| A C, C O$ & 20 \\
\hline Benjaafar and ElHafsi (2006) & $2, C, C, G|F, E| P, L|N, F, N| C|| E, 0$ & 181 \\
\hline Benjaafar, ElHafsi, et al. (2011) & $n, C, C, G|F, E| P, B L|N, F, N| C|| C E, 0$ & 33 \\
\hline Berling and Farvid (2014) & $2, D, C, G|I, C| B G, B|q, Q, N| U \| A C, F P$ & 0 \\
\hline Berling and Marklund (2006) & $2, D, C, G|I, C| N, B|q, Q, N| C \| A C, 0$ & 20 \\
\hline Berling and Marklund (2013) & $2, D, C, G|I, C| B, B|q, Q, N| C S \| A C, 0$ & 12 \\
\hline Berling and Marklund (2014) & $2, D, C, G|I, C| G, B|q, Q, N| C S \| A C F, 0$ & 13 \\
\hline Berling and Martínez-de-Albéniz (2016a) & $X, S, C, G|I, C| P, B|N, F, E| C|| E, 0$ & 1 \\
\hline Berling and Martínez-de-Albéniz (2016b) & $n, S, C, G|I, 0| P, B|N, F, E| C|| C E, 0$ & 1 \\
\hline Bertazzi et al. (2016) & $2, D, D, G|B F, C| U, L|b, F, R| C \| A C E, C 0$ & 1 \\
\hline Billington et al. (2004) & $\mathrm{n}, \mathrm{G}, \mathrm{D}, \mathrm{G}|\mathrm{I}, \mathrm{C}| \mathrm{U}, \mathrm{G}|\mathrm{b}, \mathrm{F}, \mathrm{U}| \mathrm{C} \| \mathrm{AF}, 0$ & 70 \\
\hline Bollapragada, Kuppusamy, et al. (2015) & $2, G, D, G|F, C| G, B|N, F, A| C|| A C, 0$ & 3 \\
\hline Bollapragada, Akella, et al. (1998) & $2, D, D, G|I, C| N, B|0, F, N| C|| A, 0$ & 37 \\
\hline Bossert and Willems (2007) & $n, G, D, G|I, C| U, G|b, F, U| C|| A F S, 0$ & 33 \\
\hline Boulaksil (2016) & $2, S, D, G|F, C| M, B|0, F, N| C \| A C S, 0$ & 0 \\
\hline Braun et al. (2003) & $n, G, D, G|F, C| G, B|0, F, N| C|| S, 0$ & 169 \\
\hline Burton and Banerjee (2005) & $2, D, D, G|I, C| G, B|b, F, R| M|| C S, C$ & 56 \\
\hline Buyukkurt and Parlar (1993) & $2, D, C, G|F, E| P, B|b, F, A| M|| A C S, C$ & 20 \\
\hline Cachon (1999) & $2, D, D, G|I, C| D U, B|q, Q, N| M|| C E, 0$ & 291 \\
\hline Cachon (2001) & $2, D, D, G|I, C| D, B|q, Q, N| C|| E S, 0$ & 126 \\
\hline Cachon and Fisher (1997) & $2, D, C, G|I, C| G, B|q, Q, N| C S|| F, 0$ & 271 \\
\hline Cachon and Fisher (2000) & $2, D, D, G|I, C| D, B|q, Q, N| C|| A C, C$ & 1933 \\
\hline Cachon and Zipkin (1999) & $2, S, D, E L|I, C| G, B|B b, F, N| C E \| E, C$ & 724 \\
\hline Caggiano, Jackson, et al. (2007) & $n, D, C, G|I, C| P, B|b, F, N| C S|| A, 0$ & 59 \\
\hline Caggiano, Muckstadt, et al. (2006) & $2, D, D, G|F, C| D, B|N, F, E| C|| A C, 0$ & 55 \\
\hline Cao and Silver (2005) & $2, D, D, G|I, C| N, B|B, F, A| C \| A C, 0$ & 13 \\
\hline Ceryan et al. (2012) & $2, C, C, G|F, E| P, B|N, F, N| C \| A C, 0$ & 20 \\
\hline Chao and Zhou (2007) & $n, S, D, G|I, C| G, B|B, F, N| C|| E, 0$ & 14 \\
\hline Chao and Zhou (2009) & $\mathrm{n}, \mathrm{S}, \mathrm{D}, \mathrm{G}|\mathrm{I}, \mathrm{C}| \mathrm{G}, \mathrm{B}|\mathrm{N}, \mathrm{Q}, \mathrm{N}| \mathrm{C} \| \mathrm{E}, 0$ & 44 \\
\hline Chen (1998) & $\mathrm{n}, \mathrm{S}, \mathrm{C}, \mathrm{G}|\mathrm{I}, \mathrm{C}| \mathrm{B}, \mathrm{B}|\mathrm{Qq}, \mathrm{Q}, \mathrm{N}| \mathrm{C} \| \mathrm{E}, \mathrm{CP}$ & 416 \\
\hline Chen (1999a) & $2, D S, C, G|I, C| P, B|N O, F, N| C|| A C, 0$ & 34 \\
\hline Chen (1999b) & $n, S, D, G|I, C| G, B|N, F, N| C|| C E, 0$ & 394 \\
\hline Chen $(2000)$ & $n, C S, D, G|I, C| G, B|N, Q, N| C|| E, 0$ & 163 \\
\hline Chen, Drezner, et al. (2000) & $2, S, D, L|I, C| G, B|b, F, N| U \| C E, P$ & 2108 \\
\hline Chen and Samroengraja (2000) & $2, D, D, G|I, C| D, B|0, F, A| C|| A C E, 0$ & 50 \\
\hline Chen and Song (2001) & $\mathrm{n}, \mathrm{S}, \mathrm{D}, \mathrm{G}|\mathrm{I}, \mathrm{C}| \mathrm{M}, \mathrm{B}|\mathrm{N}, \mathrm{F}, \mathrm{N}| \mathrm{C}|| \mathrm{E}, 0$ & 177 \\
\hline Chen and Zheng (1994a) & $\mathrm{n}, \mathrm{S}, \mathrm{CD}, \mathrm{G}|\mathrm{I}, \mathrm{C}| \mathrm{B}, \mathrm{B}|\mathrm{Q}, \mathrm{Q}, \mathrm{N}| \mathrm{C} \| \mathrm{ES}, \mathrm{P}$ & 131 \\
\hline Chen and Zheng (1994b) & $23 n, C D S, D, G|I, C| G, B|N, F, N| C|| A, 0$ & 247 \\
\hline Chen and Zheng (1997) & $2, D, C, G|I, C| B, B|Q, Q, N| C|| A C E, C$ & 161 \\
\hline Chen and Zheng (1998) & $\mathrm{n}, \mathrm{S}, \mathrm{C}, \mathrm{G}|\mathrm{I}, \mathrm{C}| \mathrm{B}, \mathrm{B}|\mathrm{Q}, \mathrm{Q}, \mathrm{N}| \mathrm{C} \| \mathrm{AE}, 0$ & 77 \\
\hline Chen, Feng, et al. (2002) & $2, D, D, G|I, C| G, B|q, Q, N| C|| E, P$ & 17 \\
\hline Chen and Li (2015) & $n, S, C, G|I, C| P U, G|q, Q, U| C S \| C E, 0$ & 9 \\
\hline Chen, Song, and Zhang (2016) & $\mathrm{n}, \mathrm{S}, \mathrm{D}, \mathrm{G}|\mathrm{I}, \mathrm{C}| \mathrm{M}, \mathrm{B}|\mathrm{N}, \mathrm{F}, \mathrm{N}| \mathrm{C}|| \mathrm{AC}, \mathrm{FO}$ & 0 \\
\hline
\end{tabular}




\begin{tabular}{|c|c|c|}
\hline Reference & Classification & Citations \\
\hline Chen and Muharremoglu (2014) & $n, C, D, E|I, C| G, B|N, F, N| C|| E, 0$ & 2 \\
\hline Chen and Cheng (2014) & $n, S, D, E|I, C| F, B|B, F, N| C|| E, 0$ & 3 \\
\hline Cheng, Ettl, et al. (2002) & $n, G, D, G|I, G| N, B|b, F, N| C|| A S, 0$ & 115 \\
\hline Cheng, Gao, et al. (2011) & $2, C, C, G|F, E| P, L|N, F, N| C|| A C E, 0$ & 17 \\
\hline Cheung and Hausman (2000) & $2, D, C, G|I, C| R, B|q, Q, N| C|| A C E, P$ & 39 \\
\hline Cheung and Lee (2002) & $2, D, C, G|I, C| P, B|Q, Q, R| C|| E, C$ & 262 \\
\hline Chew and Johnson (1995) & $2, D, C, G|I, C| B, B|s, F, N| S \| A S, P$ & 4 \\
\hline Chew and Tang (1995) & $2, D, C, G|I, C| P, B|s, F, N| C|| A C, P$ & 7 \\
\hline Chiang and Monahan (2005) & $2, D, C, G|I, G| P, L|b, F, R| C|| E, P$ & 217 \\
\hline Clark and Scarf (1960) & $n, D S, D, G|I, C| G, B|N, F, N| C|| E, 0$ & 1883 \\
\hline Clark and Scarf (1962) & $n, S, D, G|I, C| G, B|N, F, N| C|| A, 0$ & 123 \\
\hline Cobb (2016) & $2, S, C, G|I, G| N, L|q, Q, N| C \mid \| C E, 0$ & 1 \\
\hline Cohen, Kleindorfer, et al. (1986) & $n, D, C, G|I, C| G, B|b, F, E R| C S|| A C, 0$ & 152 \\
\hline Cohen and Lee (1988) & $n, G, C, G|I, C| G, B|q, Q, E| C|| A, 0$ & 834 \\
\hline Cohen, Kamesam, et al. (1990) & $n, D, D, G|I, C| G U, G|s, F, E R| C S|| F, 0$ & 192 \\
\hline Dada (1992) & $2, D, C, G|I, G| P, B|b, F, O R| C|| A, P$ & 107 \\
\hline Dayanik et al. (2003) & $2, G, C, G|F, G| P, B L|b, F, N| S|| A, P$ & 51 \\
\hline de Bodt and Graves (1985) & $n, S, C, G|I, C| G, B|Q, Q, N| C|| A, 0$ & 152 \\
\hline de Kok (1990) & $2, D, D, G|I, C| G, B|B, F, A| S|| A, P$ & 77 \\
\hline de Kok et al. (2005b) & $n, G, D, G|I, C| G, B|B, F, N| M \| F, 0$ & 100 \\
\hline de Kok and Visschers (1999) & $n, G, D, G|I, C| G, B|B, F, N| C|| C, F$ & 57 \\
\hline DeCroix (2006) & $n, S, D, G|I, C| G, B|N, F, N| C|| E, 0$ & 110 \\
\hline DeCroix, Song, et al. (2009) & $2, G, C, G|I, C| P, B|b, F, N| C|| A C E, 0$ & 29 \\
\hline DeCroix and Zipkin (2005) & $n, C, D, G|I, C| G, B|N, F, N| C|| A C E, 0$ & 100 \\
\hline Dekker et al. (1998) & $2, D, D, G|I, C| G, B|0, F, R| C|| A, 0$ & 14 \\
\hline Demirel et al. (2015) & $2, S, D, G|F, C| G, L|b, F, N| C \| C E, 0$ & 1 \\
\hline Deuermeyer and Schwarz (1981) & $2, D, C, G|I, C| P, B|q, Q, N| U \| A C, P$ & 249 \\
\hline Diaz and Fu (1997) & $n, D, C, G|F, G| P, B|b, F, N| S|| A C, P$ & 177 \\
\hline Diks and de Kok (1996) & $2, D, D, G|I, C| G, B|B, F, A R| S \| A C, 0$ & 89 \\
\hline Diks and de Kok (1998) & $n, D, D, G|I, C| G, B|N, F, N| C|| E, 0$ & 135 \\
\hline Diks and de Kok (1999) & $n, D, D, G|I, C| G, B|B, F, N| C|| A C, 0$ & 71 \\
\hline Doğru et al. (2010) & $2, G, C, G|I, C| B, B|b, F, A| C|| A C, 0$ & 54 \\
\hline Doğru et al. (2016) & $2, G, C, G|I, C| B, B|N, F, A| C|| A C, 0$ & 2 \\
\hline Doğru, de Kok, et al. (2009) & $2, D, D, G|I, C| D, B|N, F, N| C|| C E, 0$ & 14 \\
\hline Doğru and Özen (2015) & $2, D, C, L|I, C| P, B|b, F, N| C S \| A F, 0$ & 1 \\
\hline Dong and Lee (2003) & $\mathrm{n}, \mathrm{S}, \mathrm{D}, \mathrm{G}|\mathrm{I}, \mathrm{C}| \mathrm{G}, \mathrm{B}|\mathrm{N}, \mathrm{F}, \mathrm{N}| \mathrm{C} \| \mathrm{AE}, 0$ & 107 \\
\hline Egri (2012) & $\mathrm{n}, \mathrm{S}, \mathrm{C}, \mathrm{G}|\mathrm{I}, \mathrm{C}| \mathrm{NU}, \mathrm{G}|\mathrm{b}, \mathrm{F}, \mathrm{U}| \mathrm{CS} \| \mathrm{ES}, 0$ & 6 \\
\hline Ekanayake et al. (2016) & $2, D, D, G|I, C| P, L|s, F, 0| M \| \mid C O S, C P$ & 0 \\
\hline ElHafsi (2009) & $2, C, C, G|F, E| B, L|N, F, N| C|| A E, 0$ & 63 \\
\hline ElHafsi, Camus, et al. (2008) & $2, G, C, G|F, E| P, L|N, F, N| C \| A C E, 0$ & 23 \\
\hline ElHafsi and Hamouda (2015) & $2, C, C, G|F, E| P, B|N, F, N| C|| A C E, 0$ & 5 \\
\hline ElHafsi, Zhi, et al. (2015) & $2, C, C, G|F, E| P, L|N, F, A| C \| A C E, 0$ & 8 \\
\hline Eppen and Schrage (1981) & $2, D, D, G|I, C| N, B|B, F, N| C|| E, 0$ & 497 \\
\hline Erkip et al. (1990) & $2, D, D, G|I, C| G, B|B, F, N| C|| E, 0$ & 224 \\
\hline Ernst and Pyke (1992) & $2, C, D, G|I, C| G, B|q, Q, N| C S \| A C, 0$ & 16 \\
\hline Eruguz et al. (2013) & $\mathrm{n}, \mathrm{S}, \mathrm{D}, \mathrm{G}|\mathrm{I}, \mathrm{C}| \mathrm{N}, \mathrm{L}|\mathrm{b}, \mathrm{F}, \mathrm{U}| \mathrm{S} \| \mathrm{S}, 0$ & 5 \\
\hline Eruguz et al. (2014) & $n, G, D, G|I, C| U, G|b, F, U| C \| A C E, 0$ & 14 \\
\hline Ettl et al. (2000) & $n, G, D, G|I, G| G, B|b, F, N| C S \| A S, 0$ & 326 \\
\hline Farasyn et al. (2011) & $n, G, D, G|I, C| N, B|S, F, U| C|| F, 0$ & 42 \\
\hline Fattahi et al. (2015) & $2, S, D, G L|F, C| G, L|s, F, N| C \| A C S, 0$ & 13 \\
\hline Federgruen and Zipkin (1984a) & $2, D, D, G|I, C| N, B|0, F, N| C \|, 0$ & 130 \\
\hline Federgruen and Zipkin (1984b) & $2, D, D, G|I, C| G, B|0, F, N| C|| A, 0$ & 169 \\
\hline Federgruen and Zipkin (1984c) & $2, D S, D, G|I, C| G N, B|0, F, N| C|| E, 0$ & 360 \\
\hline Feigin (1999) & $n, G, C, G|I, G| G, B|b, F, N| C|| A C, 0$ & 22 \\
\hline Feng, Liu, et al. (2012) & $2, G, C, G|I, C| P, B|q, Q, N| S|| E, F$ & 7 \\
\hline Feng and Rao (2007) & $2, S, D, G|I, C| G P, B|B, F, N| C \| C E, C$ & 26 \\
\hline Feng and Zhang (2014) & $2, C, D, G|I, C| G, B|b, F, N| C E \| E, C F$ & 16 \\
\hline Feng, Ou, et al. (2008) & $2, C, C, G|F, E| P, B|N, F, N| C|| E, 0$ & 14 \\
\hline Fleischhacker et al. (2015) & $n, D, C, G|I, C| P, B|b q, F, N| C S|| A C F, 0$ & 5 \\
\hline Forsberg (1995) & $2, D, C, G|I, C| B, B|b, F, N| C \|, 0$ & 76 \\
\hline
\end{tabular}




\begin{tabular}{|c|c|c|}
\hline Reference & Classification & Citations \\
\hline Forsberg (1997a) & $2, D, C, G|I, C| R, B|q, Q, N| C||, P$ & 23 \\
\hline Forsberg (1997b) & $2, D, C, G|I, C| P, B|q, Q, N| C|| E, P$ & 104 \\
\hline Fu et al. (2006) & $2, C, C, G|F, C| G, L|0, F, 0| C|| E, 0$ & 46 \\
\hline Funaki (2012) & $\mathrm{n}, \mathrm{C}, \mathrm{D}, \mathrm{G}|\mathrm{I}, \mathrm{C}| \mathrm{NU}, \mathrm{G}|\mathrm{b}, \mathrm{F}, \mathrm{U}| \mathrm{CS} \| \mathrm{E}, 0$ & 29 \\
\hline Gallego and Özer (2005) & $\mathrm{n}, \mathrm{S}, \mathrm{C}, \mathrm{G}|\mathrm{I}, \mathrm{C}| \mathrm{B}, \mathrm{B}|\mathrm{N}, \mathrm{F}, \mathrm{N}| \mathrm{C} \| \mathrm{AC}, 0$ & 39 \\
\hline Gallego, Özer, and Zipkin (2007) & $2, D, C, G|I, C| P, B|B b, F, N| C|| A C, 0$ & 63 \\
\hline Gallego and Zipkin (1999) & $\mathrm{n}, \mathrm{S}, \mathrm{C}, \mathrm{G}|\mathrm{I}, \mathrm{G}| \mathrm{G}, \mathrm{B}|\mathrm{Bb}, \mathrm{F}, \mathrm{N}| \mathrm{C} \| \mathrm{A}, 0$ & 98 \\
\hline Gallien and Wein (2001) & $2, C, C, G|I, G| P, B|b, F, N| C|| A C, 0$ & 64 \\
\hline Ganeshan (1999) & $2, G, C, G|I, G| P, B|q, Q, N| C|| A S, 0$ & 362 \\
\hline Gao et al. (2010) & $2, G, C, G|F, E| P, B L|b, F, N| S|| C E, P$ & 9 \\
\hline Garcia-Herreros et al. (2016) & $n, G, D, G|F, C| G, B|B, F, N| C|| A C, 0$ & 3 \\
\hline Gavirneni (2002) & $2, S, D, G|F, C| G, B|S, F, E| C \| C E, C$ & 182 \\
\hline Gerchak and Henig (1989) & $2, G, D, G|F I, C| G, B|N, F, N| C|| E, 0$ & 125 \\
\hline Giannoccaro et al. (2003) & $n, S, D, G|I, C| G, B|B, F, N| C|| A C, 0$ & 193 \\
\hline Glasserman and Tayur (1994) & $n, C S, D, G|F, C| G, B|B, F, N| C|| E, P$ & 126 \\
\hline Glasserman and Tayur (1995) & $n, G, D, G|F, G| G, B|B, F, N| C|| A S, 0$ & 299 \\
\hline Glasserman and Tayur (1996) & $n, S, D, G|F, C| G, B|B, F, N| C|| A, 0$ & 64 \\
\hline Glasserman and Wang (1998) & $2, G, C, G|I, G| G, B|b, F, N| S|| A, P$ & 147 \\
\hline Goh and Porteus (2016) & $n, S, D, G|I, C| G, B|N, F, R| C|| C E, 0$ & 0 \\
\hline Grahl et al. (2016) & $n, G, D, G|I, C| N, G|b, F, U| C \| A C, 0$ & 5 \\
\hline Grahovac and Chakravarty (2001) & $2, D, C, G|I, G| P, B|b, F, R| C|| A, 0$ & 190 \\
\hline Graman and Rogers (1997) & $2, D, D, G|I, C| N, B|b, F, N| C \| A C, 0$ & 6 \\
\hline Graves (1985) & $2, D, C, G|I, C| B, B|b, F, N| S|| A, P$ & 545 \\
\hline Graves (1996) & $2 n, D, C, G|I, C| G, B|b, F, N| C S \| A, 0$ & 212 \\
\hline Graves, Kletter, et al. (1998) & $n, G, D, G|F, C| G, B|0, F, N| C M \| A F, 0$ & 261 \\
\hline Graves and Schoenmeyr (2016) & $n, S, D, G|F, C| U, B|b, F, N| C \| A C, C 0$ & 4 \\
\hline Graves and Willems (2000) & $n, G, D, G|I, C| G U, G|b, F, U| C|| E, 0$ & 404 \\
\hline Graves and Willems (2005) & $n, G, D, G|I, C| G U, G|b, F, U| C|| E, 0$ & 253 \\
\hline Graves and Willems (2008) & $n, G, D, G|I, C| G U, G|b, F, U| C|| E, 0$ & 97 \\
\hline Güllü and Erkip (1996) & $2, D, D, G|I, C| N, B|N, F, A| C|| C E S, 0$ & 21 \\
\hline Gupta and Albright (1992) & $2, D, C, G|F, E| P, B|b, F, N| S|| A C, P$ & 43 \\
\hline Gürbüz et al. (2007) & $2, D, C, G|F, C| P, B|0, F, A| C|| A C, C$ & 73 \\
\hline Haji et al. (2014) & $2, D, C, G|I, C| P, L|0, F, R| C \| A C, C 0$ & 2 \\
\hline Hausman and Erkip (1994) & $2, D, C, G|I, C| P, B|b, F, E 0| C|| E, C$ & 87 \\
\hline Hill et al. (2007) & $2, D, C, G|I, C| P, L|q, Q, N| C|| A C, P$ & 30 \\
\hline Hillestad and Carrillo (1980) & $3, D, C, G|I, E| P, B|b, F, N| S|| E, P$ & 54 \\
\hline Hillier (1999) & $2, G, D, G|I, C| G, B|b, F, N| C S|| E, 0$ & 52 \\
\hline Hillier (2000) & $2, C G, D, G|I, C| G, B L|b, F, N| C|| A C, 0$ & 95 \\
\hline Howard and Marklund (2011) & $2, D, C, G|I, C| P, B|q, Q, N| C|| S, P$ & 23 \\
\hline Hu and Yang (2014) & $n, S, C, G|I, C| P, B|Q, Q, N| C \| A C, 0$ & 6 \\
\hline Hua and Willems (2016a) & $2, S, D, L|I, C| U, G|b, F, U| C|| E, 0$ & 1 \\
\hline Hua and Willems (2016b) & $2, S, D, G|I, C| U, G|b, F, N| C|| E, F 0$ & 0 \\
\hline Huang (2014) & $2, G, D, G|I, C| G N, B|b, F, A| C S \| C E S, 0$ & 3 \\
\hline Huh and Janakiraman (2010) & $2, S, D, G|I, C| D, L|N, F, N| C|| E, F 0$ & 50 \\
\hline Huh and Janakiraman (2012) & $\mathrm{n}, \mathrm{S}, \mathrm{D}, \mathrm{G}|\mathrm{I}, \mathrm{C}| \mathrm{M}, \mathrm{B}|\mathrm{N}, \mathrm{Q}, \mathrm{N}| \mathrm{C}|| \mathrm{E}, 0$ & 13 \\
\hline Huh, Janakiraman, and Nagarajan (2016) & $n, S, D, G|F, C| G, B|N, F, N| C|| A C E, 0$ & 2 \\
\hline Humair, Ruark, et al. (2013) & $n, G, D, G|I, G| G U, G|b, F, U| C \| A, F$ & 19 \\
\hline Humair and Willems (2006) & $n, G, D, G|I, C| G U, G|b, F, U| C|| E, 0$ & 53 \\
\hline Humair and Willems (2011) & $n, G, D, G|I, C| G U, G|b, F, U| C \| A, 0$ & 32 \\
\hline Hwarng et al. (2005) & $n, G, D, G|I, G| G, B|b, F, N| C|| S, P$ & 93 \\
\hline lida (2001) & $n, S, D, G|I, C| G, B|0, F, N| C|| A C, 0$ & 28 \\
\hline Inderfurth (1991) & $n, D, D, G|I, C| N U, G|b, F, U| C|| E, 0$ & 112 \\
\hline Inderfurth (1992) & $n, D, D, G|I, C| N U, G|b, F, U| C|| E, 0$ & 3 \\
\hline Inderfurth (1995) & $n, D, D, G|I, C| N U, G|b, F, U| C|| E, 0$ & 18 \\
\hline Inderfurth and Minner (1998) & $n, G, D, G|I, C| N U, G|b, F, U| C|| E, 0$ & 141 \\
\hline Iravani et al. (2003) & $2, G, C, G|I, E| P, B L|b, F, R| M|| C E, 0$ & 34 \\
\hline Jackson (1988) & $2, D, D, G|I, C| N P, B|0, F, N| C|| A, 0$ & 180 \\
\hline Jackson and Muckstadt (1989) & $2, D, D, G|I, C| G, B|0, F, A| C|| A, 0$ & 2 \\
\hline Janakiraman and Muckstadt (2009) & $\mathrm{n}, \mathrm{S}, \mathrm{D}, \mathrm{G}|\mathrm{F}, \mathrm{C}| \mathrm{D}, \mathrm{B}|\mathrm{N}, \mathrm{F}, \mathrm{N}| \mathrm{C} \| \mathrm{E}, 0$ & 33 \\
\hline Ji et al. (2016) & $2, S, D, G|F, C| G, B|N, F, N| C \| C E, 0$ & 0 \\
\hline
\end{tabular}




\begin{tabular}{|c|c|c|}
\hline Reference & Classification & Citations \\
\hline Jönsson and Silver (1987a) & $2, D, D, G|I, C| N, B|0, F, R| C|| A, 0$ & 214 \\
\hline Jönsson and Silver (1987b) & $2, D, D, G|I, C| N, B|0, F, N| C|| A, 0$ & 54 \\
\hline Karaarslan et al. (2013) & $2, C, D, G|I, C| G, B|b, F, N| C \| C E, 0$ & 12 \\
\hline Karaarslan et al. (2014) & $2, S, D, G|I, C| G, B|B, F, N| C \| C E, 0$ & 5 \\
\hline Keblis and Feng (2012) & $2, C, C, G|F, E| P, B|N, F, N| C|| E, 0$ & 12 \\
\hline Kiesmüller et al. (2004) & $n, D, C, G|I, G| R, B|q, Q, N| S \| A C, P$ & 26 \\
\hline Kim et al. (2015) & $n, S, D, G|I, G| G, B|N, F, E| C|| E, 0$ & 3 \\
\hline Klosterhalfen, Dittmar, et al. (2013) & $n, S, D, G|I, C| G, B|b, F, E| C|| A C, 0$ & 16 \\
\hline Klosterhalfen and Minner (2007) & $2, S, D, G|I, C| N U, B G|b, F, E O| C \| S, C$ & 7 \\
\hline Klosterhalfen and Minner (2010) & $2, D, D, G|I, C| N U, B G|b, F, E 0| C|| S, C$ & 11 \\
\hline Klosterhalfen, Minner, and Willems (2014) & $n, G, D, G|I, C| N U, G|b, F, U| C|| C E F, 0$ & 9 \\
\hline Ko et al. (2011) & $2, C, C, G|F, E| P, B|b, F, N| U \| A C, F$ & 5 \\
\hline Köchel and Nieländer (2005) & $n, G, C D, G|I, G| G, B L|q, F, N| C \| S, 0$ & 113 \\
\hline Korugan and Gupta (1998) & $2, D, C, G|F, E| P, L|b, F, N| C|| A, P$ & 39 \\
\hline Kutanoglu and Mahajan (2009) & $2, D, C, G|I, E| P, L|b, F, R| C S|| C E, 0$ & 99 \\
\hline Lagodimos (1992) & $2, D, D, G|I, C| G, B|B S, F, N| S|| A C, C$ & 60 \\
\hline Lagodimos (1993) & $2 n, C S, D, G|I, C| N, B|0, F, N| S|| A, P$ & 18 \\
\hline Lagodimos and Anderson (1993) & $n, D, D, G|I, C| G, B|0, F, N| S \| A C S, P$ & 49 \\
\hline Lagodimos, de Kok, et al. (1995) & $2, S, D, G|I, C| N, B|B, F, N| S \| C E, P$ & 15 \\
\hline Lagodimos and Koukoumialos (2008) & $2, D, D, G|I, C| N, B|b, F, N| S \| A C, P$ & 28 \\
\hline Lagodimos, Skouri, et al. (2015) & $2, S, D, G|I, C| G, B|B, F, N| C|| E, 0$ & 2 \\
\hline Lambrecht et al. (1984) & $n, C, D, G|I, C| G, B|0, F, N| C|| A C, 0$ & 85 \\
\hline Langenhoff and Zijm (1990) & $n, C D S, C, G|I, C| G, B|N, F, N| C S|| E, 0$ & 77 \\
\hline Lee (1987) & $2, D, C, G|I, C| P, B|b, F, R| C|| A, 0$ & 358 \\
\hline Lee and Billington (1993) & $n, G, D, L|I, G| N, B|b, F, N| C|| A, P$ & 1054 \\
\hline Lee and Moinzadeh (1987a) & $2, D, C, G|I, G| P, B|q, Q, N| C|| A C, 0$ & 113 \\
\hline Lee and Moinzadeh (1987b) & $2, D, C, G|F I, C| P, B|q, Q, N| C|| A C, P$ & 114 \\
\hline Lee, So, et al. (2000) & $2, S, D, G|I, C| G, B|b, F, 0| C|| C E, C$ & 2310 \\
\hline Lee and Whang (1999) & $2, S, D, G|I, C| G, B|B, F, N| C E \| E, C$ & 640 \\
\hline Lee and Zipkin (1995) & $n, D, C, G|F, E| P, B|b, F, N| M \| A C, P$ & 28 \\
\hline Lesnaia (2004) & $n, G, D, G|I, C| U, G|b, F, U| C|| A E, 0$ & 38 \\
\hline Levi et al. (2017) & $n, S, D, G|I, C| G, B|0, F, N| C|| E, 0$ & 0 \\
\hline Li and Jiang (2012) & $n, G, D, G|B, C| N U, G|b, F, U| C|| A, 0$ & 18 \\
\hline Liberopoulos and Dallery (2003) & $n, S, C, G|F, G| G, B|0, F Q, N| U \| E, C$ & 40 \\
\hline Liberopoulos and Koukoumialos (2005) & $2, S, C, G|F, E| P, B|0, F, N| C|| S, C$ & 63 \\
\hline Lin et al. (2000) & $n, G, C, G|I, G| B, B|b, F, N| C S|| A F S, 0$ & 126 \\
\hline Liu et al. (2004) & $\mathrm{n}, \mathrm{S}, \mathrm{C}, \mathrm{G}|\mathrm{F}, \mathrm{G}| \mathrm{G}, \mathrm{B}|\mathrm{b}, \mathrm{F}, \mathrm{N}| \mathrm{CS} \| \mathrm{AC}, 0$ & 90 \\
\hline Lu, Song, and Zhang (2015) & $2, G, C, G|I, C| G, B|N, F, N| \| C E, 0$ & 13 \\
\hline Lu (2008) & $2, G, C, G|I, G| R, B|b, F, N| M \| A C, P$ & 12 \\
\hline Lu and Song (2005) & $2, G, C, G|I, G| P, B|b, F, N| C|| A E, 0$ & 126 \\
\hline Lu, Song, and Yao (2003) & $2, G, C, G|I, G| B, B|b, F, N| S \| A C, P$ & 145 \\
\hline Lu, Song, and Yao (2005) & $2, C, C, G|I, G| P, B|b, F, N| C|| A, 0$ & 45 \\
\hline Lu, Song, and Zhao (2010) & $2, G, C, G|I, G| P, B|b, F, A| C|| A C E, P$ & 45 \\
\hline Magnanti et al. (2006) & $n, G, D, G|B F I, C| N U, G|b, F, U| C|| E, 0$ & 60 \\
\hline Mahmoodi and Haji (2014) & $2, D, D, L|I, C| P, L|0, Q, N| C|| E, 0$ & 0 \\
\hline Marklund (2002) & $2, D, C, G|I, C| P, B|0, Q, N| C|| E, C$ & 39 \\
\hline Marklund (2006) & $2, D, C, G|I, C| P, B|0, F, N| C|| A C E, 0$ & 35 \\
\hline Marklund (2011) & $2, D, C, G|I, C| P, B|q, Q, N| C|| A C E, P$ & 27 \\
\hline Marklund and Rosling (2012) & $2, D, D, G|I, C| G, B|0, F, N| C \| A C E, 0$ & 17 \\
\hline Masters (1993) & $n, D, C, G|I, G| P, L|b, F, N| C|| A C, 0$ & 38 \\
\hline McGavin et al. (1993) & $2, D, D, G|I, C| G, L|0, F, N| C|| A S, C$ & 120 \\
\hline Minner (1997) & $n, C D S, D, G|I, C| N U, G|b, F, U| C S \| E, 0$ & 53 \\
\hline Minner (2001) & $n, G, D, G|I, C| N U, G|b, F, U| C|| E, 0$ & 201 \\
\hline Minner et al. (2003) & $2, D, D, G|I, C| G U, G|0, F, E| C|| A, 0$ & 21 \\
\hline Mitra and Chatterjee (2004a) & $2, S, C, G|I, C| N, B|Q, Q, N| C \| A, 0$ & 24 \\
\hline Mitra and Chatterjee (2004b) & $2, D, D, G|I, C| N, B|b, F, 0| C \| A C, P$ & 31 \\
\hline Moinzadeh (2002) & $2, D, C, G|I, C| P, B|0, Q, N| C|| E, C$ & 256 \\
\hline Moinzadeh and Aggarwal (1997) & $2, D, C, G|I, C| P, B|b, F, E| C|| A S, 0$ & 89 \\
\hline Moinzadeh and Lee (1986) & $2, D, C, G|I, C| P, B|q, Q, N| C \| A, 0$ & 180 \\
\hline Moinzadeh and Zhou (2008) & $2, D, C, G|I, C| G, B|q, Q, N| C \| C E, 0$ & 7 \\
\hline
\end{tabular}




\begin{tabular}{|c|c|c|}
\hline Reference & Classification & Citations \\
\hline Molinder (1997) & $n, C G, D, G|I, G| D, B|0, F, N| C S \| S, 0$ & 111 \\
\hline Moncayo-Martinez, Ramirez-Lopez, et al. (2016) & $n, C, D, G|I, C| U, G|b, F, N| C|| A, 0$ & 3 \\
\hline Moncayo-Martinez, Resendiz-Flores, et al. (2014) & $n, G, D, G|I, C| U U, G|b, F, U| C|| E F, 0$ & 4 \\
\hline Muckstadt (1973) & $2, G, C, G|I, G| B, B|b, F, N| C|| A, 0$ & 488 \\
\hline Muckstadt and Thomas (1980) & $2, D, C, G|I, C| P, B|b, F, N| C S \| A F, 0$ & 172 \\
\hline Muharremoglu and Tsitsiklis (2008) & $n, S, D, G|I, G| M, B|N, F, N| C \|, 0$ & 92 \\
\hline Muharremoglu and Yang (2010) & $n, S, D, G|I, G| G, B|b, F, N| C \| E, P$ & 20 \\
\hline Nadar et al. (2014) & $2, G, C, G|I, E| P, L|N, F, A| C|| E, 0$ & 18 \\
\hline Nadar et al. (2016) & $2, G, C, G|I, E| P, L|N, Q, A| C \| A C, 0$ & 3 \\
\hline Nahmias and Smith (1994) & $2, D, D, G|I, C| G, B L|0, F, N| C|| E, 0$ & 163 \\
\hline Neale and Willems (2009) & $n, G, D, G|I, C| N U, G|b, F, U| C|| A, 0$ & 39 \\
\hline Needham and Evers (1998) & $2, D, D, G|I, G| G, L|q, Q, E R| C|| A C S, C$ & 62 \\
\hline Nepal et al. (2011) & $\mathrm{n}, \mathrm{G}, \mathrm{D}, \mathrm{G}|\mathrm{I}, \mathrm{C}| \mathrm{NU}, \mathrm{G}|\mathrm{b}, \mathrm{F}, \mathrm{U}| \mathrm{M}|| \mathrm{E}, 0$ & 18 \\
\hline $\mathrm{Ni}$ and Shu (2015) & $n, G, D, G|I, C| U, G|b, F, U| C|| C E, 0$ & 4 \\
\hline Nozick and Turnquist (2001) & $2, D, C, G|I, C| G P, B|b, F, N| C|| E, 0$ & 168 \\
\hline Oh et al. (2014) & $2, G, D, G|I, C| G, B|N, F, A| C|| A C E, 0$ & 8 \\
\hline Ohno et al. (2016) & $3 n, S, D, G|F, C| U, B L|N, 0, N| C \| A C, 0$ & 3 \\
\hline Özer (2003) & $2, D, D, G|I, C| D, B|0, F, N| C|| A C E, 0$ & 129 \\
\hline Özkan et al. (2015a) & $2, D, C, G|I, C| P, B|b, F, R| C|| A C, 0$ & 10 \\
\hline Özkan et al. (2015b) & $2, D, C, G|I, C| P, B|b, F, E R| C|| A C, P$ & 10 \\
\hline Parker and Kapuscinski (2004) & $2, S, D, G|F, C| G, B|N, F, N| C|| E, 0$ & 84 \\
\hline Patriarca et al. (2016) & $2, D, C, G|I, G| P, B|b, F, R| C \| \mid A C F, 0$ & 0 \\
\hline Perlman et al. (2001) & $2, D, C, G|F, G| B, B|b, F, E| C \| \mid C E, C$ & 42 \\
\hline Petrovic et al. (1998) & $n, S, D, G|I, C| F, B|b, F, N| C S \| C S, 0$ & 366 \\
\hline Petrovic et al. (1999) & $n, S, D, G|I, C| F, B|b, F, N| C S \| C S, 0$ & 379 \\
\hline Plambeck (2008) & $2, G, C, G|F, C| R, L|0, F, E| C|| A C E, 0$ & 23 \\
\hline Plambeck and Ward (2006) & $2, G, C, G|F, O| R, B|N, F, A| C|| E, 0$ & 65 \\
\hline Plambeck and Ward (2007) & $2, G, C, G|F, C| R, L|N, F, E| C|| E, 0$ & 36 \\
\hline Pyke (1990) & $2, D, C, G|I, E| G, B|b, F, R| C \| S, C$ & 72 \\
\hline Raghunathan (2001) & $2, S, D, L|I, C| M, B|b, F, N| C|| A C, C$ & 370 \\
\hline Rambau and Schade (2010) & $n, D, D, G|I, G| D, G|b, F, E O| C \| \mid A C, 0$ & 8 \\
\hline Rambau and Schade (2014) & $n, D, D, G|I, G| D, L|s, F, E 0| C \| A C S, C O$ & 2 \\
\hline Rappold and Muckstadt (2000) & $2, D, D, G|F, C| G, B|B, F, N| C \| \mid A C, 0$ & 31 \\
\hline Rappold and van Roo (2009) & $2, D, C, G|F, E| P, B|b, F, N| C|| A C, 0$ & 60 \\
\hline Reiman et al. (2016a) & $2, G, C, G|I, C| B, B|0, F, A| C|| E, F$ & 1 \\
\hline Reiman et al. (2016b) & $2, G, C, G|I, C| B, B|b, F, N| C|| E, 0$ & 1 \\
\hline Reiman and Wang (2012) & $2, G, C, G|I, C| B, B|b, F, A| C|| E, 0$ & 21 \\
\hline Reiman and Wang (2015) & $2, G, C, G|I, C| B, B|b, F, A| C|| A, 0$ & 14 \\
\hline Rong et al. (2014) & $n, D, C, G|I, C| P, B|b, F, N| C|| A C, 0$ & 3 \\
\hline Rosenbaum (1981) & $2, D, C, G|I, G| N, B|0,0, N| S \| A C, 0$ & 48 \\
\hline Rosling (1989) & $n, C, D, G|I, C| G, B|N, F, N| C|| E, 0$ & 329 \\
\hline Routroy and Kodali (2005) & $3, S, C, G|I, C| N, L|q, Q, N| C|| A, 0$ & 35 \\
\hline Roy and Raghavan (2014) & $2, D, D, E|I, C| N, B|B, F, A| E \| \mid A, 0$ & 1 \\
\hline Salzarulo and Jacobs (2014) & $2, S, C, G L|F, C| P, B|S, F, N| C|| A C, 0$ & 11 \\
\hline Santos and Bispo (2016) & $\mathrm{n}, \mathrm{G}, \mathrm{D}, \mathrm{G}|\mathrm{F}, \mathrm{C}| \mathrm{G}, \mathrm{B}|\mathrm{B}, \mathrm{F}, \mathrm{N}| \mathrm{C} \| \mathrm{ACS}, 0$ & 0 \\
\hline Schildbach and Morari (2016) & $\mathrm{n}, \mathrm{G}, \mathrm{D}, \mathrm{G}|\mathrm{BF}, \mathrm{CG}| \mathrm{G}, \mathrm{B}|0, \mathrm{~F}, \mathrm{R}| \mathrm{CS} \| \mathrm{AC}, 0$ & 10 \\
\hline Schmidt and Nahmias (1985) & $2, C, D, G|I, C| G, B|N, F, N| C|| E, 0$ & 139 \\
\hline Schneider et al. (1995) & $2, D, D, G|I, C| G, B|s, F, N| C S \| A C, 0$ & 28 \\
\hline Schoenmeyr and Graves (2009) & $n, C S, D, G|I, C| G U, G|b, F, U| C|| E F, 0$ & 41 \\
\hline Schultz (1983) & $2, D, D, G|I, C| G, B|s, F, N| C|| E, F$ & 10 \\
\hline Schwarz (1989) & $2, D, D, G|I, C| N, B|b, F, A| C \| \mid C E, P$ & 135 \\
\hline Schwarz et al. (1985) & $2, D, C, G|I, C| P, B|q, Q, N| C|| A, 0$ & 114 \\
\hline Seferlis and Giannelos (2004) & $n, G, D, G|F, C| G, B L|N, F, N| C|| A C, 0$ & 111 \\
\hline Seifbarghy and Jokar (2006) & $2, D, C, G|I, C| P, L|q, Q, N| C|| A C, 0$ & 57 \\
\hline Seo et al. (2002) & $2, D, C, G|I, C| P, B|q, Q, E| C|| A C, 0$ & 41 \\
\hline Shang (2008) & $n, S, C, G|I, C| R, B|Q, F, N| C \| A C, 0$ & 30 \\
\hline Shang (2012) & $n, S, D, G|I, C| G, B|B, F, N| C|| A C, 0$ & 14 \\
\hline Shang and Song (2003) & $n, S, C, G|I, C| B, B|B, F, N| C|| A C, 0$ & 138 \\
\hline Shang and Song (2006) & $n, S, C, G|I, C| P, B|B, F, N| C \| \mid A C, F 0$ & 23 \\
\hline Shang and Song (2007) & $n, S, C, G|I, C| B, B|B Q, F Q, N| C|| A C, 0$ & 17 \\
\hline
\end{tabular}




\begin{tabular}{|c|c|c|}
\hline Reference & Classification & Citations \\
\hline Shang, Song, and Zipkin (2009) & $n, S, D, G|I, C| G, B|q, Q, N| C|| E, 0$ & 35 \\
\hline Shang, Tao, et al. (2015) & $n, D, D, G|I, C| P, B|B, F, N| C|| A C, 0$ & 7 \\
\hline Shang and Zhou (2009) & $n, S, D, G|I, C| G, B|Q, F, N| C \| A C, 0$ & 13 \\
\hline Shang and Zhou (2010) & $n, S, D, G|I, C| D, B|Q, Q, N| C|| A C, 0$ & 45 \\
\hline Shang, Zhou, and van Houtum (2010) & $n, S, D, G|I, C| G, B|0, F, N| C \| C E, 0$ & 19 \\
\hline Sherbrooke (1968) & $2, D, C, G|I, G| B, B|b, F, N| C|| A, 0$ & 1222 \\
\hline Sherbrooke (1986) & $3, D, C, G|I, C| P, B|b, F, N| C \| \mid A, P$ & 303 \\
\hline Sherbrooke (1992) & $2, D, C, G|I, G| P, B|b, F, R| C|| A C, 0$ & 125 \\
\hline Shi and Zhao (2014) & $2, G, C, G|I, C| G, B|b, F, A| C \| \mid C E, C$ & 1 \\
\hline Shu and Karimi (2009) & $n, G, D, G|I, C| G U, G|b, F, U| C \| A C, 0$ & 22 \\
\hline Simchi-Levi and Zhao (2003) & $2, S, D, G|F, C| D, B|0, F, N| C|| A C E, 0$ & 111 \\
\hline Simon (1971) & $2, D, C, G|I, C| P, B|b, F, N| C|| E, F$ & 158 \\
\hline Simpson (1958) & $n, S, C, G|I, C| U, G|b, F, U| C|| E, 0$ & 199 \\
\hline Simpson (1978) & $2, S, D, G|I, C| G, B|N, F, O| C \| E, 0$ & 210 \\
\hline Sinha and Krishnamurthy (2016) & $2, C, C, G|F, C| P, B|0, F, R| C|| A C E, C O P$ & 0 \\
\hline Sitompul et al. (2008) & $n, S, D, G|F, C| N U, G|b, F, U| C|| A C, 0$ & 55 \\
\hline Slay (1984) & $3, D, C, G|I, C E| P, B|b, F, N| S \| A, 0$ & 134 \\
\hline Sleptchenko et al. (2002) & $n, D, C, G|F, G| P, B|b, F, N| C|| A C, 0$ & 126 \\
\hline Song (1998) & $2, G, C, G|I, C| R, B|b, F, N| E \| E, P$ & 169 \\
\hline Song (2000) & $2, G, C, G|I, C| B P, B|q, Q, N| S|| E, P$ & 54 \\
\hline Song, Xu, et al. (1999) & $2, C, C, G|F, E| P, B L|b, F, N| S \| E, P$ & 199 \\
\hline Song and Zhao (2009) & $2, G, C, G|I, C| P, B|b, F, N| C|| A C, 0$ & 45 \\
\hline Stenius et al. (2016) & $2, D, C, G|I, C G| B, B|b q, F Q, N| C|| E, 0$ & 4 \\
\hline Svoronos and Zipkin (1988) & $2, D, C, G|I, C| P, B|q, Q, N| C|| A C, P$ & 251 \\
\hline Svoronos and Zipkin (1991) & $n, D, C, G|I, G| P, B|b, F, N| C|| A C, P$ & 234 \\
\hline Tee and Rossetti (2002) & $2, D, C, G|I, C| P, B|q, Q, N| M|| C S, P$ & 68 \\
\hline Tempelmeier (1993) & $2, D, D, G|I, G| G, B|q, Q, N| C|| A C, 0$ & 23 \\
\hline Tian et al. (2011) & $n, G, D, G|F, C| N U, G|b, F, U| C|| A, 0$ & 36 \\
\hline Topan et al. (2010) & $2, D, C, G|I, C| P, B|0, Q, N| C \| C E, 0$ & 31 \\
\hline van den Berg et al. (2016) & $2, D, C, G|I, C E| P, L|q, Q, O R| C S \| A C F, 0$ & 2 \\
\hline van der Heijden (1992) & $2 n, D, C, G|I, G| B, B|b, F, N| C|| A, P$ & 12 \\
\hline van der Heijden (1997) & $2, D, D, G|I, C| G, B|B, F, N| S \|, P$ & 46 \\
\hline van der Heijden (1999) & $2, D, D, G|I, C| G, B|b, F, N| S|| A C, 0$ & 42 \\
\hline van der Heijden (2000) & $n, D, D, G|I, C| G, B|B, F, N| C S \| A C, 0$ & 31 \\
\hline van der Heijden et al. (1997) & $n, D, D, G|I, C| G, B|B, F, N| S \| A S, C$ & 82 \\
\hline van der Heijden et al. (1999) & $n, D, D, G|I, G| G, B|B, F, N| S \|, 0$ & 22 \\
\hline van Donselaar (1990) & $2, D, D, G|I, C| G, B|B, F, N| S \| E, P$ & 46 \\
\hline van Donselaar and Wijngaard (1987) & $2, D, D, G|I, C| G, B|B, F, N| C S|| A, P$ & 47 \\
\hline van Houtum, Scheller-Wolf, et al. (2007) & $n, S, D, G|I, C| G, B|N, F, N| C|| E, 0$ & 50 \\
\hline van Houtum and Zijm (1991) & $n, C, D, G|I, C| G, B|N, F, N| C S|| E, 0$ & 84 \\
\hline van Jaarsveld and Scheller-Wolf (2015) & $2, G, C, G|I, C| P, B|b, F, A| C|| A C E S, 0$ & 12 \\
\hline van Wijk et al. (2013) & $2, D, C, G|I, E| P, B|b, F, R| C|| E, 0$ & 8 \\
\hline Veatch and Wein (1994) & $2, S, C, G|F, E| P, B|N, F, N| C|| C E, 0$ & 142 \\
\hline Verrijdt and de Kok (1995) & $n, D, D, G|I, C| G, B|B, F, N| S \| A C, P$ & 68 \\
\hline Verrijdt and de Kok (1996) & $2, D, D, G|I, C| G, B|B, F, N| S|| A C, P$ & 64 \\
\hline Wang and Axsäter (2013) & $2, D, C, G|I, C| P, B|0,0, N| C|| C E, 0$ & 8 \\
\hline Wang, Cohen, et al. (2000) & $2, D, C, G|I, G| P, B|b, F, N| M|| A C, P$ & 66 \\
\hline Wheatley et al. (2015) & $2, D, C, G|I, C| P, B|b, F, N| C S \| C, 0$ & 17 \\
\hline Wieland et al. (2012) & $n, G, D, G|I, C| U, G|b, F, U| C|| E, 0$ & 15 \\
\hline Woerner et al. (2016) & $n, C, D, G|F, C G| G, B|b, F, N| C|| A C S, 0$ & 0 \\
\hline Wong, Cattrysse, et al. (2005) & $2, D, C, G|I, E| P, B|b, F, R| C \| \mid A C, 0$ & 93 \\
\hline Wong, Kranenburg, et al. (2007) & $2, D, C, G|I, G| P, B|b, F, N| C S \| A C E, 0$ & 48 \\
\hline Xiang and Rossetti (2014) & $2, D, C, G|I, C E| P, B|q, Q, N| M|| A C S, C$ & 0 \\
\hline Xu et al. (2016) & $n, C, C, G|I, G| G, B|N, F, N| C \| C E, 0$ & 4 \\
\hline Yang et al. (2013) & $2, D, C, G|I, C| P, B|b, F, R| C S \| A C F, P$ & 17 \\
\hline Ye and You (2016) & $n, G, D, G|F, G| G, B|b, F, R| C \| \mid C S, 0$ & 6 \\
\hline Yoo et al. (1997) & $2, D, D, G|I, C| G, B|q, Q, N| C \| C, 0$ & 21 \\
\hline Yoon et al. (2015) & $2, D, C, G|F, E| P, B|b, F, N| C \||| A C S, F P$ & 0 \\
\hline You and Grossmann (2011) & $n, G, D, G|F, C| N U, G|0, F, U| C|| C E, 0$ & 71 \\
\hline Zanjani and Nourelfath (2014) & $2, G, D, G|F, G| D, B|0, F, N| C|| A C, 0$ & 10 \\
\hline
\end{tabular}




\begin{tabular}{llr}
\hline Reference & Classification & Citations \\
\hline Zhang (1997) & $2, G, D, G|I, C| N, B|b, F, N| C S \| C E, 0$ & 87 \\
Zijm and van Houtum (1994) & $n, C, D, G|F I, C| G, B|B, F, N| C|| E, C$ & 25 \\
Zipkin (1984) & $2, D, D, G|I, C| N, B|B, F, N| C|| A C, P$ & 75 \\
Zipkin (1991) & $n, D, C, G|I, G| B, B|b, F, N| S|| A C E, P$ & 29 \\
\hline
\end{tabular}

